\title{
Theoretical Studies of Natural Gas Hydrates and H-bonded Clusters and Crystals
}

\author{
Yuan Liu
}

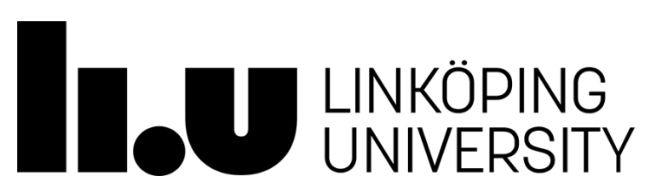

\author{
Division of Chemistry \\ Department of Physics, Chemistry and Biology (IFM) \\ Linköping University, Sweden
}

Linköping 2016 
During the course of research underlying this thesis, Yuan Liu was enrolled in Agora Materiae, a multidisciplinary doctoral program at Linköping University, Sweden.

Copyright () 2016 Yuan Liu, unless otherwise noted.

Published articles has been reprinted with the permission of the copyright holder.

Paper I (C 2014 Springer-Verlag Berlin Heidelberg

Paper II @ 2014 American Chemical Society

Paper III @ 2015 American Chemical Society

Paper IV (c) 2016 American Chemical Society

Paper V (C) 2016 American Chemical Society

Cover: Tetrahedrally coordinated oxygen framework of clathrate ice sL

Yuan Liu

Theoretical Studies of Natural Gas Hydrates and H-bonded Clusters and Crystals

ISBN: 978-91-7685-632-1

ISSN: 0345-7524

Linköping Studies in Science and Technology Dissertation No. 1808

Printed by LiU-Tryck, Linköping, Sweden, 2016 


\section{Abstract}

In this thesis H-bonded systems (natural gas hydrates, water clusters, and crystal ice) are studied by density functional theory (DFT) computations.

Natural gas hydrates (NGHs) play an important role in energy and environmental fields: NGHs are considered as a promising backup energy resource in the near-future due to their tremendous carbon content; improper exploration of NGHs could induce geological disasters and aggravate the greenhouse effect. In addition, many technologies based on gas hydrates are being applied and developed. The thermodynamic stabilities of various water cavities in different clathrate crystalline phases occupied by hydrocarbon gas molecules are studied by dispersion-corrected hybrid functionals. The Raman spectra of $\mathrm{C}-\mathrm{C}$ and $\mathrm{C}-\mathrm{H}$ stretching vibrations of hydrocarbon molecules in various water cavities in the solid state are derived. The trends of $\mathrm{C}-\mathrm{H}$ stretching vibrational frequencies are found to follow the prediction by the "loose cage tight cage" model. In addition, the trends and origins of ${ }^{13} \mathrm{C}$ NMR chemical shifts of hydrocarbon molecules in various NGHs are presented. These theoretical results will enlarge the database of $\mathrm{C}-\mathrm{C}$ and $\mathrm{C}-\mathrm{H}$ stretching vibrational frequencies and ${ }^{13} \mathrm{C}$ NMR parameters of hydrocarbon molecules in NGHs, and provide valuable information to help identify the types of clathrate phases and varieties of guest molecules included in NGHs samples taken from natural sites.

The behavior of water clusters may help to understand the properties of its liquid and solid states. The thermodynamic stabilities and IR spectra of a small-, medium-, and large-sized water cluster are studied in this work. After full optimization of $\left(\mathrm{H}_{2} \mathrm{O}\right)_{20,54,100}$ using the hybrid functional B3LYP, the electronic energies, zero-point energies, internal energies, enthalpies, entropies, and Gibbs free energies of the water clusters are computed. The $\mathrm{OH}$ stretching vibrational IR spectra of $\left(\mathrm{H}_{2} \mathrm{O}\right)_{20,54,100}$ are also presented and split into sub-spectra for different H-bond types based on the specific contributions from each group. It is found that the $\mathrm{OH}$ stretching vibrational frequencies of water are sensitive to the conformations of the H-bonds and the vibrations of the H-bonds belonging to different types are located in separated regions in the IR spectra. Thus, the spectroscopic fingerprints will reflect the $\mathrm{H}$-bond topology of the water molecules in a water cluster.

Ice XI has been suggested to be involved in the process of planetary formation as a considerable electric field might be formed from the ferroelectric ice XI in space. IR and Raman spectroscopic technology can be directly used to identify the occurrence of ferroelectric ice XI in laboratory or extraterrestrial settings. Due to the difficulty for DFT to describe non-covalent systems, the performance of 16 different DFT methods applied on the ice Ih, VIII, IX, and XI crystal phases are assessed. Based on the computational accuracy and cost, the 
IR and Raman spectra of ice Ih and XI are derived and compared. The librational vibrations are found to be the identifier which can be used to distinguish ice Ih and ice XI in the universe. In addition, the existence only one kind of H-bond in ice Ih is demonstrated from the overlapping sub-spectra for different types of $\mathrm{H}$-bonded pair configurations in 16 isomers of ice $\mathrm{Ih}$.

The region of water under negative pressure is an exotic land in lack of exploitation. Guest free clathrate hydrate (clathrate ice) of sII type has been recently confirmed experimentally at negative pressure. Does any other clathrate ice phase exist at negative pressure region? Since clathrate hydrate are isostructural with silica clathrate minerals and semiconductor clathrates, and crystal structure prediction by analogy with known structures and first-principles computations is an effective way to find new crystalline phases of solid materials, we are motived to look for new clathrate ice phases from silica or semiconductor clathrate materials based on first-principles computations. Borrowing the idea new clathrate frameworks of $\mathrm{ZnO}$ and $\mathrm{SiC}$ can be constructed by connecting their bubble clusters in different ways, new clathrate ice phases (sL, sL_I, sL_II, and sL_III) are generated by connecting the water bubble clusters according to different rules. Using the non-local dispersioncorrected vdW-DF2 functional, clathrate ice sL with ultralow density $\left(0.6 \mathrm{~g} / \mathrm{cm}^{3}\right)$ is predicted by first-principles phase diagram computations to be stable under larger negative pressures than the sII phase. The phase diagram of water is thus extended into the lower negative pressure region. 


\section{Populärvetenskaplig sammanfattning}

I denna avhandling har olika vattenbaserade kemiska system studerats, i synnerhet föreningar mellan naturgas och vatten, ofta kallade hydrater, kluster av vattenmolekyler samt kristallin is. Naturgasinnehållande hydrater (NGHs) är is-liknande föreningar, där molekyler av kolväten kapslats in i hålrum som uppkommer inuti ett ramverk av vätebundna vattenmolekyler. NGHs har även kallats för "brinnande is", då ämnet på grund av sitt naturgasinnehåll kan fås att brinna. Ett vattenkluster består däremot av ett begränsat antal vattenmolekyler vilka hålls samman genom vätebindningar. Kristallin is, eller helt enkelt is, är vatten i fast fas och är, som alla vet, vanligt förekommande under kalla årstider. Hittills har man kunnat identifiera 17 olika former av is. All naturlig is som förekommer på jordytan är av typen Ih, men i denna avhandling har jag även studerat is som förekommer vid mycket låga temperaturer (t.ex. is XI) eller låga tryck (t.ex. klatratisen sL).

NGHs anses ha stor potentiell betydelse både när det gäller energiförsörjning och som miljöhot. Pipelines som transporterar olja eller naturgas kan under vissa betingelser täppas igen genom spontan bildning av NGHs. Kanske mest anmärkningsvärt är att NGHs av vissa anses som en lovande framtida energikälla på grund av den oerhörda mängd kolväten som jordens NGHavlagringar anses inrymma. Man har uppskattat att mängden kol, som förekommer i sådana avlagringar på botten av oceanerna eller i permafrost, i varje fall uppgår till den dubbla mängden av alla fossila bränslen sammantaget. Följaktligen måste hänsyn tas till de miljöproblem som kan uppstå vid utvinning av NGHs. Om stora mängder av de NGHs som finns lagrade under havsbotten eller i permafrost, plötsligt skulle frigöras skulle det kunna framkalla en global katastrof, då den snabba ökningen av metan i atmosfären allvarligt skulle påskynda den globala uppvärmningen. I detta arbete har stabiliteten hos olika NGH-föreningar studerats och förväntade utseenden hos Raman- och NMRspektra av dessa föreningar har beräknats. De teoretiska resultaten ökar den tillgängliga kunskapen om Raman and ${ }^{13} \mathrm{C}$ NMR för dessa föreningar och kan förhoppningsvis bidra med värdefull information när det gäller identifikationen av olika NGHs och de olika typer av kolväten som förekommer i föreningarna i prover hämtade från naturen.

Vatten är ett nödvändigt ämne både för uppkomsten och vidmakthållandet av biologiskt liv och dess betydelse för oräkneliga biologiska processer är välkänd. Vatten är vår viktigaste naturresurs och inom kemin utgör vatten det viktigaste lösningsmedlet. Vid sidan av jordbruket slukar även flertalet industriella tillverkningsprocesser stora mängder vatten.

Kluster av vattenmolekyler är föremål för många vetenskapliga studier på grund av deras betydelse för till exempel den atmosfäriska kemin, bildningen av moln och is och olika biokemiska processer. Genom att undersöka 
egenskaperna hos vattenkluster kan man nå en djupare förståelse för vattnets bulkegenskaper både $\mathrm{i}$ vätskeform och $\mathrm{i}$ fast tillstånd. I föreliggande arbete har geometrin, strukturen och stabiliteten hos tre olika vattenkluster $\left(\mathrm{H}_{2} \mathrm{O}\right)_{20},\left(\mathrm{H}_{2} \mathrm{O}\right)_{54}$, och $\left(\mathrm{H}_{2} \mathrm{O}\right)_{100}$ undersökts. De tre klustertyperna benämns här små, medelstora eller stora vattenkluster. Beräknade IR-spektra för de tre klustertyperna presenteras också. Vi har funnit att vissa specifika spektroskopiska karakteristika ("fingeravtryck") är till hjälp när det gäller att avgöra hur vattenmolekylerna ordnar sig inom ett kluster.

Som nämnt känner man för närvarande till 17 olika kristallstrukturer hos is, där is Ih är den enda typen av is som förekommer naturligt på jordytan. Is Ih, som är paraelektrisk, omvandlas vid $72 \mathrm{~K}\left(-201{ }^{\circ} \mathrm{C}\right)$ till is XI, som är ferroelektrisk, med andra ord uppvisar permanent elektrisk polarisering. Som en följd av detta har is XI föreslagits spela en roll för uppkomsten av solsystemets planeter, då ett mycket starkt elektriskt fält skulle kunna skapas kring is XI i rymden. Det elektriska fältet skulle i sin tur kunnat attrahera och ordna annan materia. I detta arbete har IR- och Ramanspektra av is Ih och XI beräknats och jämförts. Spektroskopiska karakteristika för is XI har kunnat identifieras och kan användas för att särskilja ferroelektrisk is XI från paraelektrisk is Ih i universum.

Klatratis är ett slags kristallin is som existerar vid negativt tryck. Kunskapen om is under negativt tryck är synnerligen ofullständig, då detta exceptionella trycktillstånd är mycket svårt att uppnå experimentellt. En ny fas av klatratis, här döpt till sL ("structure Liu"), med mycket låg densitet $\left(0.6 \mathrm{~g} / \mathrm{cm}^{3}\right)$ har påvisats teoretiskt av oss och vi gör förutsägelsen att denna fas är stabil vid tillräckligt negativa tryck. En möjlighet är att den nya fasen i framtiden skulle kunna tjäna som ett utomordentligt lagringsmaterial för väte både på grund av de mycket stora hålrummen i strukturen men även på grund av den låga densiteten. 


\section{Papers included in the thesis}

1. Fingerprints in IR OH vibrational spectral of $\mathrm{H}_{2} \mathrm{O}$ clusters from different $\mathrm{H}$ bond conformations by means of quantum-chemical computations.

Yuan Liu and Lars Ojamäe

Journal of Molecular Modeling 2014, 20, 2281.

2. C-C stretching Raman spectra and stabilities of hydrocarbon molecules in natural gas hydrates: a quantum-chemical study.

Yuan Liu and Lars Ojamäe

Journal of Physical Chemistry A 2014, 118, 11641-11651.

3. $\mathrm{CH}$-stretching vibrational trends in natural gas hydrates studied by quantumchemical computations.

Yuan Liu and Lars Ojamäe

Journal of Physical Chemistry C 2015, 119, 17084-17091.

4. ${ }^{13} \mathrm{C}$ chemical shift in natural gas hydrates from first-principles solid-state NMR calculations.

Yuan Liu and Lars Ojamäe

Journal of Physical Chemistry C 2016, 120, 1130-1136.

5. Raman and IR spectra of ice Ih and ice XI with an assessment of DFT methods.

Yuan Liu and Lars Ojamäe

Accepted by Journal of Physical Chemistry B 2016, DOI: 10.1021/acs.jpcb.6b07001.

6. Clathrate ice sL: a new crystalline phase of ice under negative pressure with ultralow density.

Yuan Liu and Lars Ojamäe

In manuscript 


\section{My contribution to these papers}

I have mainly designed the work, performed the calculations, analyzed the data, prepared the figures, and written the manuscripts.

\section{Papers not included in the thesis}

1. Mechanical and thermal properties of methane clathrate hydrates as an alternative energy resource.

Hu Huo, Yuan Liu, Zhaoyang Zheng, Jijun Zhao, Changqing Jin, and Tianquan $\mathrm{Lv}$

Journal of Renewable and Sustainable Energy 2011, 3, 063110.

2. Improved stability of water clusters $\left(\mathrm{H}_{2} \mathrm{O}\right)_{30-48}$ : a Monte Carlo search coupled with DFT computations.

Fengyu Li, Yuan Liu, Lu Wang, Jijun Zhao, Zhongfang Chen

Theoretical Chemistry Accounts 2012, 131, 1163.

3. Nonstandard cages in the formation process of methane clathrate: stability, structure, and spectroscopic implications from first-principles.

Lingli Tang, Yan Su, Yuan Liu, Jijun Zhao, and Ruifeng Qiu

Journal of Chemistry Physics 2012, 136, 224508.

4. Dissociation mechanism of carbon dioxide hydrate by molecular dynamics simulation and ab initio calculation

Yuan Liu, Jijun Zhao, and Jingcheng Xu

Computational and Theoretical Chemistry 2012, 991, 165-173.

5. Appropriate description of intermolecular interactions in the methane hydrates: an assessment of DFT methods.

Yuan Liu, Jijun Zhao, Fengyu Li, and Zhongfang Chen

Journal of Computational Chemistry 2013, 34, 121-131.

6. Storage capacity and vibration frequencies of guest molecules in $\mathrm{CH}_{4}$ and $\mathrm{CO}_{2}$ hydrates by first-principles calculations. 
Xiaoxiao Cao, Yan Su, Yuan Liu, Jijun Zhao, and Changling Liu

Journal of Physical Chemistry A 2014, 118, 215-222.

7. Dissociation mechanism of gas hydrates (I, II, H) of alkane molecules: a comparative molecular dynamics simulation.

Yingying Huang, Yuan Liu, Yan Su, and Jijun Zhao

Molecular simulation 2015, 41, 1086.

8. Keys and regulators of nanoscale theranostics.

Amineh Ghaderi, Eduardo Antunez de Mayolo, Hirak Kumar Patra, Mohsen Golabi, Onur Parlak, Rickard Gunnarsson, Paul Campos, Revuri Vishnu, Sami Elhag, Selvakumar Subramanain, Wetra Yandi, Yuan Liu, Yugal Agrawal, and Ashutosh Tiwari

Advanced Materials Letters 2015, 6, 87-98. 


\section{Contents}

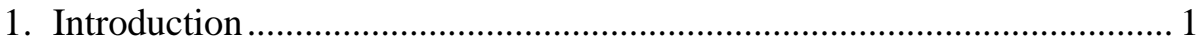

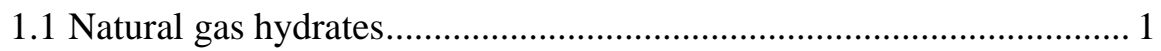

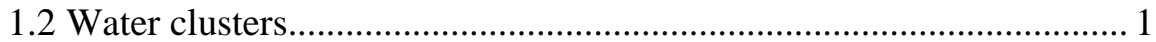

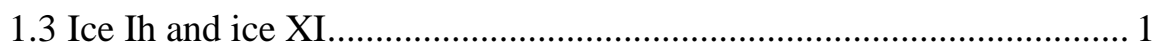

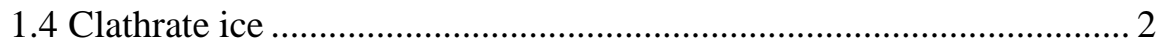

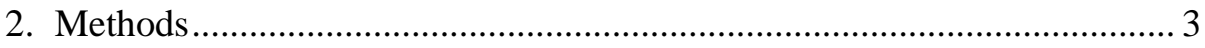

2.1 Density functional theory.............................................................. 3

2.2 Statistical thermodynamics ............................................................. 4

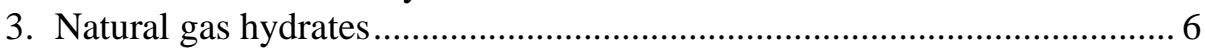

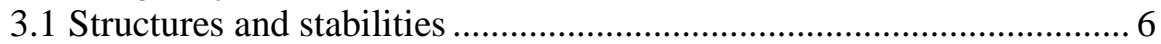

3.2 Raman spectroscopic characteristics .................................................. 9

$3.3{ }^{13} \mathrm{C}$ NMR chemical shift of hydrocarbon molecules........................... 13

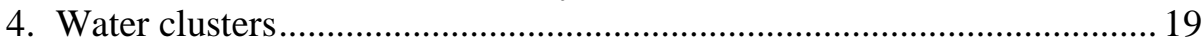

4.1 Geometry structures and thermodynamic stabilities ........................... 19

4.2 IR spectroscopic characteristics..................................................... 20

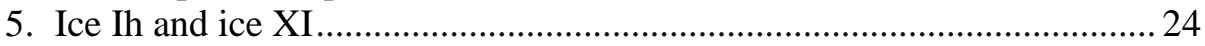

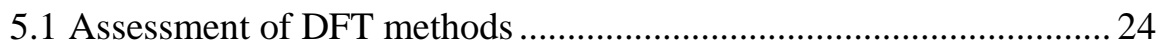

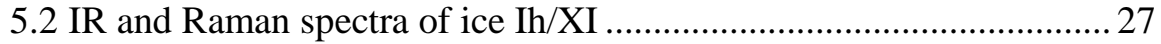

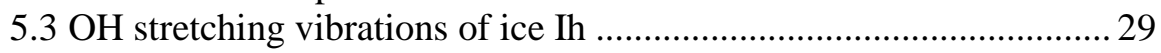

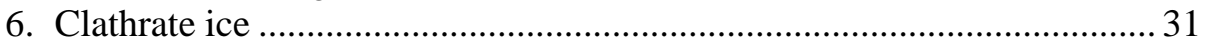

6.1 Structure parameters of various clathrate ices ................................... 31

6.2 Lattice energies, relative enthalpies and vibrational frequencies ....... 32

6.3 First-principles phase diagram of water under negative pressure ...... 35

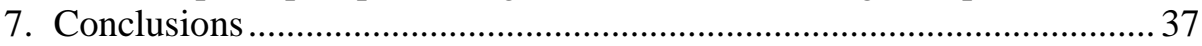

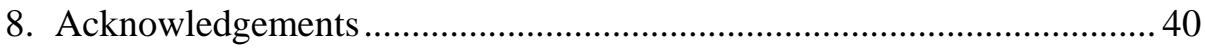

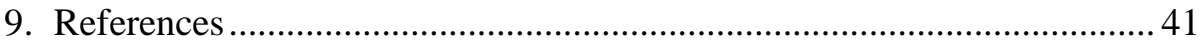




\section{Introduction}

In this thesis H-bonded systems (natural gas hydrates, ${ }^{1-3}$ water clusters, ${ }^{4}$ and crystal ice ${ }^{5}$ ) are studied by density functional theory (DFT) computations.

\subsection{Natural gas hydrates}

Natural gas hydrates (NGHs) are ice-like inclusion compounds, which have been suggested to be a promising backup energy source since the amount of carbon included in NGHs on earth is estimated to be at least twice the amount of that in all fossil fuels (e.g. coal, oil, and natural gas etc.) combined.$^{6-7}$ However, the problems that may occur during exploitation of the NGHs deposit sites must be considered. If a large amount of NGHs deposits under the ocean floor is rapidly dissociated out of control as the pressure and temperature conditions change by the exploitation, it may induce geological disasters and the release of methane gas into the atmosphere could aggravate globe warming. ${ }^{6-8}$ Besides, the pipelines of oil and natural gas may be blocked by chunks of NGH under certain conditions. ${ }^{6-8}$ Meanwhile, many technologies based on gas hydrates are being applied or developed, such as hydrogen storage, ${ }^{9-10}$ carbon dioxide sequestration, ${ }^{11-12}$ gas mixture separation, ${ }^{13-14}$ seawater desalination,,${ }^{15}$ and fire extinguishers by means of the heat absorption and large amount of $\mathrm{CO}_{2}$ release during the dissociation of $\mathrm{CO}_{2}$ hydrates. ${ }^{16}$

All the applications can be attributed to the unique clathrate structures formed by the frameworks of $\mathrm{H}$-bonded water molecules. Hydrocarbon gas molecules or other gas molecules (also called guest molecules) are encapsulated in various water cavities of the host frameworks. Different crystal phases of hydrates can be formed under appropriate pressure and temperature conditions, such as $\mathrm{sI},{ }^{17}$ sII, ${ }^{18} \mathrm{sH},{ }^{19}$ and some unusual phases (TS-I, ${ }^{20} \mathrm{HS}-\mathrm{I},{ }^{21} \mathrm{sK},{ }^{22} \mathrm{MH}-\mathrm{III},{ }^{23-24}$ and "filled ice" ${ }^{24-25}$ ).

\subsection{Water clusters}

Water is a very common substance which can be found almost everywhere. It is necessary for the origin and sustainability of life, and is essential in numerous biological processes, as well as being the foremost solvent in chemical experiments and manufacturing. ${ }^{26}$ Water clusters are formed by a few or many $\mathrm{H}$-bonded water molecules. Due to their importance in both inorganic and biochemical processes, the studies of water clusters interest many researchers. ${ }^{26-}$ 30 The structures of water clusters from small to large sizes have been investigated both experimentally and theoretically. ${ }^{31-41}$ Though studies of the properties of water clusters help in the understanding of the behavior of its liquid and solid phases.

\subsection{Ice Ih and ice XI}

The solid phase of water is ice, which has been found in 17 different crystalline phases until now. ${ }^{5}$ In each phase, the arrangements of oxygen atoms are long- 
range ordered in a specific symmetry with the hydrogen atoms arranged around the oxygen atoms following the ice rules. ${ }^{42}$ Some of the ice phases are protondisordered $\left(\mathrm{Ih},{ }^{43} \mathrm{Ic},{ }^{44} \mathrm{III},{ }^{45} \mathrm{IV},{ }^{46} \mathrm{~V},{ }^{47} \mathrm{VI},{ }^{48} \mathrm{VII},{ }^{49} \mathrm{XII},{ }^{50}\right.$ and $\mathrm{XVI}{ }^{51}$ ) and the others are proton-ordered (II, ${ }^{52} \mathrm{VIII},{ }^{53} \mathrm{IX},{ }^{54} \mathrm{X},{ }^{55} \mathrm{XI},{ }^{56} \mathrm{XIII},{ }^{57} \mathrm{XIV},{ }^{57}$ and $\mathrm{XV}^{58}$ ).

The ordinary solid phase of water is the proton-disordered ice $\mathrm{Ih}$, the only ice existing on the earth surface. A proton disorder-order transition at low temperatures can occur. The proton-ordered phase ice XI confirmed to be the orthorhombic $\mathrm{Cmc} 2_{1}$ space group by neutron diffraction ${ }^{56}$ has been measured from $\mathrm{KOH}$ doped ice Ih at $72 \mathrm{~K}^{59-60}$ The ferroelectric character of ice XI has been revealed by thermal stimulated depolarization studies. ${ }^{61}$ Ice XI has been suggested to be related with the process of planetary formation as a considerable electric field might be formed from the ferroelectric ice XI in space. ${ }^{62-64} \mathrm{~A}$ lot of effort has been put into ice Ih and ice XI studies both experimentally and theoretically.

\subsection{Clathrate ice}

Water is a very unique substance in the universe due to both its importance to life, nature, and science and its anomalous properties, e.g. maximum density at 4 ${ }^{\circ} \mathrm{C}$ and the density of solid state lower than that of liquid state at ambient pressure, negative thermal expansion of ice at low temperature, and many more. ${ }^{26,65-67}$ Life is miraculously related with the anomalous behavior of water. ${ }^{26}$, 65-67 The origin of the anomalies of water has been well understood at some extent after enduring strength efforts. ${ }^{26,65-68}$ However, the region of water under negative pressure is very less studied until now, ${ }^{69-74}$ which seems like an exotic land in lack of exploitation. Only one crystalline ice phase has been recently confirmed at negative pressure by experiment. ${ }^{51}$ As a promising backup energy resource, clathrate hydrates of natural gases have been hitherto focused on much attention. ${ }^{6-8}$ Several clathrate hydrate phases are proposed, e.g. sI, sII, sH, sK, etc. ${ }^{1-3,6}$ Clathrate ice is the guest free clathrate hydrate. Clathrate ice sII is recently obtained through pumping off the guest molecules of sII Ne clathrate hydrate by Falenty et al. ${ }^{51}$ which has negative thermal expansion below $55 \mathrm{~K}$ and is stable at negative pressure in the range of 0.4 and $1 \mathrm{GPa} .{ }^{51}$ Does any other clathrate ice phase exist at negative pressure region? 


\section{Methods}

\subsection{Density functional theory (DFT)}

For a system of electrons and nuclei, the Hamiltonian is

$$
\hat{H}=-\frac{\hbar^{2}}{2 m_{e}} \sum_{i} \nabla_{i}^{2}+\sum_{i, I} \frac{Z_{I} e^{2}}{\left|r_{i}-R_{I}\right|}+\frac{1}{2} \sum_{i \neq j} \frac{e^{2}}{\left|r_{i}-r_{j}\right|}-\sum_{I} \frac{\hbar^{2}}{2 M_{I}} \nabla_{I}^{2}+\frac{1}{2} \sum_{I \neq J} \frac{Z_{I} Z_{J} e^{2}}{\left|R_{I}-R_{J}\right|}
$$

where electrons are denoted by lower case subscripts and nuclei, with charge $Z_{I}$ and mass $M_{I}$, denoted by upper case subscripts. The first term is the kinetic energy operator on the electron, the second term is the interaction between the electrons and the nuclei, the third term is the electron-electron interaction, the fourth term is the kinetic energy of nuclei, and the last term is the nucleusnucleus interaction. As the mass of nuclei are much larger than that of an electron, the kinetic energy of nuclei (the fourth term in eq. 2.1) can be ignored. It is also called the Born-Oppenheimer or adiabatic approximation. ${ }^{75-76}$

The ground-state Schrödinger equation for a system with $N$ electrons is

$$
\hat{H} \psi\left(r_{1}, r_{2}, \cdots, r_{N}\right)=E \psi\left(r_{1}, r_{2}, \cdots, r_{N}\right)
$$

where $\hat{H}$ is the Hamiltonian of the system, $\Psi\left(r_{1}, r_{2}, \ldots, r_{N}\right)$ is the ground-state wave function of the system, and $E$ is the ground-state energy of the electrons. The wave function is a function of the spatial coordinates of each of the $N$ electrons, which is a $3 \mathrm{~N}$ dimensional function (see eq. 2.2), for which it is difficult to find solutions for large system. However, based on the HohenbergKohn theorem, the external potential and energy can be described by the functional of electron density $n(r)$, which transforms the $3 \mathrm{~N}$ dimensional problem to a 3 dimensional problem. ${ }^{75-76}$

To solve the many-body problem based on DFT, an auxiliary independentparticle approximation is proposed by Kohn and Sham. The Kohn-Sham Schrödinger-like equation is derived:

$$
\begin{gathered}
\left\{-\frac{1}{2} \nabla^{2}+V_{K S}[n(r)]\right\} \varphi_{i}(r)=\varepsilon_{i} \varphi_{i}(r) \\
V_{K S}=V_{\text {ext }}+V_{\text {Hartree }}+V_{x c}
\end{gathered}
$$

where $\varphi_{i}(r)$ is the single-electron wave function, $n(r)=\sum_{i=1}^{N}\left|\varphi_{i}(r)\right|^{2}, V_{\text {ext }}$ represents the electron-nucleus interaction, $V_{\text {Hartree }}$ represents the electron-electron coulomb interaction, $V_{x c}$ represents the exchange-correlation interaction. The ground-state energy $E_{K S}$ of the full interaction many-body system by the Kohn-Sham approach is 


$$
E_{K S}=T_{s}[n(r)]+\int d r V_{\text {ext }}(r) n(r)+E_{\text {Harree }}[n(r)]+E_{I I}+E_{x c}[n(r)]
$$

where $T_{s}$ is the independent-particle kinetic energy, the second term is the electron-nucleus interaction energy, $E_{\text {Hartree }}$ is the electron-electron coulomb interaction energy, $E_{I I}$ is the nucleus-nucleus interaction energy, $E_{x c}$ is the exchange-correlation energy.

$$
E_{x c}=\langle\hat{T}\rangle-T_{s}+\left\langle\hat{V}_{\text {int }}\right\rangle-E_{\text {Hartree }}
$$

where $\langle\hat{T}\rangle$ is the kinetic energy of the true interacting many-body system, $\left\langle\hat{V}_{\text {int }}\right\rangle$ is the electron-electron interaction of the true interacting many-body system. Thus, all the many-body effects are grouped into the exchange-correlation energy $E_{x c}$, which is the difference between the kinetic and the interaction energy of the true interacting many-body system and those of the fictitious independent-particle system with electron-electron interaction energy replaced by the Hartree energy. ${ }^{75-76}$

The Kohn-Sham equation is solved by a numerical procedure to get a selfconsistent solution. Based on an initial guess wave functions, an initial function of electronic density is obtained, then each term of the Hamiltonian of the studied systems is expressed as a function of the electronic density. After solving the Kohn-Sham equation, if the new electronic density is the same with the last step, the exact solution is achieved and the total energy of the system will be output. ${ }^{75-76}$

\subsection{Statistical thermodynamics}

Based on thermodynamics, if the total partition function $\left(q_{\text {Total }}\right)$ of a system is known, all the thermodynamic quantities can be computed. The total partition function can be written:

$$
q_{\text {Total }}=q_{T} q_{R} q_{V} q_{E}
$$

where the subscripts $T, R, V$, and $E$ represent translational, rotational, vibrational, and electronic energetic degrees of freedom, respectively. ${ }^{77}$

The internal energy is given by:

$$
U=-N\left[\left(\frac{\partial \ln q_{T}}{\partial \beta}\right)_{V}+\left(\frac{\partial \ln q_{R}}{\partial \beta}\right)_{V}+\left(\frac{\partial \ln q_{V}}{\partial \beta}\right)_{V}+\left(\frac{\partial \ln q_{E}}{\partial \beta}\right)_{V}\right]=U_{T}+U_{R}+U_{V}+U_{E}
$$

For translation, the translational energy $\left(U_{T}\right)$ and the translational entropy $\left(S_{T}\right)$ are given by:

$$
\begin{aligned}
& U_{T}=\frac{3}{2} N k_{B} T=\frac{3}{2} n R T \\
& S_{T}=n R\left(\ln \left(\left(\frac{2 \pi m k_{B} T}{h^{2}}\right)^{3 / 2} \frac{V e}{n N_{A}}\right)+\frac{3}{2}\right)
\end{aligned}
$$


where $m$ is the mass of a molecule, $R=N \times N_{A}, k_{B}$ is Boltzmann constant, and $h$ is Planck constant.

For rotation, the corresponding quantities are:

for linear polyatomic molecules: $U_{R}=n R T$

$$
S_{R}=n R\left(\ln \left(\frac{\pi^{1 / 2}}{\sigma}\left(\frac{T^{3 / 2}}{\left(\Theta_{r, x} \Theta_{r, y} \Theta_{r, z}\right)^{1 / 2}}\right)\right)+1\right)
$$

and for nonlinear polyatomic molecules: $U_{R}=\frac{3}{2} n R T$

$$
S_{R}=n R\left(\ln \left(\frac{\pi^{1 / 2}}{\sigma}\left(\frac{T^{3 / 2}}{\left(\Theta_{r, x} \Theta_{r, y} \Theta_{r, z}\right)^{1 / 2}}\right)\right)+\frac{3}{2}\right)
$$

where $\Theta_{r}=h^{2} / 8 \pi^{2} I k_{B}$, and $I$ is the moment of inertia.

Finally, for vibrational motion, the energy and entropy are given by:

$$
\begin{aligned}
U_{V} & =n R \sum_{i} \frac{h v_{i}}{k_{B}}\left(\frac{1}{2}+\frac{1}{\exp \left(h v_{i} / k_{B} T\right)-1}\right) \\
S_{V} & =n R \sum_{i}\left(\frac{h v_{i} / k_{B} T}{\exp \left(h v_{i} / k_{B} T\right)-1}-\ln \left(1-\exp \left(-h v_{i} / k_{B} T\right)\right)\right)
\end{aligned}
$$

where $v_{i}$ are the vibrational frequencies.

The Enthalpy is given by $H=U+P V$, and the Helmholtz free energy and Gibbs free energy are given by $A=U-T S$ and $G=U+P V-T S$.

At a constant temperature, the Pressure can be obtained by $P=-\left(\frac{\partial A}{\partial V}\right)_{T}$.

Based on the formula mentioned above, all the thermodynamic quantities can be computed. ${ }^{77}$ Then a first-principles phase diagram of solid materials can be established. 


\section{Natural gas hydrates}

\subsection{Structures and stabilities (Paper II)}
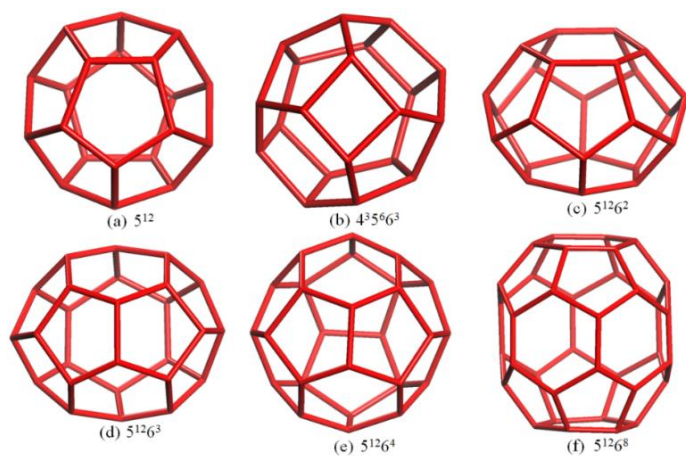

Figure 3.1. The six types of water cavities in NGHs. The $4^{x} 5^{y} 6^{z}$ means the cage is made up of $\mathrm{x}$ four-, $\mathrm{y}$ five-, and $\mathrm{z}$ six-membered rings.

The host lattice of natural gas hydrates is made up of hydrogen bonded water molecules, and hydrocarbon gas molecules are enclosed in different types of water cavities of the host framework. Six types of polyhedral cavities exsit in the well-known phases sI, sII, and sH, and in the unusual phase sK (see Figure 3.1), which are dodecahedral (D) cavities $\left(5^{12}\right)$, irregular dodecahedral (ID) cavities $\left(4^{3} 5^{6} 6^{3}\right)$, tetrakaidecahedral $(\mathrm{T})$ cavities $\left(5^{12} 6^{2}\right)$, pentakaidehedral $(\mathrm{P})$ cavities $\left(5^{12} 6^{3}\right)$, hexakaidecahedral $(\mathrm{H})$ cavities $\left(5^{12} 6^{4}\right)$, and icosahedral (I) cavities $\left(5^{12} 6^{8}\right)$, respectively. ${ }^{1,}{ }^{6}$ Detailed structure information on the unit cells of various crystal phases is given in Table 3.1.

Table 3.1. Structural properties of the cavities in different crystal phases of hydrates.

\begin{tabular}{|c|c|c|c|c|c|c|c|c|c|c|}
\hline Crystal phase & \multicolumn{2}{|c|}{ sI } & \multicolumn{2}{c|}{ sII } & \multicolumn{3}{c|}{ sH } & \multicolumn{3}{c|}{ sK } \\
\hline Formula & $2 \mathrm{X} 6 \mathrm{Y} \bullet 46 \mathrm{H}_{2} \mathrm{O}$ & \multicolumn{1}{|c|}{$16 \mathrm{X} 8 \mathrm{Y} \cdot 136 \mathrm{H}_{2} \mathrm{O}$} & \multicolumn{2}{|c|}{$3 \mathrm{X} 2 \mathrm{Y} 1 \mathrm{Z}^{3} 34 \mathrm{H}_{2} \mathrm{O}$} & \multicolumn{3}{c|}{$6 \mathrm{X} 4 \mathrm{Y} 4 \mathrm{Z}^{\circ} 80 \mathrm{H}_{2} \mathrm{O}$} \\
\hline Cavity & $5^{12}$ & $5^{12} 6^{2}$ & $5^{12}$ & $5^{12} 6^{4}$ & $5^{12}$ & $4^{3} 5^{3} 6^{3}$ & $5^{12} 6^{8}$ & $5^{12}$ & $5^{12} 6^{2}$ & $5^{12} 6^{3}$ \\
\hline Description & $\mathrm{D}$ & $\mathrm{T}$ & $\mathrm{D}$ & $\mathrm{H}$ & $\mathrm{D}$ & $\mathrm{ID}$ & $\mathrm{I}$ & $\mathrm{D}$ & $\mathrm{T}$ & $\mathrm{P}$ \\
\hline $\begin{array}{c}\text { No. of cavities } \\
\text { per unit cell }\end{array}$ & 2 & 6 & 16 & 8 & 3 & 2 & 1 & 6 & 4 & 4 \\
\hline Average cavity radius/A & 3.95 & 4.33 & 3.91 & 4.73 & 3.91 & 4.06 & 5.71 & 4.00 & 4.30 & 4.60 \\
\hline Coordination number & 20 & 24 & 20 & 28 & 20 & 20 & 36 & 20 & 24 & 26 \\
\hline
\end{tabular}

Note: $\mathrm{X}, \mathrm{Y}$, and $\mathrm{Z}$ represent the suitable guest molecules. 

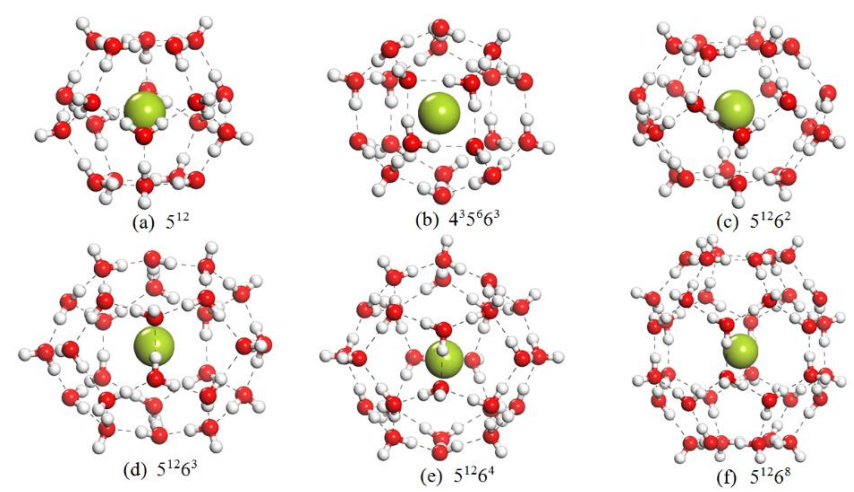

Figure 3.2. Structures of hydrocarbon molecules encapsulated in various water cages: (a) D cage, (b) ID cage, (c) T cage, (d) P cage, (e) H cage, (f) I cage, from different crystal phases of clathrate hydrates. Colour scheme: red spheres represent oxygen atoms, white spheres represent hydrogen atoms, green spheres represent various hydrocarbon molecules, and black lines represent hydrogen bonds.

In NGHs system, the van der Waals (vdW) interactions between guest molecule and host water cavity and the H-bonding interactions among water molecules determine the stability of the clathrate lattice. ${ }^{78}$ Thus, we evaluated the host-guest interactions $\left(\Delta E_{\text {host-guest }}\right)$ between each hydrocarbon molecule and the occupied water cavity and cohesive energy per water molecule $\left(\Delta E_{c o h}\right)$ employing the dispersion-corrected $\omega \mathrm{B} 97 \mathrm{X}-\mathrm{D}^{79}$ density functional together with the $6-311++\mathrm{G}(2 \mathrm{~d}, 2 \mathrm{p})^{80}$ basis set. As listed in Table 3.2, the $\Delta E_{\text {host-guest }}$ of $\mathrm{CH}_{4} @ \mathrm{D}$ and $\mathrm{CH}_{4} @ \mathrm{ID}$ is lower than for the other cages. For ethane, it interacts more favorably when encapsulated in a $\mathrm{T}$ and $\mathrm{P}$ cage than in the other cages. $\mathrm{C}_{3} \mathrm{H}_{6}, \mathrm{C}_{3} \mathrm{H}_{8}$, and $\mathrm{C}_{4} \mathrm{H}_{8}$ interact most strongly with the cage when trapped in $\mathrm{P}$ cages. Both $\mathrm{i}-\mathrm{C}_{4} \mathrm{H}_{10}$ and $\mathrm{n}-\mathrm{C}_{4} \mathrm{H}_{10}$ binds the strongest in an $\mathrm{H}$ cage. Regarding the cohesive energy listed in Table 3.3, the water cavity occupied by a guest molecule will be more stable than the empty cage except when the guest molecule does not fit into the cage, i.e. $\mathrm{C}_{3} \mathrm{H}_{8}$ and $\mathrm{C}_{4} \mathrm{H}_{8}$ in a $\mathrm{D}$ cage. The empty water cages have similar cohesion energies. For $\mathrm{CH}_{4}$, the largest stabilization is obtained when it occupies a D cage. For $\mathrm{C}_{2} \mathrm{H}_{6}, \mathrm{C}_{3} \mathrm{H}_{6}$, and $\mathrm{C}_{3} \mathrm{H}_{8}$, the maximum stabilization occurs when they are encapsulated in a $\mathrm{T}$ cage. However, very similar cohesive energy is obtained when $\mathrm{C}_{4} \mathrm{H}_{8}$ occupies a $\mathrm{T}, \mathrm{P}$, or an $\mathrm{H}$ cage. Finally, both $\mathrm{i}-\mathrm{C}_{4} \mathrm{H}_{10}$ and $\mathrm{n}-\mathrm{C}_{4} \mathrm{H}_{10}$ will gain the most cohesive energy when occupying an $\mathrm{H}$ cage. In addition, the zero-point energy (ZPE) effect is also studied, which is quite significant for both $\Delta E_{\text {host-guest }}$ and $\Delta E_{c o h}{ }^{1}$ 
Table 3.2. Interaction energies between host water cages and guest molecules for each water cavity occupied by different hydrocarbon molecules with and without ZPE correction.

\begin{tabular}{|c|c|c|c|c|c|c|}
\hline & \multicolumn{7}{|c|}{$\Delta E_{\text {Host-Gust }}$ with/without $\mathrm{ZPE}$ correction $(\mathrm{kcal} / \mathrm{mol})$} \\
\hline $\begin{array}{c}\text { Host } \\
\text { Gues }\end{array}$ & D cage & ID cage & T cage & P cage & H cage & I cage \\
\hline $\mathrm{CH}_{4}$ & $-5.51 /-7.16$ & $-5.41 /-6.81$ & $-4.80 /-6.01$ & $-4.93 /-5.66$ & $-4.40 /-5.12$ & $-3.33 /-5.36$ \\
\hline $\mathrm{C}_{2} \mathrm{H}_{6}$ & $-6.69 /-9.71$ & $-6.74 /-9.31$ & $-9.01 /-10.11$ & $-9.10 /-9.56$ & $-8.34 /-8.74$ & $-6.82 /-8.23$ \\
\hline $\mathrm{C}_{3} \mathrm{H}_{6}$ & $-6.09 /-8.81$ & $-6.11 /-8.77$ & $-10.79 /-11.76$ & $-11.10 /-11.80$ & $-10.80 /-11.64$ & $-8.94 /-10.25$ \\
\hline $\mathrm{C}_{3} \mathrm{H}_{8}$ & $0.86 /-1.89$ & $-3.65 /-7.43$ & $-10.68 /-12.99$ & $-11.22 /-12.74$ & $-10.92 /-12.25$ & $-9.67 /-11.27$ \\
\hline $\mathrm{C}_{4} \mathrm{H}_{8}$ & $0.36 /-2.66$ & $-2.82 /-6.08$ & $-11.55 /-14.48$ & $-13.94 /-15.36$ & $-13.87 /-15.10$ & $-11.56 /-12.46$ \\
\hline $\mathrm{i}-\mathrm{C}_{4} \mathrm{H}_{10}$ & - & - & $-6.91 /-9.53$ & $-12.74 /-15.12$ & $-13.29 /-15.07$ & $-11.93 /-13.65$ \\
\hline $\mathrm{n}-\mathrm{C}_{4} \mathrm{H}_{10}$ & - & - & $-6.98 /-10.20$ & $-12.63 /-14.36$ & $-13.74 /-15.43$ & $-12.40 /-13.73$ \\
\hline
\end{tabular}

Table 3.3. Cohesive energies per water molecule $\left(\Delta E_{c o h}\right)$ of empty water cavities and water cavities occupied by different hydrocarbon molecules with and without ZPE correction.

\begin{tabular}{|c|c|c|c|c|c|c|}
\hline & \multicolumn{6}{|c|}{$\Delta E_{\text {coh }}$ with/without ZPE correction $(\mathrm{kcal} / \mathrm{mol})$} \\
\hline Guest Host & D cage & ID cage & T cage & P cage & H cage & I cage \\
\hline Empty & $-8.13 /-10.79$ & $-8.08 /-10.73$ & $-8.16 /-10.81$ & $-8.09 /-10.76$ & $-8.14 /-10.80$ & $-8.12 /-10.77$ \\
\hline $\mathrm{CH}_{4}$ & $-8.40 /-11.14$ & $-8.35 /-11.07$ & $-8.36 /-11.06$ & $-8.28 /-10.98$ & $-8.30 /-10.98$ & $-8.22 /-10.92$ \\
\hline $\mathrm{C}_{2} \mathrm{H}_{6}$ & $-8.46 /-11.27$ & $-8.42 /-11.19$ & $-8.53 /-11.23$ & $-8.44 /-11.13$ & $-8.44 /-11.11$ & $-8.31 /-11.00$ \\
\hline $\mathrm{C}_{3} \mathrm{H}_{6}$ & $-8.43 /-11.23$ & $-8.39 /-11.17$ & $-8.61 /-11.30$ & $-8.52 /-11.22$ & $-8.53 /-11.22$ & $-8.37 /-11.06$ \\
\hline $\mathrm{C}_{3} \mathrm{H}_{8}$ & $-8.09 /-10.88$ & $-8.27 /-11.10$ & $-8.60 /-11.36$ & $-8.53 /-11.25$ & $-8.53 /-11.24$ & $-8.39 /-11.08$ \\
\hline $\mathrm{C}_{4} \mathrm{H}_{8}$ & $-8.11 /-10.92$ & $-8.22 /-11.03$ & $-8.64 /-11.42$ & $-8.63 /-11.35$ & $-8.63 /-11.34$ & $-8.45 /-11.12$ \\
\hline $\mathrm{i}-\mathrm{C}_{4} \mathrm{H}_{10}$ & - & - & $-8.44 /-11.21$ & $-8.58 /-11.34$ & $-8.61 /-11.34$ & $-8.46 /-11.15$ \\
\hline $\mathrm{n}^{-} \mathrm{C}_{4} \mathrm{H}_{10}$ & - & - & $-8.45 /-11.24$ & $-8.58 /-11.32$ & $-8.63 /-11.35$ & $-8.47 /-11.15$ \\
\hline
\end{tabular}

The reaction enthalpies $\left(\Delta H_{\text {host-guest }}\right.$ and $\left.\Delta H_{c o h}\right)$ and the changes in Gibbs free energy $\left(\Delta G_{\text {host-guest }}\right.$ and $\left.\Delta G_{c o h}\right)$ of forming various water cavities encapsulated with hydrocarbon molecules in the NGH models at 77 atm and $273 \mathrm{~K}$ are also computed, shown in Figure 3.3. Both the formation processes of enclathrated molecules from free guest molecules and water cages (except for encapsulation of $\mathrm{C}_{3} \mathrm{H}_{8}$ or $\mathrm{C}_{4} \mathrm{H}_{8}$ in a $\mathrm{D}$ cage) and the formation of the complexes from free water molecules and a hydrocarbon molecule are exothermic processes. From comparison of $\Delta G_{\text {host-guest }}$ for the same guest molecule encapsulated in different water cavities, $\mathrm{CH}_{4}$ prefer to be trapped in an $\mathrm{H}$ (or possibly $\mathrm{P}$ ) cage; $\mathrm{C}_{2} \mathrm{H}_{6}$ and $\mathrm{C}_{4} \mathrm{H}_{8}$ a $\mathrm{H}$ cage; $\mathrm{C}_{3} \mathrm{H}_{6}$ a $\mathrm{P}$ (or possibly $\mathrm{H}$ ) cage; $\mathrm{C}_{3} \mathrm{H}_{8}$ a I (or possibly $\mathrm{H}$ ) cage; i$\mathrm{C}_{4} \mathrm{H}_{10}$ and $\mathrm{n}-\mathrm{C}_{4} \mathrm{H}_{10}$ prefer a $\mathrm{I}$ cage. If the complexes are formed from isolated water molecules and hydrocarbons, the most favorable combination (lowest $\left.\Delta G_{c o h}\right)$ for each guest molecule is $\mathrm{CH}_{4} @ \mathrm{ID}, \mathrm{C}_{2} \mathrm{H}_{6} @ \mathrm{~T}, \mathrm{C}_{3} \mathrm{H}_{6} / \mathrm{C}_{3} \mathrm{H}_{8} @ \mathrm{~T}$ or $\mathrm{H}$, $\mathrm{C}_{4} \mathrm{H}_{8} / \mathrm{i}-\mathrm{C}_{4} \mathrm{H}_{10} @ \mathrm{H}$, and n- $\mathrm{C}_{4} \mathrm{H}_{10} @ \mathrm{I}^{1}$ 


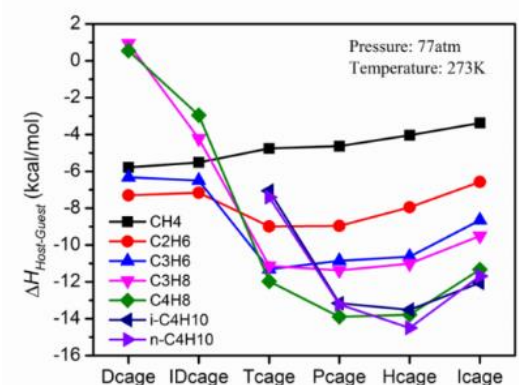

(a)

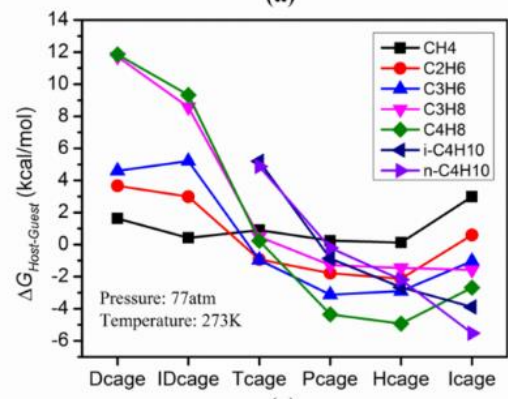

(c)

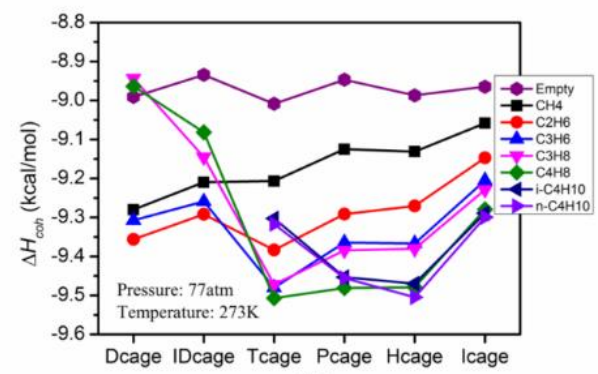

(b)

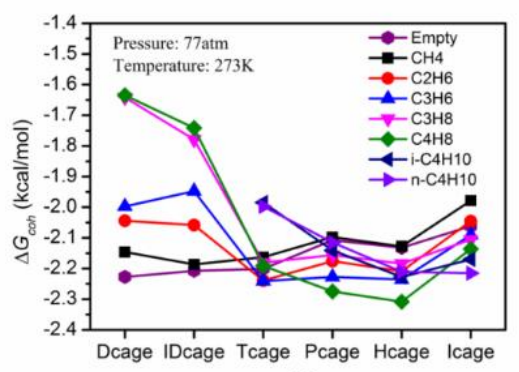

(d)

Figure 3.3. Host-guest interaction enthalpies and Gibbs free energies, and cohesive enthalpies and Gibbs free energies for water cavities enclosing hydrocarbon molecules. (a) $\Delta H_{\text {host-guest }}$, (b) $\Delta H_{\text {coh }}$, (c) $\Delta G_{\text {host-guest }},(\mathrm{d}) \Delta G_{\text {coh }}$.

\subsection{Raman spectroscopic characteristics (Paper II and III)}

The Raman spectra of guest molecules are often used to identify the types of crystal structure of NGHs and the types of guest molecules. ${ }^{1-2,81-83}$ In papers II and III, the C-C and C-H stretching vibrational Raman spectra of hydrocarbon molecules trapped in various water cavities of NGHs were computed at the $\omega \mathrm{B} 97 \mathrm{X}-\mathrm{D}^{79} / 6-311++\mathrm{G}(2 \mathrm{~d}, 2 \mathrm{p})^{80}$ level in Gaussian 09 program. ${ }^{84}$

As seen in Figure 3.4a, the $\mathrm{C}-\mathrm{C}$ stretching frequencies of ethane in various water cavities are red-shifted when going from the $\mathrm{D}$ to the $\mathrm{H}$ cage and the frequency of ethane in the I cage is almost equal to that in the gas phase. The Raman spectra of the C-C stretching modes of $\mathrm{C}_{3} \mathrm{H}_{8}$ and i- $\mathrm{C}_{4} \mathrm{H}_{10}$ are depicted in Figure $3.4 \mathrm{~b}$ and Figure $3.5 \mathrm{a}$, both the symmetric and antisymmetric frequencies are blue-shifted compared to in the gas phase. The C-C stretching frequencies are red-shifted as the radii of the water cavities increase. Regarding $n-C_{4} H_{10}$, it has two well-known isomers: trans $n-\mathrm{C}_{4} \mathrm{H}_{10}$ and gauche $\mathrm{n}-\mathrm{C}_{4} \mathrm{H}_{10}$. The trans form is stable in the $\mathrm{P}$ and I water cages, but it will transform into the gauche form in the $\mathrm{T}$ and $\mathrm{H}$ water cages. For both the two cases, the frequencies of guest molecules encapsulated in the water cages are blue-shifted in comparing with the frequencies in the gas phase, and they are red-shifted as the water cavity radius increases as shown in Figure $3.5 \mathrm{~b} .^{1}$ 

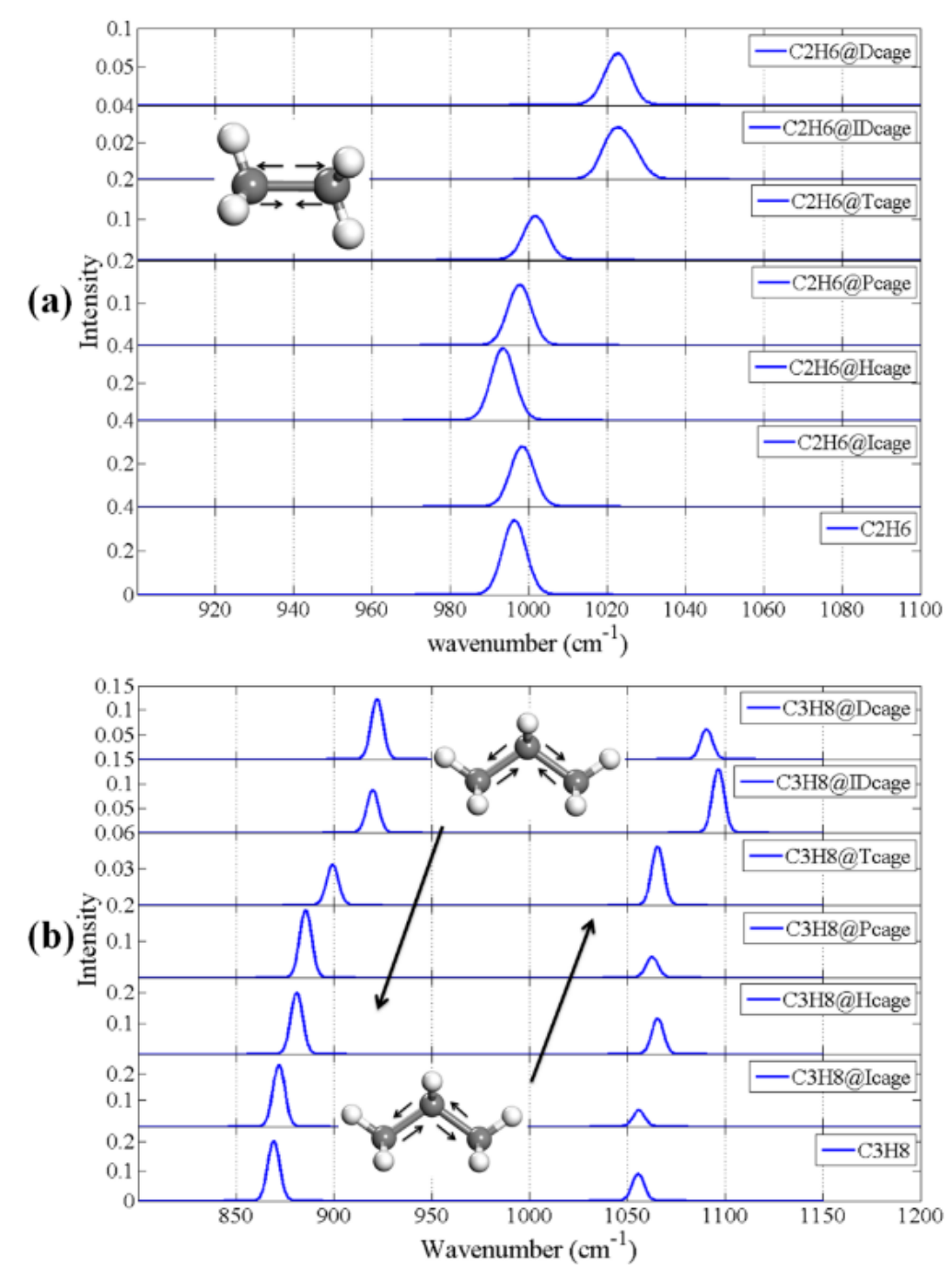

Figure 3.4. Raman spectra for the C-C stretching vibrational mode of (a) $\mathrm{C}_{2} \mathrm{H}_{6}$ and (b) $\mathrm{C}_{3} \mathrm{H}_{8}$ encapsulated in water cavities in NGHs. The small arrows along the bonds of the molecule denote the vibrational mode.

The C-H stretching vibrations of hydrocarbon molecules are usually used as the fingerprints to identify the types of clathrate structure by means of Raman spectroscopy. In paper III, the $\mathrm{C}-\mathrm{H}$ stretching vibrational Raman spectra of hydrocarbon molecules $\left(\mathrm{CH}_{4}, \mathrm{C}_{2} \mathrm{H}_{6}, \mathrm{C}_{3} \mathrm{H}_{6}, \mathrm{C}_{3} \mathrm{H}_{8}, \mathrm{C}_{4} \mathrm{H}_{8}, \mathrm{i}-\mathrm{C}_{4} \mathrm{H}_{10}\right.$, and $\left.\mathrm{n}-\mathrm{C}_{4} \mathrm{H}_{10}\right)$ encapsulated in the water cavities ( $\mathrm{D}, \mathrm{ID}, \mathrm{T}, \mathrm{P}, \mathrm{H}$, and I) of the sI, sII, sH, and sK crystal phases were derived from quantum-chemical computations, as shown in Figure 3.6. ${ }^{2}$ 

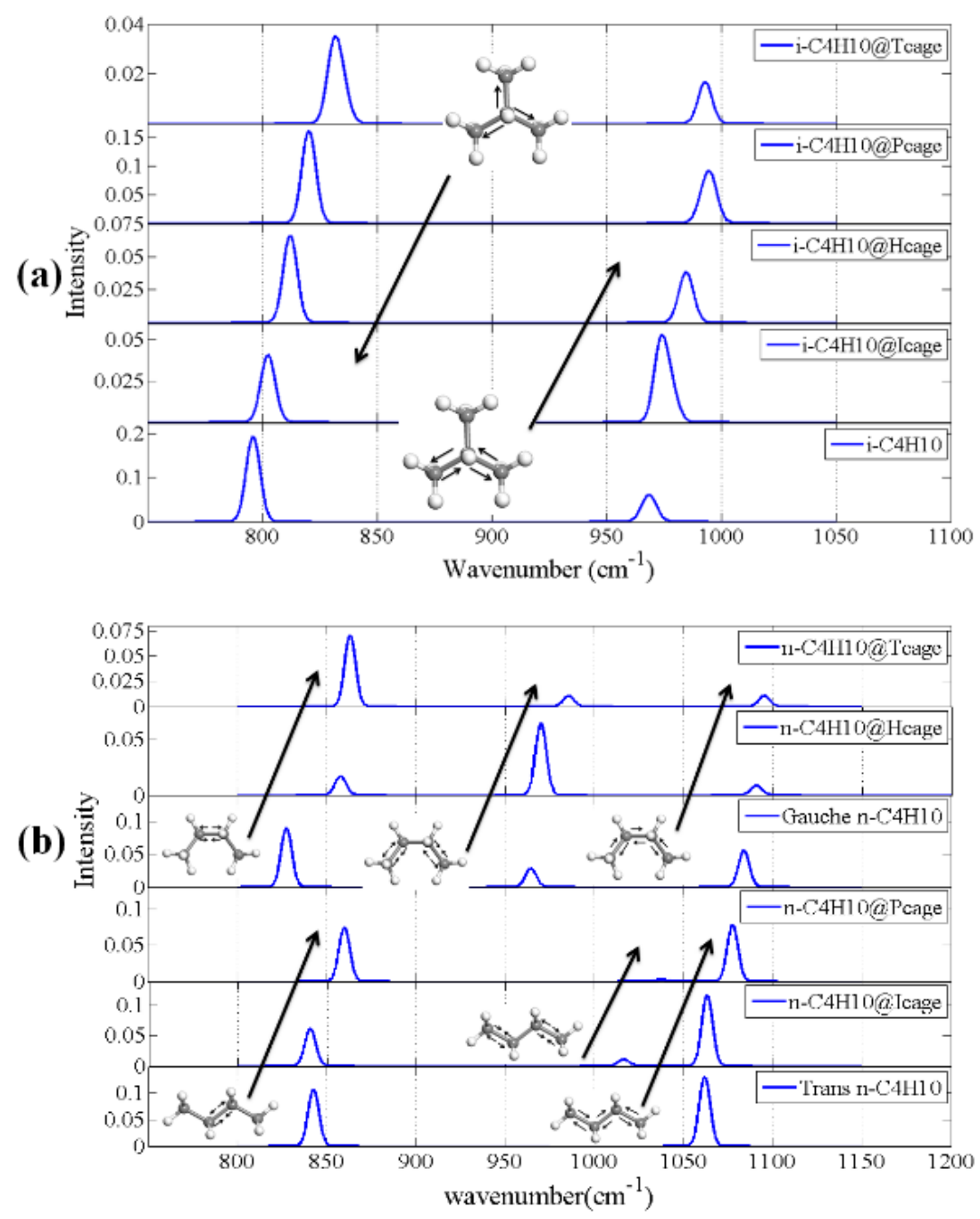

Figure 3.5. Raman spectra for the C-C stretching vibrational mode of (a) $\mathrm{i}-\mathrm{C}_{4} \mathrm{H}_{10}$ and (b) n$\mathrm{C}_{4} \mathrm{H}_{10}$ encapsulated in water cavities in NGHs.

For $\mathrm{CH}_{4}, \mathrm{C}_{2} \mathrm{H}_{6}$, and $\mathrm{C}_{3} \mathrm{H}_{6}$ (see Figure $3.6 \mathrm{a}, \mathrm{b}$, and c), both the symmetric and antisymmetric $\mathrm{C}-\mathrm{H}$ stretching vibrational frequencies are found to decrease and then increase tending to that in the gas phase as the size of the occupied water cavities increase. For $\mathrm{C}_{3} \mathrm{H}_{8}, \mathrm{C}_{4} \mathrm{H}_{8}, \mathrm{i}-\mathrm{C}_{4} \mathrm{H}_{10}$, and $\mathrm{n}-\mathrm{C}_{4} \mathrm{H}_{10}$ (see Figure $3.6 \mathrm{~d}$, e, f, and $\mathrm{g}$ ), both the symmetric and antisymmetric $\mathrm{C}-\mathrm{H}$ stretching vibrational frequencies continuously decrease going from the small cage to the large cage, and all of them are greater than in the gas phase. ${ }^{2}$ 
(b)

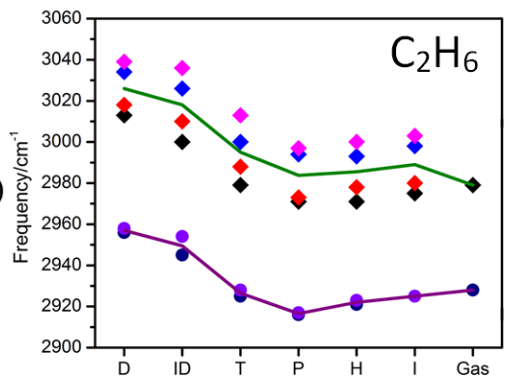

(d)

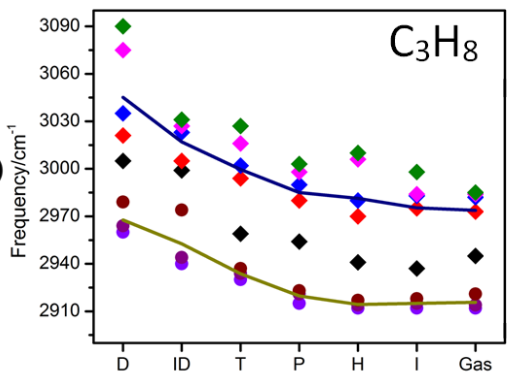

(f)

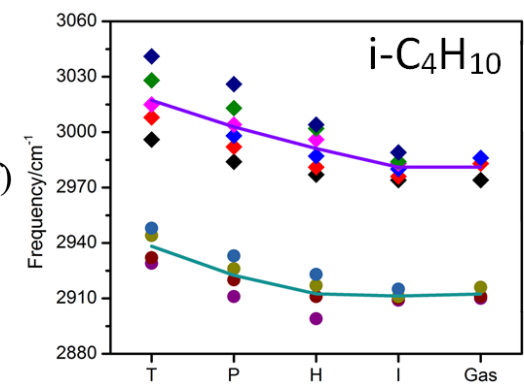

(c)

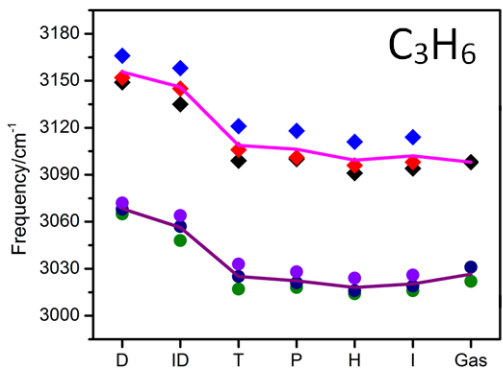

(e)

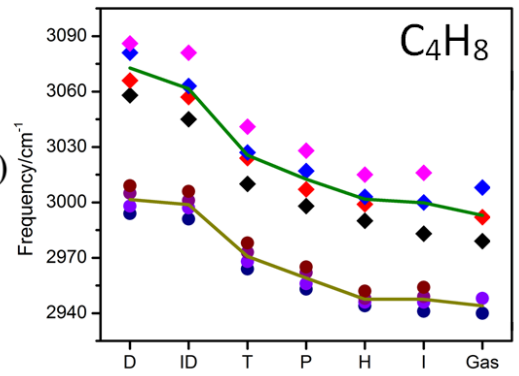

(g)

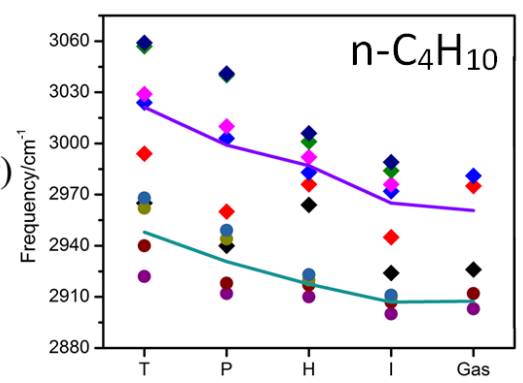

Figure 3.6. The $\mathrm{C}-\mathrm{H}$ stretching frequencies of (a) $\mathrm{CH}_{4}$, (b) $\mathrm{C}_{2} \mathrm{H}_{6}$, (c) $\mathrm{C}_{3} \mathrm{H}_{6}$, (d) $\mathrm{C}_{3} \mathrm{H}_{8}$, (e) $\mathrm{C}_{4} \mathrm{H}_{8}$, (f) $\mathrm{i}-\mathrm{C}_{4} \mathrm{H}_{10}$, and $(\mathrm{g}) \mathrm{n}-\mathrm{C}_{4} \mathrm{H}_{10}$ in the different water cages and in the gas phase. The diamonds denote antisymmetric ("A") and the circles symmetric ("S") stretching vibrations. The solid lines represent the mean values of the antisymmetric and symmetric frequencies, respectively. 


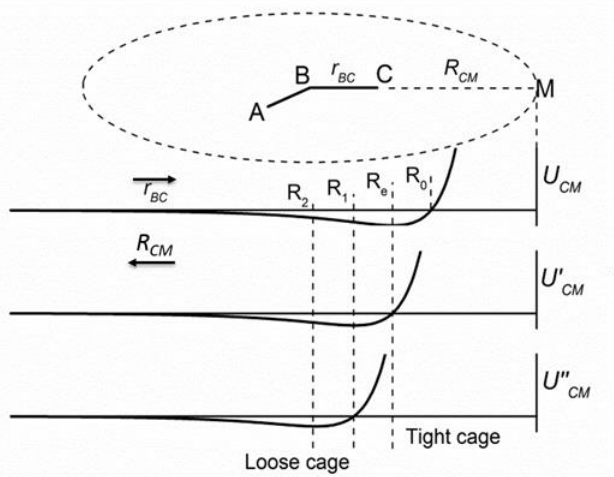

(a)

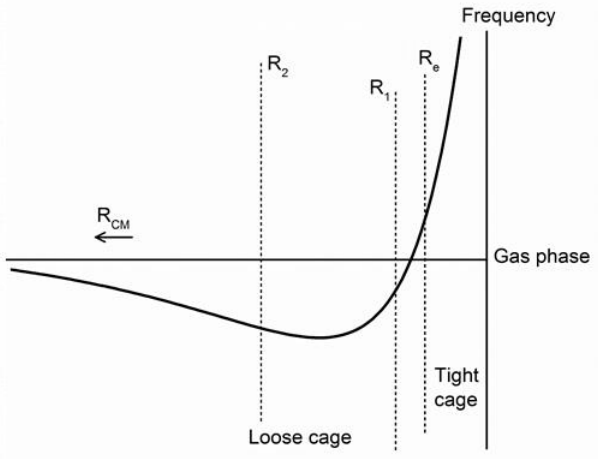

(b)

Figure 3.7. (a) Dependence of interaction potential functions $U, U^{\prime}$ and $U^{\prime \prime}$ on cage size. (b) The $\mathrm{CH}$ stretching frequency of a guest molecule in clathrate hydrate as a function of the size of the water cavities as deduced from LCTC model.

The trend of the $\mathrm{C}-\mathrm{H}$ stretching vibrations of hydrocarbons in NGHs are found to follow the "loose cage - tight cage" (LCTC) model, as depicted in Figure 3.7:

(a) In the "tight cage" situation $\left(\mathrm{R}_{\mathrm{CM}}<\mathrm{R}_{\mathrm{e}}\right)$, the vibrational frequency will be larger than in gas phase; in the "loose cage" situation $\left(\mathrm{R}_{\mathrm{CM}}>\mathrm{R}_{1}\right)$, the vibrational frequency will be smaller than that in the gas phase.

(b) If $\mathrm{R}_{\mathrm{CM}}<\mathrm{R}_{1}$, the vibrational frequency of the guest molecule will decrease as the size of cage increases or the size of the guest molecule decreases.

(c) If $R_{C M}>R_{2}$, the vibrational frequency of the guest molecule will increase as the size of the cage increases or the size of the guest molecule decreases, and vice versa.

The host-guest complex exhibits an attractive $\mathrm{H}$ - wall interaction in the "loose cage" situation causing the $\mathrm{C}-\mathrm{H}$ bond of the guest molecule to be elongated and $\mathrm{C}-\mathrm{H}$ stretching frequency to be red-shifted relative the gas phase. The opposite is true in the "tight cage" situation, where the $\mathrm{C}-\mathrm{H}$ bond is contracted and the $\mathrm{C}-\mathrm{H}$ stretching frequency is blue-shifted. The cases of $\mathrm{CH}_{4}$, $\mathrm{C}_{2} \mathrm{H}_{6}$, and $\mathrm{C}_{3} \mathrm{H}_{6}$ correspond to a continuous transition from the "tight cage" to the "loose cage" situation in the LCTC model; the cases of $\mathrm{C}_{4} \mathrm{H}_{8}, \mathrm{i}-\mathrm{C}_{4} \mathrm{H}_{10}$, and n$\mathrm{C}_{4} \mathrm{H}_{10}$ correspond to the "tight cage" situation or a little beyond the border of "tight cage" in the LCTC model. ${ }^{2}$

\section{3 ${ }^{13} \mathrm{C}$ NMR chemical shift of hydrocarbon molecules (Paper IV)}

Different clathrate phases of NGHs can be formed with the water cavities occupied by various hydrocarbon molecules under appropriate temperature and pressure conditions. ${ }^{7}$ A certain molecular species can be encapsulated into one or more cavities with varying occupancies in different crystalline phases. 
Especially the NGHs samples taken from the natural sites are usually complex and probably include various hydrocarbon molecules and several clathrate phases. The NMR parameters are sensitive to the environment that a molecule experiences, thus ${ }^{13} \mathrm{C}$ NMR spectroscopy can be used to identify NGHs both qualitatively and quantitatively. ${ }^{3}$

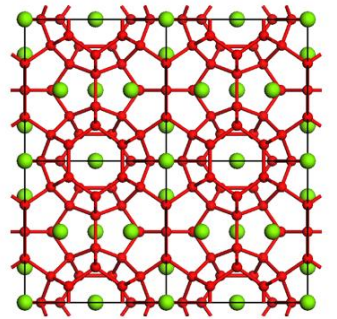

(a) $\mathrm{sI}$

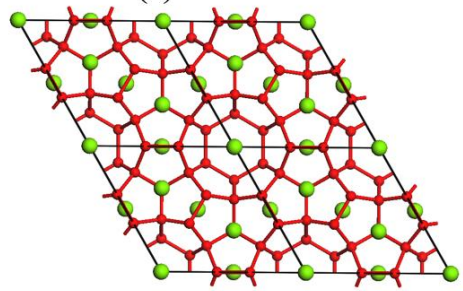

(c) $\mathrm{sH}$

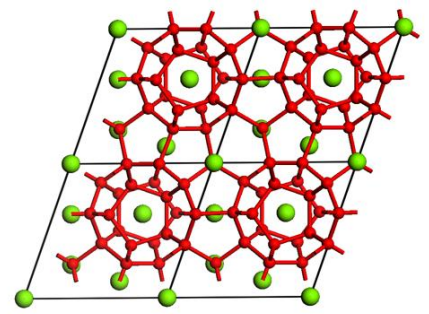

(b) sII

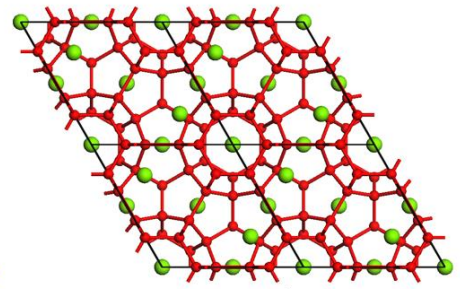

(d) $\mathrm{sK}$

Figure 3.8. The unit cell structures of clathrate hydrates: (a) phase $\mathrm{I}\left(2 \mathrm{D} 6 \mathrm{~T} \bullet 46 \mathrm{H}_{2} \mathrm{O}\right),(\mathrm{b})$ primitive cell of phase II $\left(4 \mathrm{D} 2 \mathrm{H} \cdot 34 \mathrm{H}_{2} \mathrm{O}\right)$, (c) phase $\mathrm{H}\left(3 \mathrm{D} 2 \mathrm{ID} 1 \mathrm{I} \cdot 34 \mathrm{H}_{2} \mathrm{O}\right)$, (d) phase $\mathrm{K}$ $\left(3 \mathrm{D} 2 \mathrm{~T} 2 \mathrm{P} \cdot 40 \mathrm{H}_{2} \mathrm{O}\right) . \mathrm{D}, \mathrm{ID}, \mathrm{T}, \mathrm{P}, \mathrm{H}$, and I represent the various water cavities $\left(5^{12}, 4^{3} 5^{6} 6^{3}, 5^{12} 6^{2}\right.$, $5^{12} 6^{3}, 5^{12} 6^{4}$, and $\left.5^{12} 6^{8}\right)$ in the different clathrate phases. The water molecules are represented by red balls, the hydrogen bonds are represented by red sticks, and the hydrocarbon molecules encapsulated in the various water cavities are represented by larger green balls.

The unit cell structures (shown in Figure 3.8) of sI, sII, sH, and sK clathrates with single occupancy of each cavity by $\mathrm{CH}_{4}, \mathrm{C}_{2} \mathrm{H}_{6}, \mathrm{C}_{3} \mathrm{H}_{8}, \mathrm{i}-\mathrm{C}_{4} \mathrm{H}_{10}$, or $\mathrm{n}-\mathrm{C}_{4} \mathrm{H}_{10}$ were first fully relaxed by first-principles calculations employing the dispersion corrected functional PBE-TS ${ }^{85-86}$ in the CASTEP ${ }^{87}$ module of Materials Studio 6.1. Then the NMR parameters of the carbon atoms in the NGHs were computed by the linear response GIPAW method ${ }^{88-90}$ In addition, to explore the origin of ${ }^{13} \mathrm{C}$ chemical shift of hydrocarbon molecules in clathrate hydrates, the chemical shielding constants of the carbon atoms were split into contributions from different natural localized molecular orbitals (NLMO) $)^{91}$ based on a natural bond orbital (NBO) analysis. ${ }^{92-93}$ The NBO calculations were carried out with isolated cluster models optimized by the $\omega \mathrm{B} 97 \mathrm{X}-\mathrm{D}^{79} / 6-311++\mathrm{G}(2 \mathrm{~d}, 2 \mathrm{p})^{80}$ method in the Gaussian 09 program. ${ }^{84}$ 
Table 3.4. ${ }^{13} \mathrm{C}$ NMR chemical shift of $\mathrm{CH}_{4}$ in different cavities and phases of clathrate hydrates for fully optimized cell/cell lattice fixed at the experimental values.

\begin{tabular}{|c|c|c|c|c|c|c|c|}
\hline \multicolumn{4}{|c|}{$\begin{array}{l}{ }^{13} \mathrm{C} \text { NMR Chemical } \mathrm{Shift}_{\text {of }} \mathrm{CH}_{4} \text { in Clathrate } \\
\text { Hydrate Relative to } \mathrm{CH}_{4} \text { in } \mathrm{Gas}_{\text {Phase } / \mathrm{ppm}}\end{array}$} & \multicolumn{4}{|c|}{$\begin{array}{c}\text { Chemical Shift Difference }(\Delta) \text { of } \mathrm{CH}_{4} \text { Enclosed } \\
\text { in Different Cavities /ppm }\end{array}$} \\
\hline $\mathrm{MH}$ & Small & Medium & Large & \multicolumn{3}{|c|}{ Theor. } & Expt. \\
\hline sI & D & - & $\mathbf{T}$ & \multicolumn{3}{|c|}{$\Delta_{\text {D-T }}$} & $\Delta_{\text {D-T }}$ \\
\hline $8 \mathrm{CH}_{4} @ \mathrm{sI}$ & $8.91 / 6.92$ & - & $6.12 / 4.39$ & \multicolumn{3}{|c|}{$2.79 / 2.53$} & $2.1(2.3)$ \\
\hline sK & D & $\mathbf{T}$ & $\mathbf{P}$ & $\Delta_{\text {D-T }}$ & $\Delta_{\text {D-P }}$ & $\Delta_{\text {T-P }}$ & - \\
\hline $7 \mathrm{CH}_{4} @ \mathrm{sK}$ & $9.21 / 7.22$ & $5.69 / 4.13$ & $4.90 / 3.57$ & $3.52 / 3.09$ & $4.31 / 3.65$ & $0.79 / 0.56$ & - \\
\hline sII & D & - & H & \multicolumn{3}{|c|}{$\Delta$ D-H } & $\Delta_{\mathrm{D}-\mathrm{H}}$ \\
\hline $6 \mathrm{CH}_{4} @ \mathrm{sII}$ & $8.62 / 6.91$ & - & $4.72 / 3.78$ & \multicolumn{3}{|c|}{$3.90 / 3.13$} & $3.75(3.54)$ \\
\hline sH & D & ID & I & $\Delta$ D-ID & $\Delta$ D-I & $\Delta_{\text {ID-I }}$ & - \\
\hline $6 \mathrm{CH}_{4} @ \mathrm{sH}$ & $8.42 / 7.14$ & $7.99 / 6.66$ & $4.62 / 3.68$ & $0.43 / 0.48$ & $3.80 / 3.46$ & $3.37 / 2.98$ & - \\
\hline $7 \mathrm{CH}_{4} @ \mathrm{sH}$ & $8.54 / 7.17$ & $7.98 / 6.63$ & $4.91 / 3.95$ & \multicolumn{3}{|c|}{-} & - \\
\hline $8 \mathrm{CH}_{4} @ \mathrm{sH}$ & $8.39 / 7.24$ & $7.97 / 6.70$ & $15.26 / 12.97$ & \multicolumn{3}{|c|}{-} & - \\
\hline $9 \mathrm{CH}_{4} @ \mathrm{sH}$ & $8.26 / 7.31$ & $7.76 / 6.66$ & $16.83 / 14.16$ & \multicolumn{3}{|c|}{-} & - \\
\hline $10 \mathrm{CH}_{4} @ \mathrm{sH}$ & $8.06 / 7.32$ & $7.47 / 6.68$ & $18.10 / 15.72$ & \multicolumn{3}{|c|}{-} & - \\
\hline
\end{tabular}

(a)

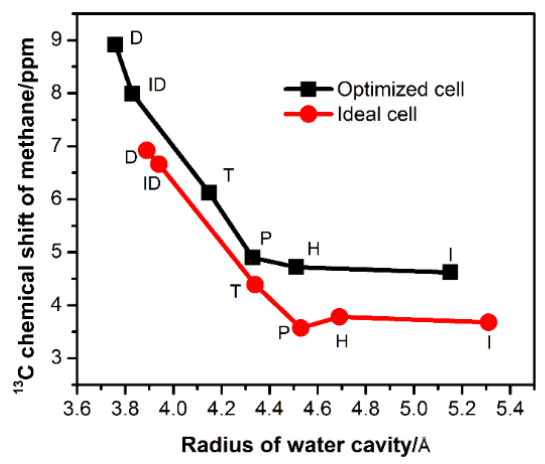

(b)

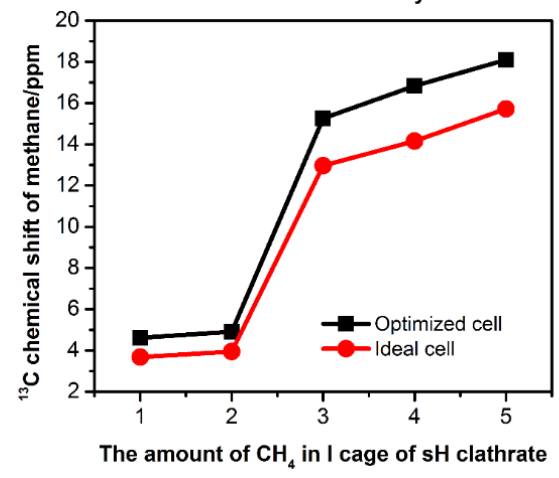

Figure 3.9. The ${ }^{13} \mathrm{C}$ NMR chemical shift of methane in different phases of clathrate hydrates: (a) the chemical shift as a function of cavity size of methane enclosed in different types of water cavities of clathrate hydrates, (b) the chemical shift as a function of number of methane molecules occupying the large water cavity of the phase $\mathrm{H}$ clathrate hydrate. Note: optimized cell means that both the atom coordinates and cell lattice parameters were optimized; ideal cell means the cell lattice parameters were fixed at the experimental values, and only the atom coordinates were optimized. 
The chemical shifts $(\delta)$ of the alkane molecules in NGHs were calculated relative the chemical shielding constant of methane in the gas phase as the reference: $\delta_{i}=\sigma_{r e f}-\sigma_{i}$ (the subscript $i$ and $r e f$ represent each alkane molecule and the reference), ${ }^{89}$ as listed in Table 3.4 and Table 3.5. The computational results in this work are consistent with the experimental measurements with the difference less than $1 \mathrm{ppm}$ for sI and sII methane hydrates.

Table 3.5. ${ }^{13} \mathrm{C}$ NMR chemical shift of the larger hydrocarbon molecules $\left(\mathrm{C}_{2} \mathrm{H}_{6}, \mathrm{C}_{3} \mathrm{H}_{8}, \mathrm{i}-\mathrm{C}_{4} \mathrm{H}_{10}\right.$ and $\mathrm{n}-\mathrm{C}_{4} \mathrm{H}_{10}$ ) encapsulated in the large cavities of different clathrate hydrates, where simultaneously the small cavities are occupied by methane.

\begin{tabular}{|c|c|c|c|c|c|c|c|c|c|c|c|c|}
\hline \multicolumn{13}{|c|}{${ }^{13} \mathrm{C}$ NMR Chemical Shift of Guest Molecules in Clathrate Hydrate Relative to $\mathrm{CH}_{4}$ in Gas Phase /ppm } \\
\hline \multirow{2}{*}{\multicolumn{2}{|c|}{ Guest molecules }} & \multicolumn{2}{|c|}{ sI } & \multicolumn{3}{|c|}{ sK } & \multicolumn{2}{|c|}{ SII } & \multicolumn{3}{|c|}{ sH } & \multirow{2}{*}{$\begin{array}{c}\text { Gas } \\
\text { phase }\end{array}$} \\
\hline & & D & $\mathbf{T}$ & D & $\mathbf{T}$ & $\mathbf{P}$ & D & $\mathbf{H}$ & D & ID & I & \\
\hline \multicolumn{2}{|c|}{$\mathrm{CH}_{4}$} & 8.56 & - & 9.16 & 5.69 & - & 8.69 & - & 8.38 & 7.96 & - & - \\
\hline \multirow{2}{*}{\multicolumn{2}{|c|}{$\frac{\mathrm{C}_{2} \mathrm{H}_{6}}{\mathrm{CH}_{4}}$}} & - & 22.31 & - & - & 20.64 & - & 20.30 & - & - & 20.14 & 17.39 \\
\hline & & - & - & 9.12 & 5.38 & - & 8.59 & - & 8.46 & 7.97 & - & - \\
\hline \multirow{2}{*}{$\mathrm{C}_{3} \mathrm{H}_{8}$} & $-\mathrm{CH}_{2-}$ & - & - & - & - & 30.62 & - & 31.35 & - & - & 31.41 & 31.10 \\
\hline & $-\mathrm{CH}_{3}$ & - & - & - & - & 33.91 & - & 32.59 & - & - & 30.55 & 27.53 \\
\hline \multicolumn{2}{|c|}{$\mathrm{CH}_{4}$} & - & - & 8.73 & 5.20 & - & 8.33 & - & 8.47 & 8.02 & - & - \\
\hline \multirow{2}{*}{$\mathrm{i}-\mathrm{C}_{4} \mathrm{H}_{10}$} & $-\mathrm{CH}-$ & - & - & - & - & 37.68 & - & 38.33 & - & - & 39.98 & 39.45 \\
\hline & $-\mathrm{CH}_{3}$ & - & - & - & - & 43.32 & - & 41.88 & - & - & 38.49 & 35.66 \\
\hline \multicolumn{2}{|c|}{$\mathrm{CH}_{4}$} & - & - & 8.57 & 5.36 & - & 8.36 & - & 8.54 & 7.98 & - & - \\
\hline \multirow{2}{*}{$\mathrm{n}-\mathrm{C}_{4} \mathrm{H}_{10}$} & $-\mathrm{CH}_{2-}$ & - & - & - & - & 38.95 & - & 37.50 & - & - & 41.61 & 41.29 \\
\hline & $-\mathrm{CH}_{3}$ & - & - & - & - & 31.10 & - & 27.88 & - & - & 28.41 & 25.89 \\
\hline
\end{tabular}

As depicted in Figure 3.9, the ${ }^{13} \mathrm{C}$ chemical shift of methane with single occupancy in various NGHs decreases as the size of the water cavity increases, which is consistent with the experimental observations. ${ }^{82}$ For the multioccupancy case, the chemical shift of methane increases as the amount of methane increases. The two phenomenons are related since increasing the amount of methane in a cage is equivalent to decreasing the average space per methane molecule. ${ }^{3}$ 
Table 3.6. ${ }^{13} \mathrm{C}$ NMR chemical shielding constants of methane in the gas phase and encapsulated in the water cavities in various clathrate hydrates split into the contributions from each natural localized molecular orbitals (NLMO), and the paramagnetic and diamagnetic components of the chemical shielding constant. BD, CR, and LP represent bond, core, and lone electron pairs. Unit: ppm

\begin{tabular}{|c|c|c|c|c|c|c|c|c|c|}
\hline & \multicolumn{3}{|c|}{$\mathrm{CH}_{4}$ in gas phase } & \multicolumn{3}{|c|}{$\mathrm{CH}_{4} @ \mathbf{D}$ cage } & \multicolumn{3}{|c|}{$\mathrm{CH}_{4} @$ ID cage } \\
\hline NLMO & Total & $\sigma^{\text {para }}$ & $\sigma^{\text {dia }}$ & Total & $\sigma^{\text {para }}$ & $\sigma^{\text {dia }}$ & Total & $\sigma^{\text {para }}$ & $\sigma^{\mathrm{dia}}$ \\
\hline $\mathrm{BD} \mathrm{OH}$ & - & - & - & 8.50 & -14.33 & 22.83 & 7.97 & -14.82 & 22.79 \\
\hline $\mathrm{BD} \mathrm{CH}$ & -9.80 & -51.63 & 41.83 & -17.37 & -65.28 & 47.91 & -15.90 & -58.97 & 43.07 \\
\hline $\mathrm{CR} \mathrm{O}$ & - & - & - & -1.29 & -1.19 & -0.10 & -1.21 & -1.12 & -0.09 \\
\hline CR C & 203.72 & 0.01 & 203.71 & 203.72 & 0.01 & 203.71 & 203.72 & 0.01 & 203.71 \\
\hline LP O & - & - & - & -4.94 & -3.45 & -1.49 & -5.87 & -4.04 & -1.83 \\
\hline \multirow[t]{2}{*}{ sum } & 193.92 & -51.62 & 245.54 & 188.62 & -84.24 & 272.86 & 188.71 & -78.94 & 267.65 \\
\hline & \multicolumn{3}{|c|}{$\mathrm{CH}_{4} @ \mathbf{T}$ cage } & \multicolumn{3}{|c|}{$\mathrm{CH}_{4} @ \mathbf{P}$ cage } & \multicolumn{3}{|c|}{$\mathrm{CH}_{4} @ \mathbf{H}$ cage } \\
\hline NLMO & Total & $\sigma^{\text {para }}$ & $\sigma^{\text {dia }}$ & Total & $\sigma^{\text {para }}$ & $\sigma^{\text {dia }}$ & Total & $\sigma^{\text {para }}$ & $\sigma^{\mathrm{dia}}$ \\
\hline $\mathrm{BD} \mathrm{OH}$ & 8.60 & -16.00 & 24.60 & 8.99 & -16.53 & 25.52 & 9.03 & -17.27 & 26.30 \\
\hline $\mathrm{BD} \mathrm{CH}$ & -14.64 & -56.56 & 41.92 & -13.76 & -54.66 & 40.90 & -11.95 & -49.73 & 37.78 \\
\hline $\mathrm{CR} \mathrm{O}$ & -1.20 & -1.10 & -0.10 & -1.20 & -1.10 & -0.10 & -1.15 & -1.04 & -0.11 \\
\hline CR C & 203.72 & 0.01 & 203.71 & 203.72 & 0.01 & 203.71 & 203.72 & 0.01 & 203.71 \\
\hline LP O & -7.30 & -4.52 & -2.78 & -7.49 & -4.53 & -2.96 & -8.30 & -4.78 & -3.52 \\
\hline sum & 189.18 & -78.17 & 267.35 & 190.26 & -76.81 & 267.07 & 191.35 & -72.81 & 264.16 \\
\hline
\end{tabular}

To elucidate the origin of the ${ }^{13} \mathrm{C}$ chemical shift in NGHs, the chemical shielding constants of methane in gas phase and in the water cavities of various clathrates were split into the contributions from each NLMO based on a NBO analysis (see Table 3.6). The contribution from the carbon core is seen to be almost the same irrespective of whether methane is in the gas phase or in water cavities of clathrates. For methane in a tight environment (e.g. D cage), the chemical shift are mainly attributed to the electrons in $\mathrm{CH}$ bonding orbitals and a small part is due to the water molecules. The ratios of guest diameter to cavity diameter (RGTC) are 0.855 (in sI) or 0.868 (in sII) for methane in the D cage, while 0.744 and 0.652 for methane in the $\mathrm{T}$ and in the $\mathrm{H}$ cage. When $\mathrm{CH}_{4}$ is in a loose environment (the RGTC is relatively small), the chemical shift almost completely can be attributed to the contributions from $\mathrm{CH}$ bond electrons. Since the electronic distribution of the $\mathrm{CH}$ bond is influenced by the van der Waals interaction between the guest molecule and the host water cage wall, we can conclude that the chemical shift of methane depends on the host-guest interaction with a small contribution from the water molecules when $\mathrm{CH}_{4}$ is in a relatively tight environment, and mainly determined by the host-guest interaction when $\mathrm{CH}_{4}$ experiences a relatively loose environment. ${ }^{3}$ 


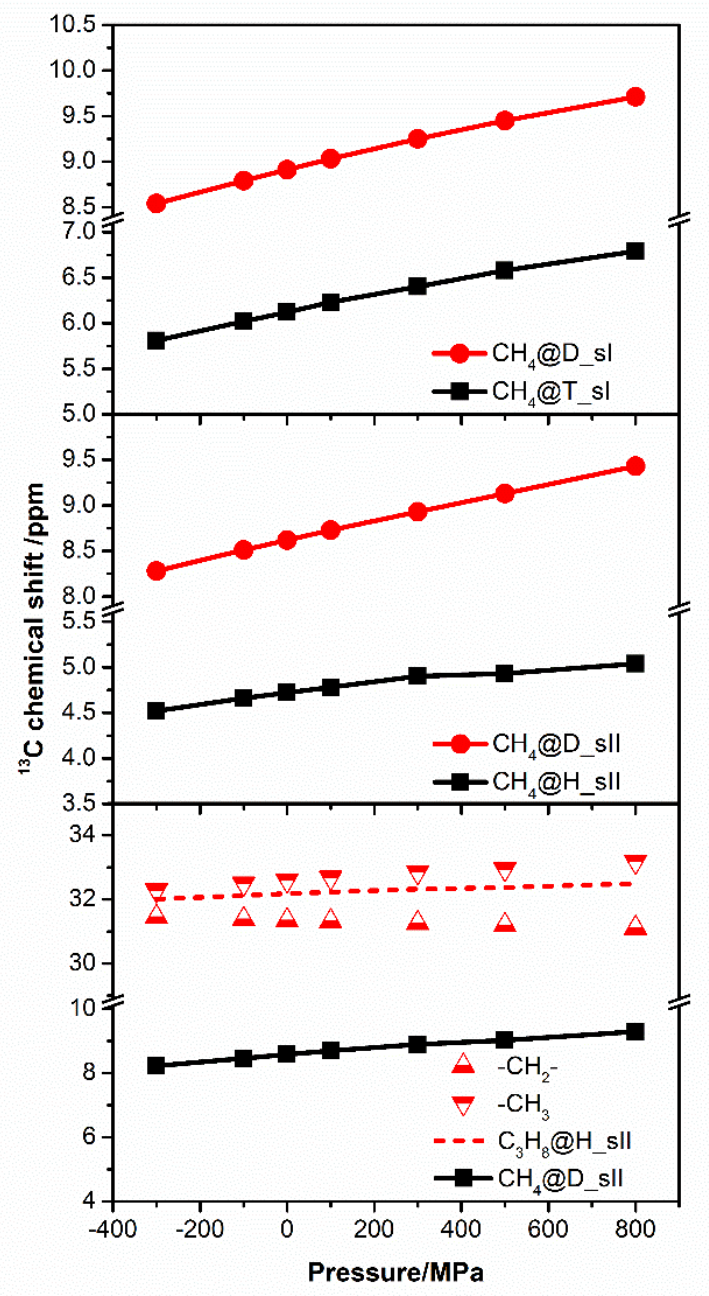

Figure 3.10. The ${ }^{13} \mathrm{C}$ NMR chemical shift of pure sI and sII methane hydrate and of $\mathrm{CH}_{4}$ $\mathrm{C}_{3} \mathrm{H}_{8}$ mixed sII hydrate as a function of external pressure.

As presented in Figure 3.10, the ${ }^{13} \mathrm{C}$ chemical shifts in pure sI and sII methane hydrate and in sII $\mathrm{CH}_{4}-\mathrm{C}_{3} \mathrm{H}_{8}$ hydrate were computed in the pressure range -300 $\mathrm{MPa}$ to $800 \mathrm{MPa}$. The negative pressure corresponds to an expansion of the clathrate cell. The chemical shift of methane in both the small and large cavities increases as the pressure increase in both the sI phase and the sII phase. Similar trends are found for $\mathrm{CH}_{4}$ and $\mathrm{C}_{3} \mathrm{H}_{8}$ in the sII mixed hydrate. However, the trends for methyl-C and methylene- $\mathrm{C}$ of $\mathrm{C}_{3} \mathrm{H}_{8}$ differ. As the pressure increases, the chemical shift of methyl-C increases while that of methylene-C slightly decreases. ${ }^{3}$ 


\section{Water clusters (Paper I)}

Since infrared (IR) vibrational spectroscopy is sensitive to the molecular structure of water, it is often used in the studies of water both experimentally and theoretically. ${ }^{31-32,34,94-99}$ The arrangement of water molecules in bulk water or water clusters can be explored through the particular spectral fingerprints of water molecules bonded in different H-bond conformations. In paper I, the IR spectra of water clusters for small-, medium-, and large-sized cluster (shown in Figure 4.1) were investigated by quantum-chemical calculations at the level of B3LYP ${ }^{100-101} / 6-31+\mathrm{G}(\mathrm{d}, \mathrm{p})^{80}$ in Gaussian 09 program. ${ }^{84}$

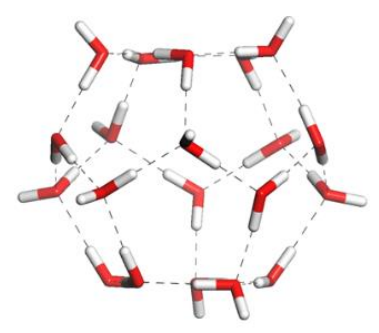

(a) $\left(\mathrm{H}_{2} \mathrm{O}\right)_{20}$
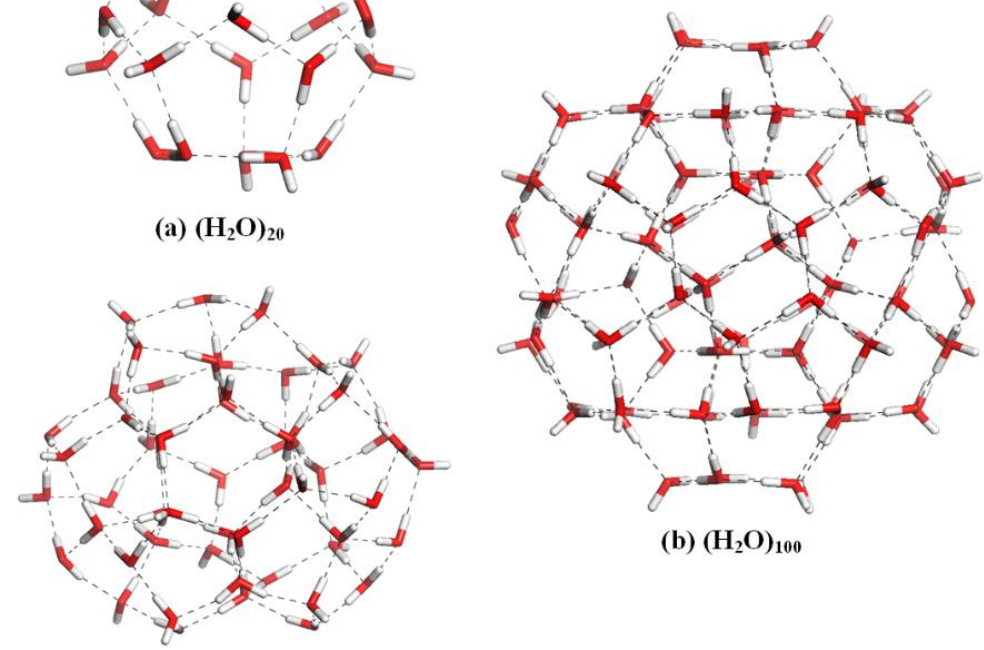

(b) $\left(\mathrm{H}_{2} \mathrm{O}\right)_{100}$

(c) $\left(\mathrm{H}_{2} \mathrm{O}\right)_{54}$

Figure 4.1. The structures of the water clusters: (a) $\left(\mathrm{H}_{2} \mathrm{O}\right)_{20}$, (b) $\left(\mathrm{H}_{2} \mathrm{O}\right)_{54}$, (c) $\left(\mathrm{H}_{2} \mathrm{O}\right)_{100}$. The red sticks represent oxygen atoms, the white sticks represent hydrogen atoms, and the black dashed lines represent hydrogen bonds.

\subsection{Geometric structures and thermodynamic stabilities}

The geometries of water clusters $\left(\mathrm{H}_{2} \mathrm{O}\right)_{20,54,100}$ were fully relaxed to the energyminimized structures and the results are listed in Table 4.1. The average $\mathrm{H}$ bonded O-O distances of the three water clusters are $2.76 \AA$ for $\left(\mathrm{H}_{2} \mathrm{O}\right)_{20}, 2.77 \AA$ for $\left(\mathrm{H}_{2} \mathrm{O}\right)_{54}$, and $2.75 \AA$ for $\left(\mathrm{H}_{2} \mathrm{O}\right)_{100}$. The larger difference between the minimum value and maximum value of $\left(\mathrm{H}_{2} \mathrm{O}\right)_{54}$ shows that the $\mathrm{H}$-bond network in $\left(\mathrm{H}_{2} \mathrm{O}\right)_{54}$ is more irregular compared to that in $\left(\mathrm{H}_{2} \mathrm{O}\right)_{20}$ and $\left(\mathrm{H}_{2} \mathrm{O}\right)_{100}$. All the molecules are 3-coordinated in $\left(\mathrm{H}_{2} \mathrm{O}\right)_{20}$, but both 3- and 4-coordinated water molecules are present in both $\left(\mathrm{H}_{2} \mathrm{O}\right)_{54}$ and $\left(\mathrm{H}_{2} \mathrm{O}\right)_{100}$ with mean $\mathrm{H}$-bond coordination number 3.33 and 3.40 , respectively. ${ }^{4}$ 
Table 4.1. The H-bonded $\mathrm{O}-\mathrm{O}$ distances in $\left(\mathrm{H}_{2} \mathrm{O}\right)_{20,54,100}$, and coordination number per water molecule. N3 and N4 denote the number of 3- and 4-coordinated molecules.

\begin{tabular}{|c|c|c|c|c|c|c|c|}
\hline & \multicolumn{4}{|c|}{ H-bonded O-O distance/ $\AA$} & \multicolumn{3}{c|}{ Coordinate number } \\
\cline { 2 - 8 } & Min & Max & Mean & Standard deviation & N3 & N4 & Mean \\
\hline$\left(\mathrm{H}_{2} \mathrm{O}\right)_{20}$ & 2.60 & 2.88 & 2.76 & 0.10 & 20 & 0 & 3.00 \\
\hline$\left(\mathrm{H}_{2} \mathrm{O}\right)_{54}$ & 2.54 & 2.97 & 2.77 & 0.10 & 36 & 18 & 3.33 \\
\hline$\left(\mathrm{H}_{2} \mathrm{O}\right)_{100}$ & 2.56 & 2.88 & 2.75 & 0.08 & 60 & 40 & 3.40 \\
\hline
\end{tabular}

The electronic energy $E$ with and without zero point energy correction (ZPE), internal energy $U$, enthalpy $H$, entropy $S$, and Gibbs free energy $G$ at $298 \mathrm{~K}$ are calculated. Then the interaction energy $\Delta E$, etc., (see Table 4.2) of water clusters formed from gas-phase water molecules were computed by the following formula, where $X=E, U, H, S$ or $G$ :

$$
\Delta X=\left(X_{\left(\mathrm{H}_{2} \mathrm{O}\right)_{\mathrm{n}}}-n \cdot X_{\mathrm{H}_{2} \mathrm{O}}\right) / n .
$$

Table 4.2. The binding energy $(\Delta E)$, internal energy $(\Delta U)$, entropy $(\Delta S)$, formation enthalpy $(\Delta H)$, and Gibbs free energy $(\Delta G)$ at $\mathrm{T}=298 \mathrm{~K}$ per water molecule. ZPE denotes the zero point energy correction. The unit is $\mathrm{kcal} / \mathrm{mol}$.

\begin{tabular}{|c|c|c|c|c|c|c|}
\hline Cluster & $\Delta E$ & $\Delta E+Z \mathrm{ZPE}$ & $\Delta U$ & $T \Delta S$ & $\Delta H$ & $\Delta G$ \\
\hline$\left(\mathrm{H}_{2} \mathrm{O}\right)_{20}$ & -11.31 & -8.53 & -8.87 & -9.59 & -9.44 & 0.15 \\
\hline$\left(\mathrm{H}_{2} \mathrm{O}\right)_{54}$ & -11.99 & -9.08 & -9.43 & -10.13 & -10.01 & 0.12 \\
\hline$\left(\mathrm{H}_{2} \mathrm{O}\right)_{100}$ & -12.90 & -9.90 & -10.29 & -10.40 & -10.88 & -0.48 \\
\hline
\end{tabular}

The interaction energy $\Delta E$ increases as the size of the cluster increases, in which $\left(\mathrm{H}_{2} \mathrm{O}\right)_{100}$ is the most stable according to the $\Delta E$. The $\mathrm{ZPE}$ effect on $\Delta \mathrm{E}$ is quite significant: $24.6 \%$ for $\left(\mathrm{H}_{2} \mathrm{O}\right)_{20}, 24.3 \%$ for $\left(\mathrm{H}_{2} \mathrm{O}\right)_{54}$, and $23.3 \%$ for $\left(\mathrm{H}_{2} \mathrm{O}\right)_{100}$. In addition, the same trends are present for $\Delta H, \Delta U, \Delta S$ and $\Delta G$ all decrease as the size of clusters increase. Thus, the $\left(\mathrm{H}_{2} \mathrm{O}\right)_{100}$ cluster is thermodynamically more stable than the other two clusters. The $\left(\mathrm{H}_{2} \mathrm{O}\right)_{100}$ cluster could be spontaneously formed from isolated water molecules at $298 \mathrm{~K}$ and $1 \mathrm{~atm}$ as implied by the negative value of $\Delta G .^{4}$

\subsection{IR spectroscopic characteristics}

Normal-mode calculations to obtain vibrational frequencies and dipole moment derivatives were carried out for the optimized structure of the three water clusters $\left(\mathrm{H}_{2} \mathrm{O}\right)_{20,54,100}$. Since the neglect of anharmonicity in the normal-mode computations and the deficiencies of the computational scheme, the computed frequencies were overestimated in comparison with the experimental measurements. Thus, the calculated $\mathrm{OH}$ stretching frequencies are scaled by the following formula, which is obtained from least-squares fitting to the experimental ${ }^{31,34}$ versus computed frequencies for small water clusters $\left(\mathrm{H}_{2} \mathrm{O}\right)_{2-6}$.

$$
\tilde{v}_{\text {scaled }}=-472.02+\tilde{v}_{\text {calc }} \cdot\left(1.4244-8.9176 \cdot 10^{-5} \cdot \tilde{v}_{\text {calc }}\right) \text {. }
$$




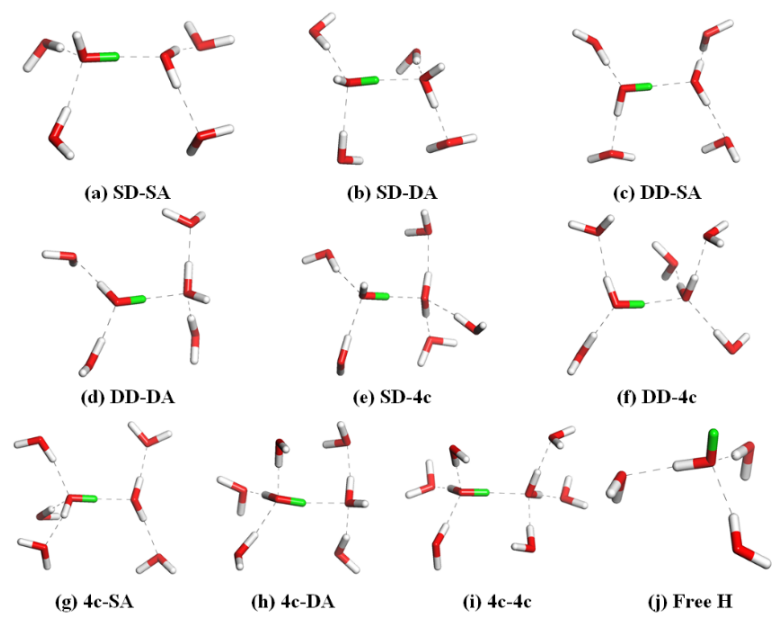

Figure 4.2. The conformations of different donor-acceptor groups: (a) SD-SA, (b) SD-DA, (c) DD-SA, (d) DD-DA, (e) SD-4c, (f) DD-4c, (g) 4c-SA, (h) 4c-DA, (i) 4c-4c, (j) Free H. SD: single donor, SA: single acceptor, DD: double donor, DA: double acceptor, 4c: four coordinated water molecules. The green color denotes the $\mathrm{OH}$ stretching mode under study.

As shown in Figure 4.2, the H-bonds can be classified as 9 different groups according to specific donor-acceptor cases: (a) SD-SA, (b) SD-DA, (c) DD-SA, (d) DD-DA, (e) SD-4c, (f) DD-4c, (g) 4c-SA, (h) 4c-DA, (i) 4c-4c. Each of the three IR spectra in the $\mathrm{OH}$ stretching region were split into sub-spectra for different groups of hydrogen bonds based on the specific contributions from each group, depicted in Figure 4.3. Since each vibrational mode in principle has contributions from all the atoms in a system, the contribution of each atom to the vibrational mode can be quantified by the ratio of the square of the amplitude of the normal-coordinate of that atom to the sum of amplitudes squared of all atoms. This enabled us to project out the contribution to the intensity of a given normal mode from atoms of a specific type:

$$
I_{i}^{\mathrm{X}}=\frac{\sum_{j=\text { atom } \in \mathrm{X}} C_{x, j, i}^{2}+C_{y, j, i}^{2}+C_{z, j, i}^{2}}{\sum_{k=1, \text { all atoms }} C_{x, k, i}^{2}+C_{y, k, i}^{2}+C_{z, k, i}^{2}} \cdot I_{i} .
$$

$I_{i}$ denotes the amplitude of the vibrational mode $i ; X$ represents a group of atoms of a specific type, in our case the hydrogens that participate in H-bonds in one of the H-bond conformation groups, i.e. $\mathrm{X}=\mathrm{SD}-\mathrm{SA}$, SD-DA, DD-SA, DD-DA, SD-4c, DD-4c, 4c-SA, 4c-DA, 4c-4c, or Free H; $C_{x, j, i}, C_{y, j, i}$, and $C_{z, j, i}$ are the amplitudes of normal-mode $i$ for atom $j ; I_{i}$, is the contribution to the IR intensity of normal mode $i$ from the atoms that belong to group X. ${ }^{4}$ 
(a)

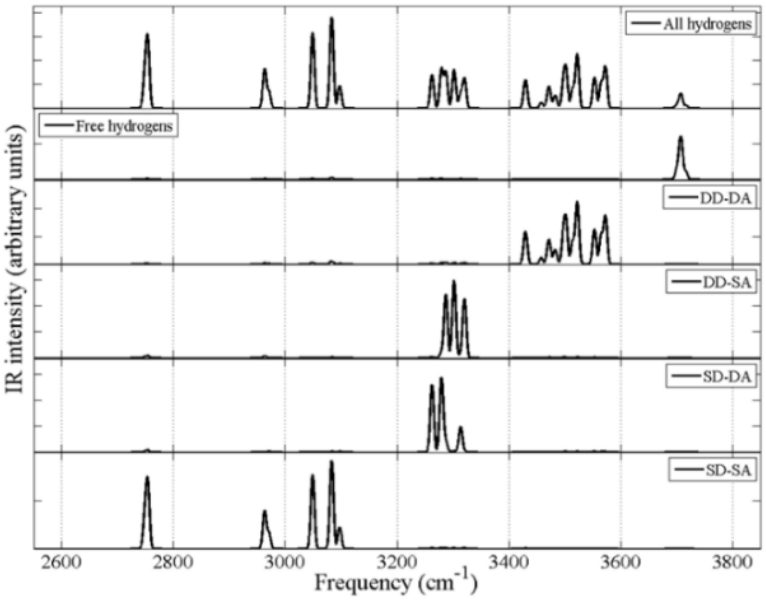

(b)

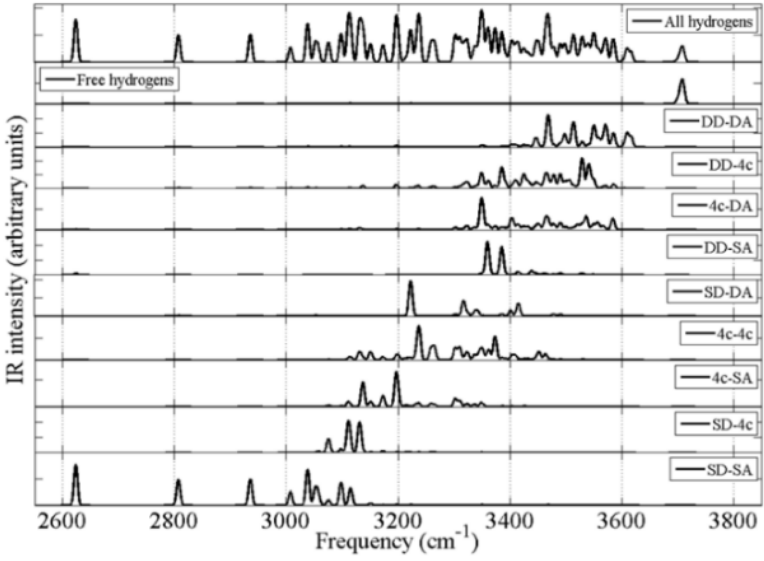

(c)

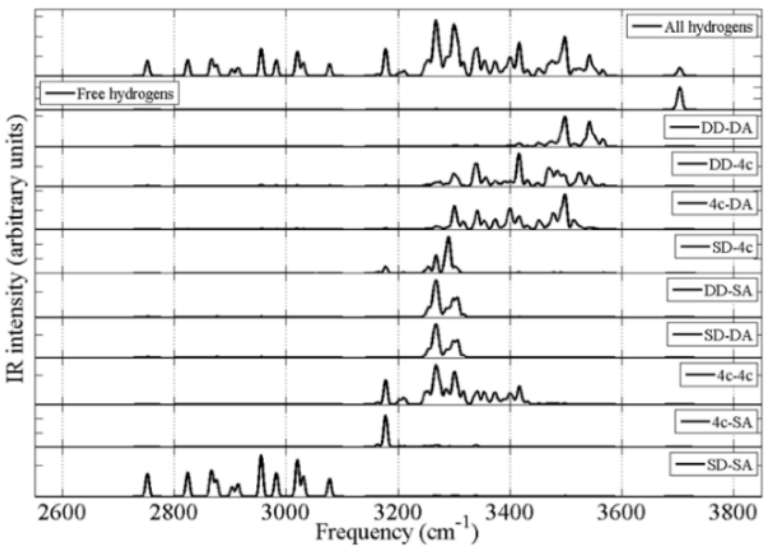

Figure 4.3. The computed vibrational spectra for the a) 20 -membered, b) 54 -membered and c) 100-membered water cluster (top) and the contributions from different donor-acceptor conformations (bottom spectra). SD: single donor, SA: single acceptor, DD: double donor, DA: double acceptor, $4 \mathrm{c}$ : four coordinated water molecules. 
As shown in Figure 4.3a, the $\mathrm{OH}$ stretching frequencies of $\left(\mathrm{H}_{2} \mathrm{O}\right)_{20}$ belonging to different $\mathrm{H}$-bond group are located in distinct regions. The frequencies of SD groups exhibit lower frequencies than those of DD groups, i.e. SD-SA lower than DD-SA and SD-DA lower than DD-DA; and SA groups are lower than DA groups, i.e. SD-SA lower than SD-DA and DD-SA lower than DD-DA. According to the relation between the $\mathrm{H}$-bond strength and $\mathrm{OH}$ stretching frequency: the greater the strength of the $\mathrm{H}$-bond, the smaller the corresponding $\mathrm{OH}$ frequency. Thus, the H-bonds of the SD-SA type are stronger than those of other types since the $\mathrm{OH}$ frequencies of the SD-SA group are located in the lowest-frequency part. ${ }^{4}$

The IR spectra of $\left(\mathrm{H}_{2} \mathrm{O}\right)_{54}$ and $\left(\mathrm{H}_{2} \mathrm{O}\right)_{100}$ are more complicated than that of $\left(\mathrm{H}_{2} \mathrm{O}\right)_{20}$ since both $3 \mathrm{c}$ and $4 \mathrm{c}$ water molecules exist in their structures. As shown in Figure 4.3b and 4.3c, the same trends are presented for both $\left(\mathrm{H}_{2} \mathrm{O}\right)_{54}$ and $\left(\mathrm{H}_{2} \mathrm{O}\right)_{100}$ as for $\left(\mathrm{H}_{2} \mathrm{O}\right)_{20}$ : the frequencies of SD groups are lower than those of DD groups, and the SA groups are lower than the DA groups. In addition, for the molecules at the surface (SD-SA, SD-DA, DD-SA, DD-DA, SD-4c, DD-4c, 4c-SA, 4c-DA, and Free $\mathrm{H}$ ), the $\mathrm{OH}$ stretching frequencies are spread over the whole stretching vibrational region from 2624 to $3712 \mathrm{~cm}^{-1}$. Therefore, the $\mathrm{OH}$ frequency bands of bulk molecules and surface molecules overlap in the middle part of the IR spectrum, an observation that might be helpful for the analysis of IR spectra of amorphous ice. ${ }^{4}$ 


\section{Ice Ih and ice XI (Paper V)}

Since IR and Raman spectra can be used to study the structure and dynamics of ice, one can envision that IR and Raman spectroscopic measurements could be utilized to determine whether ice XI exist in extraterrestrial situations. To clarify the relation between the planetary formation and ice XI, the identification of ice Ih and ice XI should be carried out through IR and Raman spectroscopic investigations. $^{5}$

\subsection{Assessment of DFT Methods}

$\mathrm{H}$-bonding between water molecules is the fundamental interaction in ice. The correct descriptions of ice properties depend on accurate calculations of $\mathrm{H}$-bond interactions. The description of non-covalent interactions is a challenge for DFT calculation; no one functional has been the common preferred choice in the studies of ice. Thus, we evaluated the performance of 16 different DFT methods on ice Ih, VIII, IX, and XI.

Table 5.1. The lattice energy per molecule of ice VIII, IX, and XI without/with cell parameters kept fixed at the experimental values in the geometry optimization. unit: $\mathrm{kcal} / \mathrm{mol}$

\begin{tabular}{|c|c|c|c|c|c|c|c|c|c|}
\hline & Expt. & B3LYP & $\begin{array}{c}\text { B3LYP- } \\
\text { TS }\end{array}$ & $\begin{array}{c}\text { B3LYP- } \\
\text { Grimme }\end{array}$ & PBE0 & $\begin{array}{c}\text { PBE0- } \\
\text { TS }\end{array}$ & PBE & PBE-TS & $\begin{array}{c}\text { PBE- } \\
\text { Grimme }\end{array}$ \\
\hline VIII & $13.3^{a}$ & $9.1 / 8.6$ & $14.8 / 14.8$ & $15.6 / 15.5$ & $10.7 / 10.6$ & $14.1 / 14.2$ & $10.8 / 10.6$ & $14.5 / 14.4$ & $15.5 / 15.4$ \\
\hline IX & $14.0^{a}$ & $11.9 / 11.8$ & $15.2 / 15.1$ & $15.8 / 15.7$ & $15.8 / 13.3$ & $15.8 / 15.7$ & $14.1 / 13.9$ & $16.7 / 16.5$ & $16.8 / 16.6$ \\
\hline XI & $14.1^{a, b}$ & $13.0 / 13.0$ & $15.3 / 15.3$ & $16.1 / 16.0$ & $14.3 / 14.2$ & $16.0 / 15.7$ & $15.1 / 15.0$ & $17.0 / 16.7$ & $17.5 / 17.1$ \\
\hline & Expt. & RPBE & PBEsol & PW91 & $\begin{array}{c}\text { PW91- } \\
\text { OBS }\end{array}$ & HSE03 & HSE06 & BLYP & HCTH \\
\hline VIII & $13.3^{a}$ & $6.9 / 4.9$ & $14.3 / 14.2$ & $11.3 / 11.1$ & $25.0 / 22.5$ & $10.6 / 10.4$ & $10.5 / 10.3$ & $12.9 / 12.4$ & $11.1 / 8.7$ \\
\hline IX & $14.0^{a}$ & $10.3 / 9.7$ & $17.3 / 16.9$ & $14.7 / 14.5$ & $24.4 / 22.1$ & $13.1 / 13.1$ & $13.0 / 13.0$ & $14.1 / 14.0$ & $12.9 / 12.6$ \\
\hline XI & $14.1^{a, b}$ & $11.3 / 11.2$ & $18.5 / 17.7$ & $15.8 / 15.7$ & $24.0 / 21.6$ & $14.4 / 14.3$ & $14.2 / 14.2$ & $14.9 / 14.9$ & $13.2 / 13.2$ \\
\hline
\end{tabular}

${ }^{a}$ Reference 104 and $105,{ }^{b}$ Reference 106. 

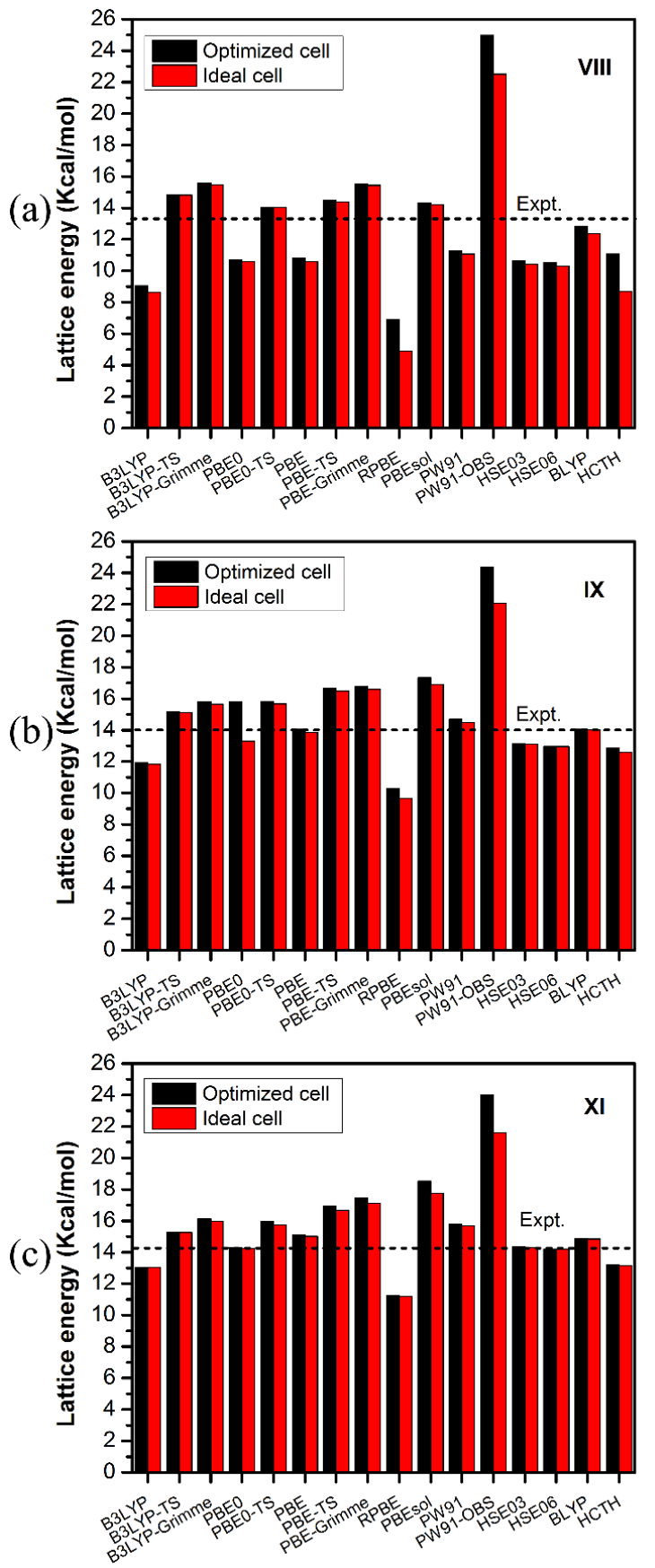

Figure 5.1. The lattice energies of ice VIII, IX, and XI calculated using different DFT methods. The term "ideal cell" implies that the unit cell was optimized with the lattice parameters fixed at the experimental values. 
The lattice energy per molecule of ice VIII, IX, and XI was calculated by B3LYP, PBE0, HSE03, HSE06, PBE, RPBE, PBEsol, PW91, B3LYP-TS, B3LYP-Grimme, PBE0-TS, PBE-TS, PBE-Grimme, and PW91-OBS with plane-wave methods in CASTEP, ${ }^{87}$ and BLYP and HCTH with TNP basis set in $\mathrm{DMol}^{3}{ }^{3}{ }^{102-103}$ In Table 5.1 and Figure 5.1, the lattice energies obtained using different functionals are shown. From comparison with the experimental result, ${ }^{104-106}$ PBE0-TS, PBE-TS, PBEsol, and BLYP work well for ice VIII (see Figure 5.1a), where the error is less than $1.2 \mathrm{kcal} / \mathrm{mol}$, among which BLYP performs best (underestimation by $0.4 \mathrm{kcal} / \mathrm{mol}$ ). For ice IX (see Figure $5.1 \mathrm{~b}$ ), PBE, PW91, HSE03, HSE06, and BLYP perform excellent with errors less than $1.0 \mathrm{kcal} / \mathrm{mol}$, in which PBE and BLYP are particularly good with an error of 0.1 $\mathrm{kcal} / \mathrm{mol}$. Regarding ice XI (see Figure 5.1c), PBE0, PBE, HSE03, HSE06, BLYP, and HCTH perform well with errors less than $1.0 \mathrm{kcal} / \mathrm{mol}$. However, RPBE and PW91-OBS are the worst computational schemes for all the three systems. Hence, for the lattice energy BLYP combined with the TNP basis set perform best with the average absolute error $3.13 \%$ for all the three ice phases. Compared to the other schemes, B3LYP-TS and PBE0-TS perform well with average absolute errors of $9.5 \%$ and $10.8 \%$, respectively. However, the method that is best at predicting the energy differences between the ices is B3LYP with the TS dispersion correction scheme. Considering the unit cell volumes in Table 5.2, the average absolute errors by BLYP, B3LYP-TS, and PBE0-TS are 5.0\%, $4.1 \%$, and $8.1 \%$, respectively, compared to the experimental results. ${ }^{54,56,107-110}$

Table 5.2. The unit cell volumes per molecule of ice VIII, IX, and XI. unit: $\AA^{3}$

\begin{tabular}{|c|c|c|c|c|c|c|c|c|c|}
\hline & Expt. & B3LYP & $\begin{array}{c}\text { B3LYP- } \\
\text { TS }\end{array}$ & $\begin{array}{c}\text { B3LYP- } \\
\text { Grimme }\end{array}$ & PBE0 & $\begin{array}{c}\text { PBE0- } \\
\text { TS }\end{array}$ & PBE & $\begin{array}{c}\text { PBE- } \\
\text { TS }\end{array}$ & $\begin{array}{c}\text { PBE- } \\
\text { Grimme }\end{array}$ \\
\hline VIII & $18.6^{a}, 20.1^{b}$ & 21.5 & 18.6 & 17.5 & 19.8 & 19.8 & 20.5 & 20.0 & 17.7 \\
\hline IX & $25.6^{c}, 25.8^{d}$ & 27.0 & 23.9 & 23.9 & 23.9 & 23.2 & 27.0 & 23.7 & 23.5 \\
\hline XI & $32.0^{e}, 32.2^{f}$ & 32.1 & 30.2 & 30.2 & 30.2 & 29.3 & 30.3 & 29.2 & 29.0 \\
\hline & Expt. & RPBE & PBEsol & PW91 & $\begin{array}{c}\text { PW91- } \\
\text { OBS }\end{array}$ & HSE03 & HSE06 & BLYP & HCTH \\
\hline & & & & & & & & & \\
VIII & $18.6^{a}, 20.1^{b}$ & 26.0 & 17.6 & 20.1 & 14.3 & 20.3 & 21.5 & 20.7 & 27.4 \\
\hline IX & $25.6^{c}, 25.8^{d}$ & 30.8 & 24.1 & 26.8 & 19.1 & 27.0 & 25.4 & 24.9 & 28.7 \\
\hline XI & $32.0^{e}, 32.2^{f}$ & 33.8 & 27.5 & 30.0 & 24.8 & 30.2 & 32.1 & 31.7 & 33.2 \\
\hline
\end{tabular}

${ }^{a}$ Reference $107,{ }^{b}$ Reference $108,{ }^{c}$ Reference $109,{ }^{d}$ Reference $54,{ }^{e}$ Reference $110,{ }^{f}$ Reference56.

BLYP/TNP, PBE, and PBE-TS methods were further evaluated by application on the 16 different proton-ordered structures of ice Ih. The lattice energies of each structure is shown in Figure 5.2. Negligible functional dependence of the relative energies for the different polymorphs is found for both the ideal cell and the fully optimized cell. ${ }^{5}$ 

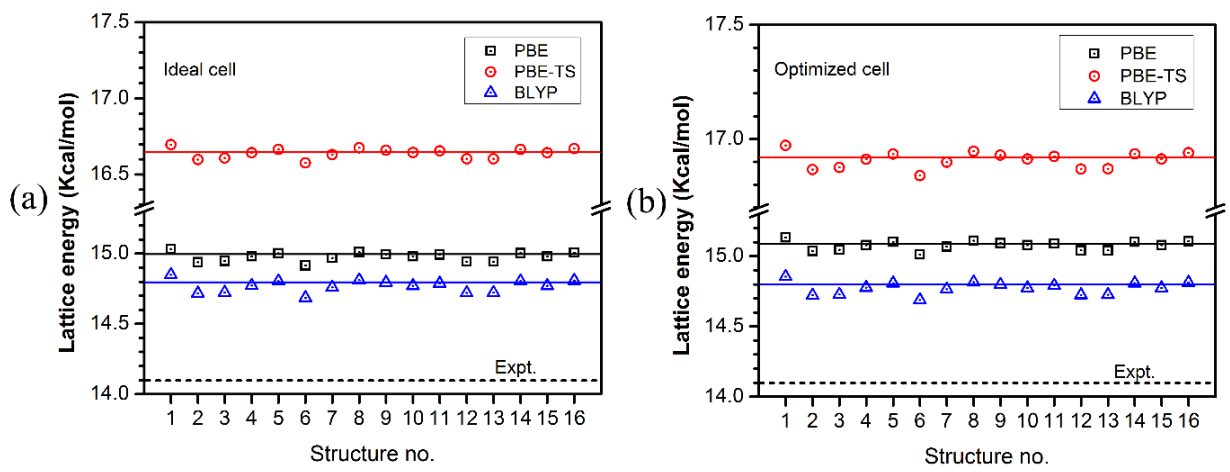

Figure 5.2. The lattice energies of 16 unique structures of ice Ih calculated by PBE, PBE-TS, and BLYP/TNP. The solid lines represent the Boltzmann-averaged values for the 8-molecule unit cell.

From the energies of the 16 isomers, the Boltzmann-averaged lattice energy of ice Ih was computed. Compared to the experiment result, the lattice energy is overestimated $0.7 \mathrm{kcal} / \mathrm{mol}, 1.0 \mathrm{kcal} / \mathrm{mol}$ and $2.8 \mathrm{kcal} / \mathrm{mol}$, respectively, for BLYP, PBE and PBE-TS. The energy difference between ice Ih and XI is 0.05 $\mathrm{kcal} / \mathrm{mol}$ as obtained by the BLYP/TNP computations, which is very close to the value $(0.06 \mathrm{kcal} / \mathrm{mol})$ estimated from experimental data by Johari. ${ }^{106}$

\subsection{IR and Raman Spectra of Ice Ih/XI}

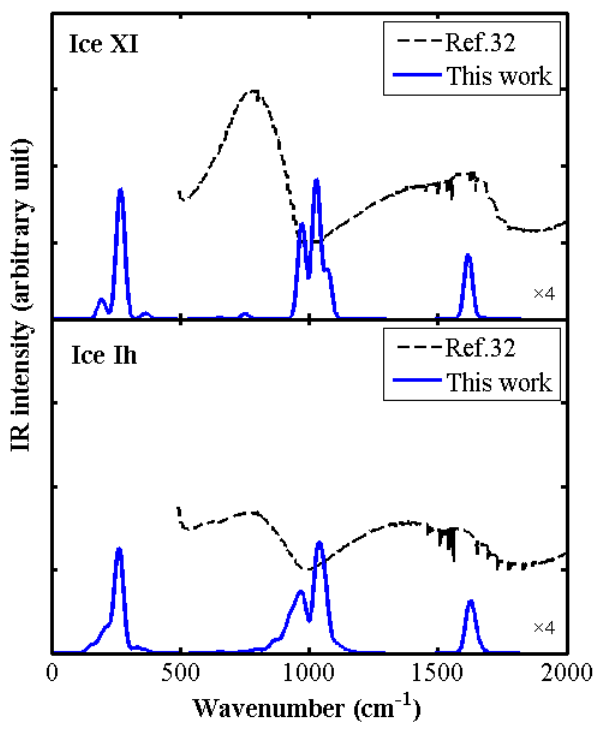

(a)

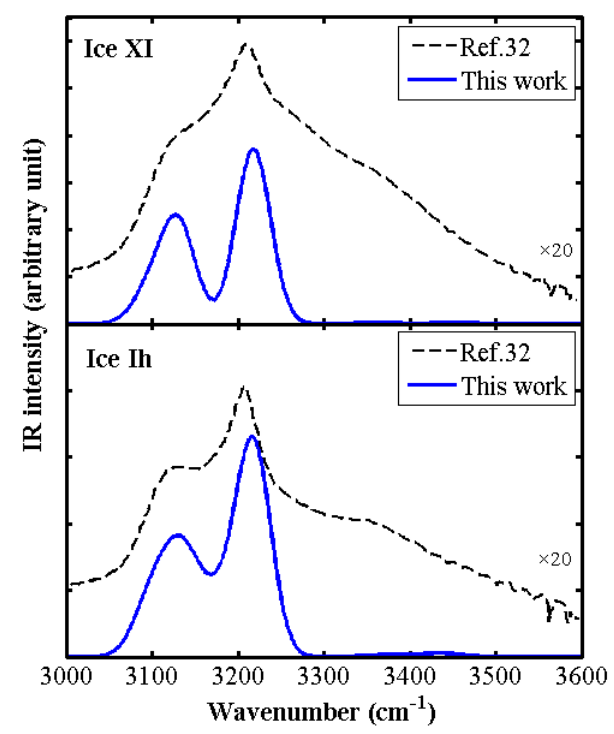

(b)

Figure 5.3. The IR spectra of ice Ih and XI: (a) the low frequency region and (b) the stretching vibration region. The experimental spectra are extracted from Ref. 111. 
Since PBE exhibited good performance in the calculations for 16 isomers of ice Ih and the dispersion interactions have been found to have little influence on IR spectra in liquid water, the PBE functional was chosen for the simulations of IR and Raman spectra.

The Boltzmann-averaged IR and Raman spectra of ice Ih depicted in Figure 5.3 and 5.4, respectively, were derived by introducing the specific weighting factor from the Boltzmann distribution of each isomer. As shown in Figure 5.3 and 5.4, the computed frequencies are roughly consistent with the experimental reports. The translational vibrational modes $\left(\boldsymbol{v}_{T}\right)$ are located below $380 \mathrm{~cm}^{-1}$; librational $\left(\boldsymbol{v}_{L}\right)$, bending $\left(\boldsymbol{v}_{B}\right)$, and stretching $\left(\boldsymbol{v}_{S}\right)$ vibrations are located at the range of $650-1190 \mathrm{~cm}^{-1}, 1610-1710 \mathrm{~cm}^{-1}$, and $3090-3460 \mathrm{~cm}^{-1}$, respectively. For the IR spectra (see Figure 5.3a and 5.3b), the most obvious difference between ice Ih and XI is that a narrower band and sharper peaks in the librational region are observed for ice XI, which is consistent with previous reports by Shigenari and Abe ${ }^{111-112}$ and by Wójcik et al. ${ }^{113-114}$ In Figure 5.4 the Raman spectra of ice Ih and XI are shown. As reported in previous studies, ${ }^{111}$, 115-116 also for the Raman spectra the most apparent difference between ice Ih and XI is in the librational region, where several split sharp peaks are found in ice XI as compared to a continuous weak broad band in ice Ih. Thus, the librational modes are more sensitive to the proton ordering, which is a spectroscopic signature that can be used to distinguish ice XI from ice Ih. No obvious difference between ice Ih and XI is found in the OH stretching part of the spectrum, which might suggest that the intramolecular vibrations are little affected by the proton-ordering. ${ }^{5}$

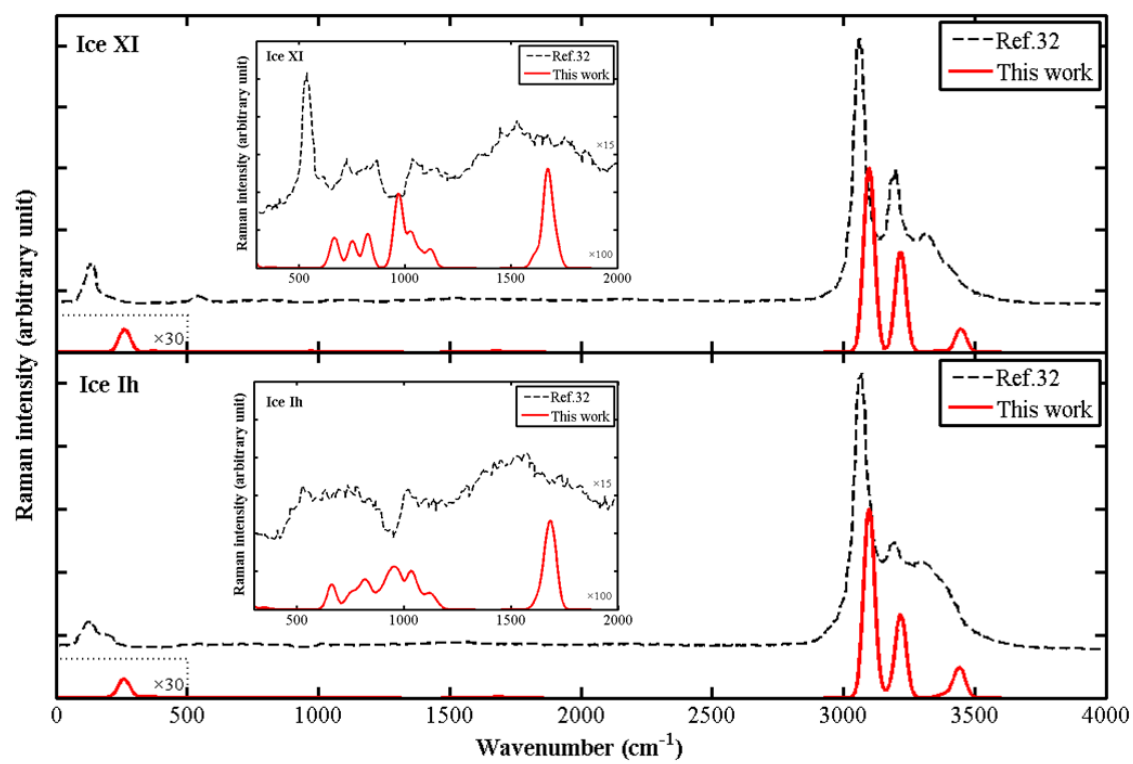

Figure 5.4. The Raman spectra of ice Ih and XI. Amplifications are shown as inserts. 


\subsection{OH Stretching Vibrations of Ice Ih}

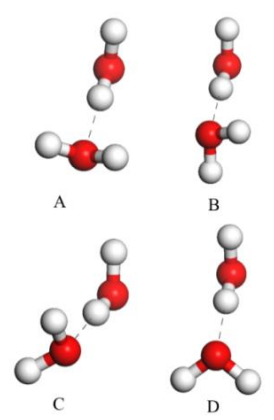

Figure 5.5. The dimer configurations of H-bond in ice Ih: A (h-cis), B (h-trans), $\mathrm{C}$ (c-cis), and $\mathrm{D}(c$-trans).

The hydrogen atoms were divided into four different groups based on the types of H-bonded pair configurations A (h-cis), B (h-trans), C (c-cis), and D (c-trans) (see Figure 5.5). The $\mathrm{OH}$ stretching spectra of each ice Ih isomer were split into five different sub-spectra according to the contribution from each group, depicted in Figures 5.6 and 5.7.

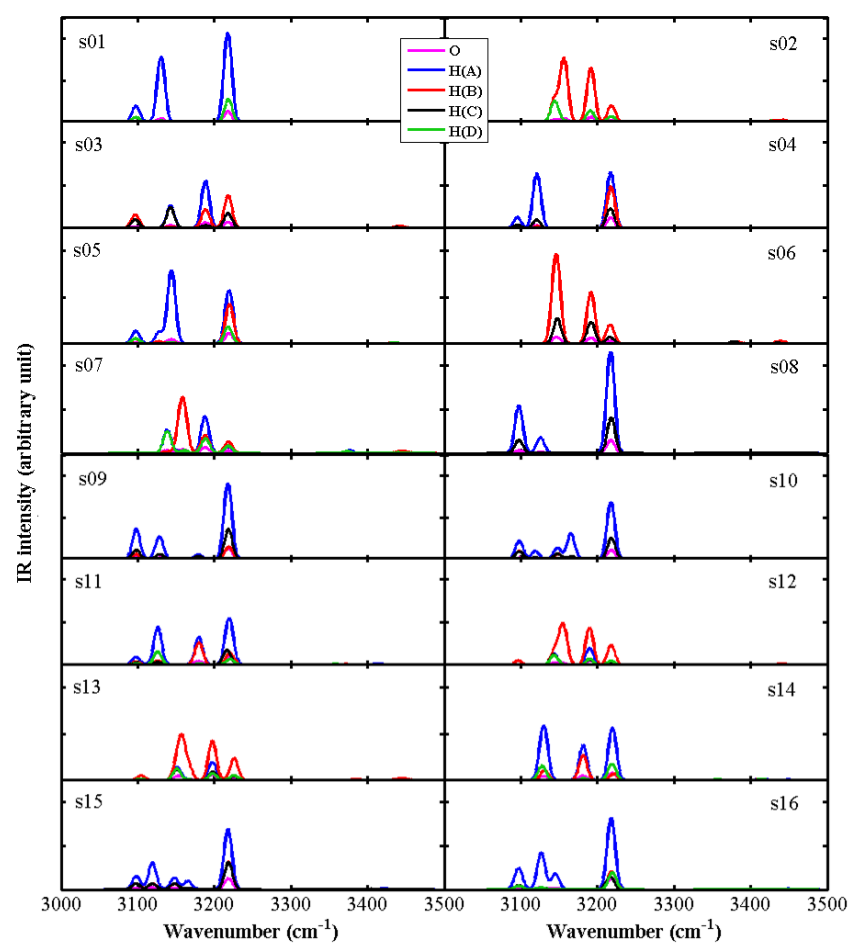

Figure 5.6. The IR spectra in the $\mathrm{OH}$ stretching region from 16 unique structures of ice $\mathrm{Ih}$ split into different sub-spectra based on the specific contributions from each H-bond group (A, $\mathrm{B}, \mathrm{C}, \mathrm{D})$. 
In Figure 5.6, the IR spectra of stretching vibrations in 16 different isomers of ice Ih are shown in the range of $3090-3460 \mathrm{~cm}^{-1}$. Unlike the distinct distribution of the sub-spectra of each proton group in water clusters (see Figure 5 in Paper III), ${ }^{2,4}$ the sub-spectra in ice overlap in all the 16 cases. This is also observed for the Raman spectra, shown in Figure 5.7. The $\mathrm{OH}$ stretching vibration is very sensitive to the strength of the H-bond (the Badger-Bauer rule). ${ }^{17-119}$ Each peak in the $\mathrm{OH}$ stretching region essentially contains contributions from all the H-bonded pair configurations in ice. This differs from the water clusters with different kinds of $\mathrm{H}$-bonds (being revealed by the therein separated sub-spectra), and there is thus only one kind of H-bond in ice. ${ }^{5}$ This observation provides an illustration to the historic debate on the existence of two kinds of H-bond in ice. ${ }^{120-122}$

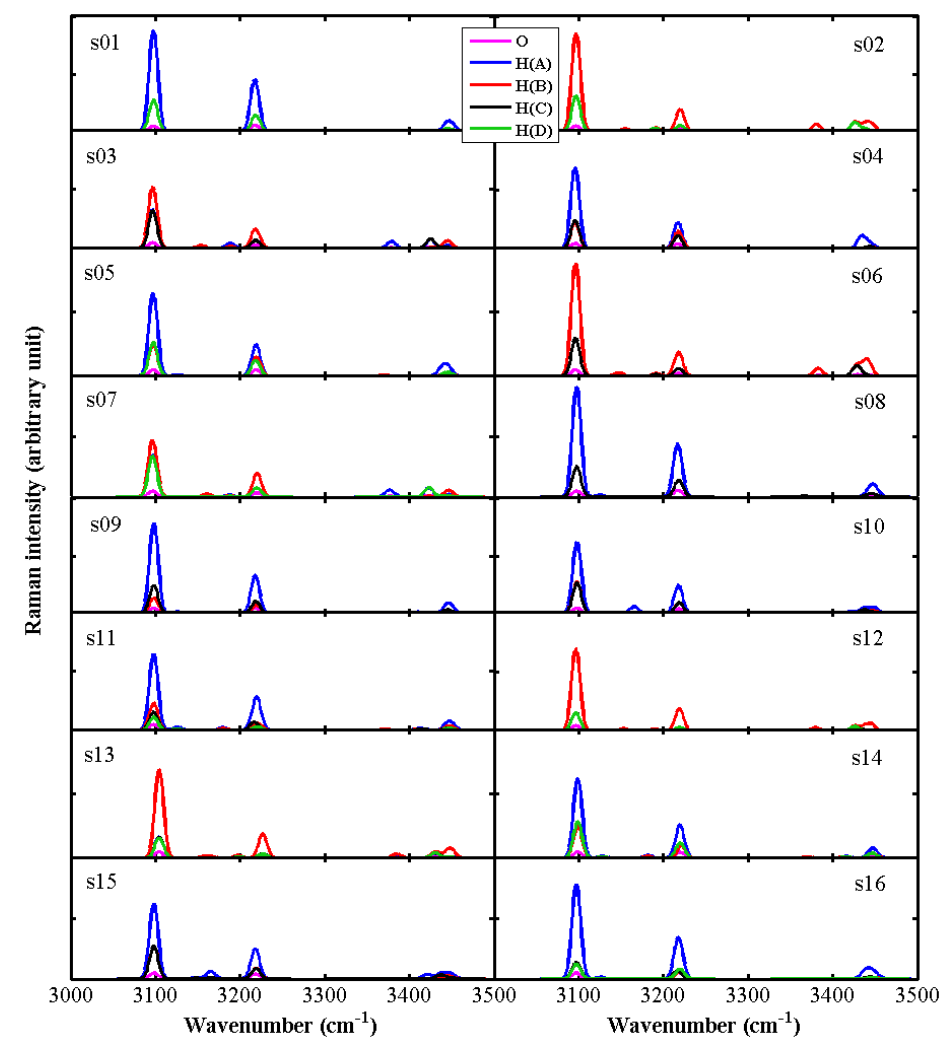

Figure 5.7. The Raman spectra in the $\mathrm{OH}$ stretching region from 16 unique structures of ice Ih split into different sub-spectra based on the specific contributions from each H-bond group (A, B, C, D). 


\section{Clathrate ice (Paper VI)}

It has been found silica clathrate minerals are isostructural with clathrate hydrate of natural gases, i.e. MEP $\leftrightarrow$ sI, MTN $\leftrightarrow$ sII, and DOH $\leftrightarrow \mathrm{sH} .{ }^{123}$ The guest free silicon, germanium, and alloyed $\mathrm{Si}-\mathrm{Ge}$ clathrates isostructural with the sII clathrate hydrate of natural gases have been synthesized experimentally. ${ }^{124-128} \mathrm{It}$ is reported that ice and silica can share the same tetrahedrally coordinated framework between oxygen atoms of water and silicon atoms of silica. ${ }^{129-131}$ Crystal structure prediction by analogy with known structures and firstprinciples computations can be used to find new crystalline phases of solid materials. ${ }^{132-134}$ Inspired by these ideas, we were motived to seach for candidates of new clathrate ice phases from silica or semiconductor clathrate materials from first-principles.

Recently some new clathrate frameworks of $\mathrm{ZnO}$ and $\mathrm{SiC}$ have been constructed by connecting their cages in different ways. ${ }^{135-136}$ Borrowing this idea, new clathrate ice phases (sL, sL_I, sL_II, and sL_III) can be generated by connecting the water cages. Using the non-local dispersion-corrected functional vdW-DF2, ${ }^{137}$ a new clathrate ice sL was predicted to be stable under even lower negative pressure than sII clathrate ice from the first-principles solid-state phase diagram computations. Due to the ultralow density of sL clathrate ice, the hydrogen storage capacity in a solid material would be made breakthrough based on the technology of hydrogen clathrate hydrates.

Table 6.1. The structure and energetic parameters of ice XI and various clathrate ices: number of water molecules per unit cell $(\mathbf{N})$, equilibrium volume of the unit cell ( $\left.\boldsymbol{V}_{\text {cell }}\right)$, average O-O distance between the nearest water molecules $\left(\boldsymbol{d}_{\mathbf{0}-\mathbf{0}}\right)$, mass density $(\boldsymbol{\rho})$, and lattice energy per molecule $\left(\boldsymbol{E}_{\text {latt }}\right)$.

\begin{tabular}{|c|c|c|c|c|c|}
\hline Phase & $\mathbf{N}$ & $V_{\text {cell }}\left(\AA^{3}\right)$ & $d_{0-0}(\AA)$ & $\rho\left(\mathrm{g} / \mathrm{cm}^{3}\right)$ & $E_{\text {latt }}(\mathrm{kJ} / \mathbf{m o l})$ \\
\hline Ice XI & 8 & $262\left(257^{*}\right)$ & $2.772\left(2.735^{*}\right)$ & $0.913\left(0.93^{*}\right)$ & $-63.61\left(-58.99^{\dagger}\right)$ \\
\hline sI & 46 & 1721 & 2.784 & 0.799 & -61.72 \\
\hline sII & 136 & $5156\left(5022^{\ddagger}\right)$ & $2.783\left(2.751^{\ddagger}\right)$ & $0.789\left(0.81^{\ddagger}\right)$ & -61.91 \\
\hline $\mathrm{sII}^{\S}$ & 34 & 1289 & 2.785 & 0.789 & -61.91 \\
\hline $\mathrm{sH}$ & 68 & 2637 & 2.785 & 0.771 & -61.49 \\
\hline sK & 80 & 3009 & 2.785 & 0.795 & -61.49 \\
\hline sL & 24 & 1229 & 2.797 & 0.584 & -56.90 \\
\hline sL_I & 12 & 494 & 2.794 & 0.727 & -59.01 \\
\hline sL_II & 40 & 1740 & 2.790 & 0.687 & -58.39 \\
\hline sIII & 48 & 2486 & 2.799 & 0.577 & -56.30 \\
\hline
\end{tabular}

"Ref. $56,{ }^{~}$ Ref. 105, 106, ${ }^{*}$ Ref. $51,{ }^{8}$ primitive cell of sII.

\subsection{Structure parameters of various clathrate ices}

To evaluate the reliability of the computational scheme employed in paper VI, the structure parameters and lattice energies of ice XI and various clathrate ices were studied and compared with the available experimental data ${ }^{51,56,105-106}$ as listed in Table 6.1. After the unit cell of each ice polymorph was fully optimized 
by vdW-DF2 functional, the equilibrium volume, the averaged distance of the nearest $\mathrm{O}-\mathrm{O}$ atoms, mass density, and lattice energy of each unit cell were computed. Compared to the experimental values, the volume of unit cell is overestimated by $1.9 \%$ for ice XI and $2.6 \%$ for clathrate ice sII, the averaged O$\mathrm{O}$ distance is overestimated by $1.3 \%$ for ice XI and $1.2 \%$ for clathrate ice sII, and the mass density is underestimated by $1.8 \%$ for ice XI and $2.6 \%$ for clathrate ice sII. The lattice energy of ice XI is overestimated by $7.3 \%$ in comparison with the experimental value. Thus, the H-bonding systems overall can be given an accurate description by the vdW-DF2 functional.

\subsection{Lattice energies, relative enthalpies and vibrational frequencies}

As reported in an earlier paper, ${ }^{138}$ the lattice energy of each structure is overall proportional to the density. Ice XI is the densest one $\left(0.91 \mathrm{~g} / \mathrm{cm}^{3}\right)$ among the ices listed in Table 6.1, which also obtained the largest magnitude of the lattice energy $(63.61 \mathrm{~kJ} / \mathrm{mol})$ release. The densities of clathrate ice sI, sII, sH, and sK are all approximately $0.8 \mathrm{~g} / \mathrm{cm}^{3}$, and their lattice energies are around $62 \mathrm{~kJ} / \mathrm{mol}$. The lattice energies of the new clathrate ices SL_I and SL_II are 59.01 and 58.39 $\mathrm{kJ} / \mathrm{mol}$, respectively. The mass density of clathrate ice $\mathrm{sL} \_\mathrm{I}$ and $\mathrm{sL} \_\mathrm{II}$ is around $0.7 \mathrm{~g} / \mathrm{cm}^{3}$ ranking therein third among all the ice polymorphs. Clathrate ice $\mathrm{sL}$ and sIII $^{138}$ have the lowest density $\left(0.6 \mathrm{~g} / \mathrm{cm}^{3}\right)$, which also have the smallest magnitude of lattice energies $(56.90 \mathrm{~kJ} / \mathrm{mol}$ by sL and $56.30 \mathrm{~kJ} / \mathrm{mol}$ by sIII). Interestingly, the average distance of the nearest O-O atoms are nearly $2.8 \AA$ in all the ice phases listed in Table 1 . In addition, the average values of hydrogen bonds between two water molecules are all approximately $1.8 \AA$ and the average length of $\mathrm{OH}$ bond in a water molecule are around $0.99 \AA$ for all the structures (see Table 6.2). Therefore, compared to conventional ice (e.g. ice XI in this work), the low density of clathrate ice phases owes to the unique clathrate framework of the H-bond topological network in clathrate ices. The ultralow density of clathrate ice sL and sIII $\left(0.6 \mathrm{~g} / \mathrm{cm}^{3}\right)$ are caused by the type of much larger polyhedral cages formed by H-bonded water molecules in sL and sIII phase.

Table 6.2. The longest, shortest, and averaged lengths of $\mathrm{OH}$ bond of a water molecule $\left(d_{\mathrm{OH}}\right)$ and hydrogen bond between two water molecules $\left(d_{O \ldots H}\right)$ and the longest, shortest, and averaged distance of the nearest O-O between two water molecules $\left(d_{\mathrm{OO}}\right)$ for ice XI and various clathrate ices.

\begin{tabular}{|c|l|l|c|c|c|c|c|c|c|c|c|}
\hline \multicolumn{2}{|c|}{ Phase } & Ice XI & sI & sII & sII* & sH & sK & sL & sL_I & sL_II & sIII \\
\hline \multirow{3}{*}{$d_{\text {OO }}(\AA)$} & The longest & 2.774 & 2.815 & 2.811 & 2.804 & 2.808 & 2.861 & 2.845 & 2.798 & 2.857 & 2.822 \\
\cline { 2 - 11 } & The shortest & 2.770 & 2.759 & 2.754 & 2.767 & 2.764 & 2.737 & 2.766 & 2.789 & 2.759 & 2.787 \\
\cline { 2 - 11 } & The averaged & 2.772 & 2.784 & 2.783 & 2.785 & 2.785 & 2.785 & 2.797 & 2.794 & 2.790 & 2.799 \\
\hline \multirow{3}{*}{$d_{\text {OH }}(\AA)$} & The longest & 0.995 & 0.995 & 0.996 & 0.996 & 0.995 & 0.996 & 0.993 & 0.993 & 0.994 & 0.991 \\
\cline { 2 - 11 } & The shortest & 0.994 & 0.992 & 0.992 & 0.993 & 0.992 & 0.990 & 0.988 & 0.992 & 0.987 & 0.989 \\
\cline { 2 - 10 } & The averaged & 0.995 & 0.994 & 0.994 & 0.994 & 0.994 & 0.994 & 0.991 & 0.993 & 0.992 & 0.990 \\
\hline \multirow{3}{*}{$d_{O \ldots H}(\AA)$} & The longest & 1.780 & 1.825 & 1.819 & 1.812 & 1.821 & 1.871 & 1.889 & 1.817 & 1.917 & 1.864 \\
\cline { 2 - 10 } & The shortest & 1.778 & 1.764 & 1.759 & 1.773 & 1.774 & 1.742 & 1.776 & 1.810 & 1.765 & 1.810 \\
\cline { 2 - 10 } & The averaged & 1.779 & 1.792 & 1.791 & 1.793 & 1.794 & 1.793 & 1.828 & 1.814 & 1.812 & 1.828 \\
\hline
\end{tabular}

"primitive cell of sII. 


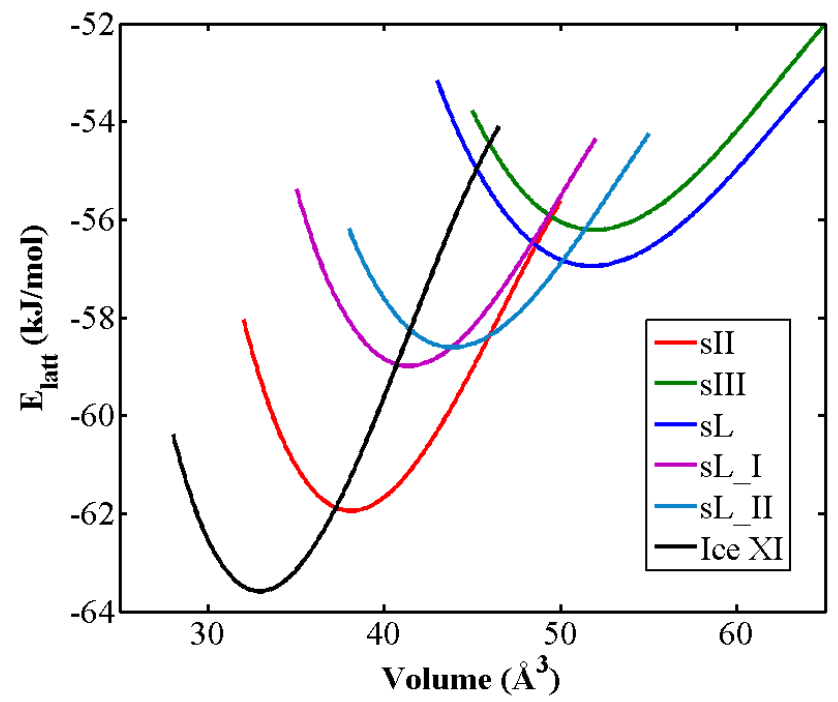

Figure 6.1. Lattice energies $\left(E_{\text {latt }}\right)$ of ice XI and various clathrate ices as function of volume per water molecule. Note: $E_{\text {latt }}=\left(E_{\text {total }}-N \times E_{\text {monomer }}\right) / N$, where $E_{\text {total }}$ is the total energy of a unit cell, $N$ is the number of water molecules in the unit cell, and $E_{\text {monomer }}$ is the total energy of a water molecule.

The lattice energies of ice XI and various clathrate ices are depicted as a function of volume per water molecule in Figure 6.1. The absolute value of lattice energy is inversely proportional to the equilibrium volume: the smaller the equilibrium volume, the larger the absolute value of the lattice energy. It is consistent with the results between lattice energy and mass density since density and volume are inversely proportional. The density of clathrate ice sL and sIII are nearly the same, however, sL phase is a little more stable than sIII as seen by the lower $E_{\text {latt }}-V$ curve of the sL phase than that of the sIII phase in Figure 6.1. The relative enthalpies of clathrate ice sII, sL, sL_I, sL_II, and sIII with ice XI as a reference are plotted as a function of pressure for each phase at $0 \mathrm{~K}$ in Figure 6.2. Since the Gibbs free energy is equal to the enthalpy at $0 \mathrm{~K}$, the phase transition pressures at $0 \mathrm{~K}$ between two different phases are displayed by the cross point in Figure 6.2. Ice XI will transform to clathrate ice sII at the negative pressure -5080 bar, which can be compared to -4009 bar as obtained in the calculations by Huang et al. ${ }^{138}$ The difference may arise from different proton arrangements in the sII structures employed in each work, which influences the total energy of the structure. In the region between -5584 and -5080 bar, the sII phase is the most stable one with the lowest enthalpy. If the pressure goes below -5584 bar, the sL phase will be the most stable phase of water. Due to the lower enthalpy of the sL phase than that of the sIII phase, the sIII phase will be replaced by the sL phase at negative pressure below -5584 bar at $0 \mathrm{~K}$. Thus, 
based on the DFT results in this work, clathrate ice sL is the most stable phase of water with the lowest mass density among all the proposed crystalline ices under sufficiently low negative pressure at $0 \mathrm{~K}$.

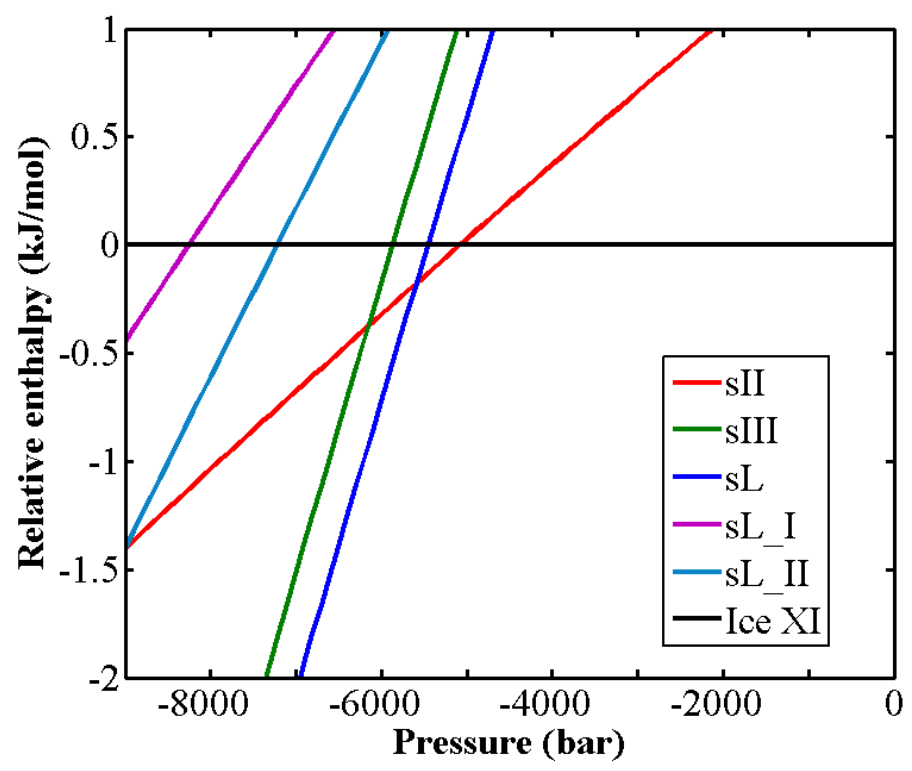

Figure 6.2. Relative enthalpy per molecule at $0 \mathrm{~K}$ without zero point energy (ZPE) correction as a function of pressure for various clathrate ices with ice XI as a reference. The crossing point between ice XI and sII, sII and sL, and sII and sIII are $-5080,-5584$, and -6146 bar, respectively.

The vibrational frequencies of clathrate ice $\mathrm{sL}$ were also investigated through phonon calculations based on the unit cell optimized using the vdW-DF2 functional. The dynamic stability of the structure sL is confirmed as shown by the lack of imaginary frequencies. In the upper part of Figure 6.3, the translational, librational, and bending vibrations are shown up to $2000 \mathrm{~cm}^{-1}$ for both ice XI and sL. In the lower part of the figure, the stretching vibrations locate in the region from 3200 to $3450 \mathrm{~cm}^{-1}$ for the sL phase are shown. Comparing the stretching vibrational modes of ice XI $\left(3100 \sim 3400 \mathrm{~cm}^{-1}\right)$ with the stretching frequencies of $\mathrm{sL}$, it is seen that the latter are apparently blueshifted. It implies that the strengths of $\mathrm{H}$-bonds in the sL phase are weaker than those in ice XI since the $\mathrm{OH}$ stretching frequency of $\mathrm{H}_{2} \mathrm{O}$ depends on the strength of $\mathrm{H}$-bond. This is in agreement with the lower absolute value of the lattice energy per molecule of the sL phase $(56.90 \mathrm{~kJ} / \mathrm{mol})$ than that of ice XI $(63.61 \mathrm{~kJ} / \mathrm{mol})$. As for the origin of ultralow density of sL phase, the weak $\mathrm{H}$ bond in sL phase may also be attributed to the unique polyhedral $\mathrm{H}$-bond network. 
(a)
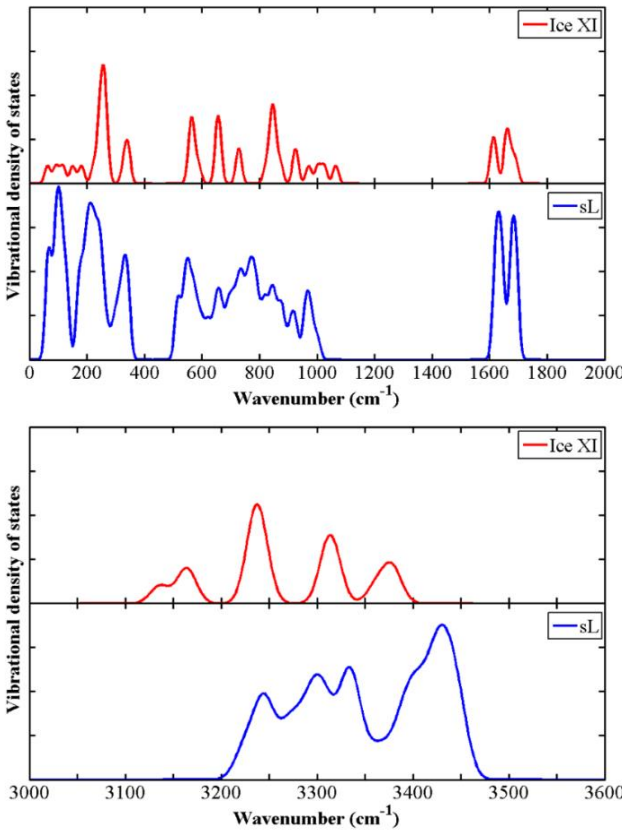

Figure 6.3. The vibrational density of states of ice XI and clathrate ice sL from phonon computations using the vdW-DF2 functional in the Quantum Espresso suite: (a) low frequency region (translational vibrational modes, librational vibrational modes, and bending vibrational modes), (b) stretching vibrational modes.

\subsection{First-principles phase diagram of water under negative pressure}

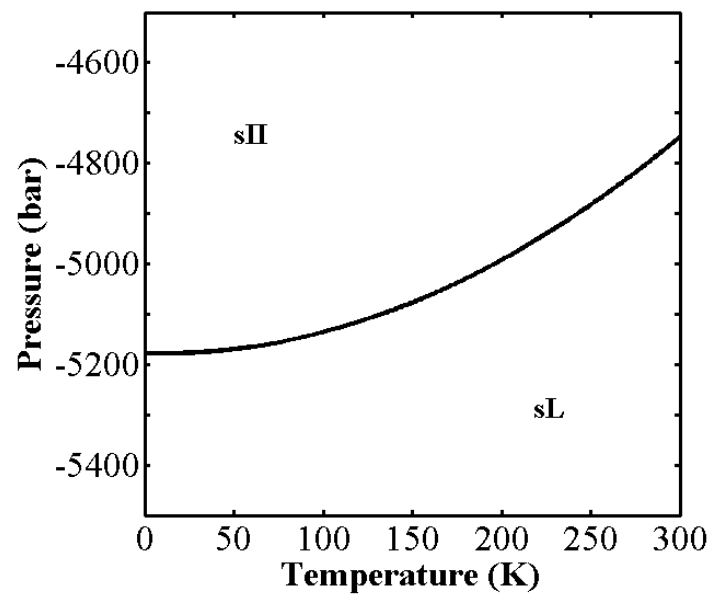

Figure 6.4. Pressure versus temperature phase diagram of clathrate ice sII and sL. The phase transition pressure between sII and sL phase with ZPE correction at $0 \mathrm{~K}$ is -5170 bar. 
After computation of the vibrational energies and entropies at finite temperature, a $P-T$ phase diagram can be established from first-principles computations. In Figure 6.4, the phase boundary between clathrate ice sII and $\mathrm{sL}$ is depicted. At 0 $\mathrm{K}$, the phase transition pressure between the sII phase and the sL phase is -5170 bar with zero point vibrational energy correction. As the temperature increasing, the phase transition pressure gradually increases up to -4761 bar at $300 \mathrm{~K}$. In paper VI, the phase diagram of water is extended to lower negative pressure regions by first-principles computations. 


\section{Conclusions}

\subsection{Natural gas hydrates}

The thermodynamic stabilities, Raman vibrational spectra and ${ }^{13} \mathrm{C}$ NMR parameters of various water cavities occupied by different guest molecules typically present in NGHs have been investigated by quantum-chemical computations.

The water cavities of NGHs will shrink if occupied by small molecules; if occupied by a large molecule (the ratio of molecular diameter to cavity diameter is greater than 1.0), both the average $\mathrm{O}-\mathrm{O}$ distance and the radius of the cage will increase. From the point of view that the largest magnitudes of cohesive energies will be obtained, the energetically optimal host-guest combinations among these seven hydrocarbon gas molecules in various water cavities in NGHs are $\mathrm{CH}_{4} @ \mathrm{D}, \mathrm{C}_{2} \mathrm{H}_{6} @ \mathrm{~T}, \mathrm{C}_{3} \mathrm{H}_{6} @ \mathrm{~T}, \mathrm{C}_{3} \mathrm{H}_{8} @ \mathrm{~T}, \mathrm{C}_{4} \mathrm{H}_{8} @ \mathrm{~T}$ (or possibly $\mathrm{P}$ or H), i- $\mathrm{C}_{4} \mathrm{H}_{10} @ \mathrm{H}$, and n- $\mathrm{C}_{4} \mathrm{H}_{10} @ \mathrm{H}$. According to the cohesive free energies $\left(\Delta G_{c o h}\right)$, the most favorable combination for each guest molecule is $\mathrm{CH}_{4} @ \mathrm{ID}, \mathrm{C}_{2} \mathrm{H}_{6} @ \mathrm{~T}$, $\mathrm{C}_{3} \mathrm{H}_{6} / \mathrm{C}_{3} \mathrm{H}_{8} @ \mathrm{~T}$ or $\mathrm{H}, \mathrm{C}_{4} \mathrm{H}_{8} / \mathrm{i}-\mathrm{C}_{4} \mathrm{H}_{10} @ \mathrm{H}$, and n- $\mathrm{C}_{4} \mathrm{H}_{10} @ \mathrm{I}$. In addition, the ZPE effect of $\Delta E_{\text {host-guest }}$ and $\Delta E_{\text {coh }}$ is substantial.

For the C-C stretching vibrations of hydrocarbon molecules in NGHs, a blue shift is found after the guest molecule is trapped from the gas phase into various water cages, due to the host-guest interactions between water cages and hydrocarbon molecules. The frequencies will shift to the red as the radius of water cages increases. In addition, the results indicate that $n-\mathrm{C}_{4} \mathrm{H}_{10}$ with the gauche conformation is present in $\mathrm{T}$ and $\mathrm{H}$ cages, which is consistent with the experimental conclusion for $\mathrm{n}-\mathrm{C}_{4} \mathrm{H}_{10}$ in $\mathrm{H}$ cages of sII hydrates.

Regarding the $\mathrm{CH}$ stretching frequency shifts of hydrocarbon molecules in clathrate hydrates, it follow the trend predicted by the "loose cage - tight cage" model: when the size of the water cavity change from small to large, the $\mathrm{CH}$ stretching vibrational frequency of a trapped hydrocarbon molecule will first decrease and then increase until equal to that in gas phase; in the "tight cage" situation, the $\mathrm{CH}$ stretching vibrational frequency will be greater than in gas phase; in the "loose cage" situation, the $\mathrm{CH}$ stretching vibrational frequency will be below that in the gas phase.

The trends and origins of the ${ }^{13} \mathrm{C}$ NMR chemical shift of hydrocarbon molecules in NGHs from first-principles calculations on solid state phases have been presented in this thesis. For single occupancy $\mathrm{CH}_{4}$ hydrates, the chemical shift decreases as the size of the water cavities increase. For multi-occupancy cases, the chemical shift increases as the amount of $\mathrm{CH}_{4}$ increase. For $\mathrm{C}_{2} \mathrm{H}_{6}$, $\mathrm{C}_{3} \mathrm{H}_{8}, \mathrm{i}-\mathrm{C}_{4} \mathrm{H}_{10}$, and $\mathrm{n}-\mathrm{C}_{4} \mathrm{H}_{10}$ hydrates, the chemical shift all gradually decrease as the size of the water cavities increase. Furthermore, the chemical shifts of pure 
sI and sII $\mathrm{CH}_{4}$ hydrate and of sII $\mathrm{CH}_{4}-\mathrm{C}_{3} \mathrm{H}_{8}$ hydrate increase as the external pressure increases. The chemical shift can be mainly attributed to the host-guest interaction with a small contributions from water molecules when the guest molecule is in a relatively tight environment, whereas it mainly depends on only the host-guest interaction when the guest molecule experiences a relatively loose environment.

\section{2 water clusters}

In this work, the thermodynamic stabilities and IR spectra of the three water clusters $\left(\mathrm{H}_{2} \mathrm{O}\right)_{20,54,100}$ have been studied using quantum-chemical computations. The stability increases as the size of the water cluster increases. The change in Gibbs free energy when $\left(\mathrm{H}_{2} \mathrm{O}\right)_{100}$ is formed from isolated water molecules is negative at $298 \mathrm{~K}$, which implies spontaneous formation from the monomers. The IR spectra in the $\mathrm{OH}$ stretching region of $\left(\mathrm{H}_{2} \mathrm{O}\right)_{20,54,100}$ were simulated and split into different sub-spectra based on the contribution from different groups of $\mathrm{H}$-bonds. The IR fingerprint of water molecules bonded by different conformations of $\mathrm{H}$-bonds in $\left(\mathrm{H}_{2} \mathrm{O}\right)_{20,54,100}$ were demonstrated. The $\mathrm{OH}$ stretching frequencies of the SD groups are lower than that of corresponding DD groups, i.e. the SD-SA/DA/4c group exhibits lower frequencies than the DD$\mathrm{SA} / \mathrm{DA} / 4 \mathrm{c}$ group. If the acceptors of the $\mathrm{H}$-bonds are DA, the $\mathrm{OH}$ vibrational frequencies are higher than when the acceptors are SA, i.e. the DD/SD/4c-DA group exhibits higher frequencies than the DD/SD/4c-SA group. Furthermore, the $\mathrm{OH}$ stretching vibration of bulk molecules and surface molecules overlap in the middle part of the IR spectrum. The $\mathrm{OH}$ vibrational frequencies of water molecules are sensitive to the conformations of the H-bonds, and the different groups of H-bonds have features that are located at different regions in the IR spectra. Thus the specific spectroscopic signatures can aid to identify the $\mathrm{H}$ bond topology of water molecules in water clusters.

\subsection{Ice Ih and ice XI}

It is suggested that BLYP combined with TNP basis set is a good method for studies of ice with an average absolute error of 3\% for the energy and 5\% for the volume. B3LYP and PBE0 with the TS dispersion correction can provide an overall fair description of ice with an average absolute error around $10 \%$, as concluded from the present studies on ice VIII, IX, and XI. It is also shown that PBE performs well in studies of 16 different isomers of ice Ih. The IR and Raman spectra of ice Ih and XI have been calculated and compared. The librational vibrations were found to be the most affected by the proton ordering from the comparison of both the IR and Raman spectra between ice Ih and XI, in agreement with the measurements by Shigenari and Abe. ${ }^{111}$ This can be used as a spectroscopic signature of ice XI to distinguish ferroelectric ice XI from ice Ih. Furthermore, only one kind of H-bonds, rather than two, was observed in ice Ih as concluded from the existence of overlapping sub-spectra for different types of $\mathrm{H}$-bonded pair configurations in 16 isomers of ice Ih. 


\subsection{Clathrate ice}

Using the non-local dispersion-corrected vdW-DF2 functional, a new crystalline phase of ice is predicted by first-principles phase diagram computations. The new phase is called clathrate ice $\mathrm{sL}$, which has ultralow mass density $\left(0.6 \mathrm{~g} / \mathrm{cm}^{-1}\right)$ and is stable at lower negative pressures than the experimentally confirmed sII phase. The phase diagram of water is extended to lower negative pressure region using first-principles calculations. According to the enthalpy at $0 \mathrm{~K}$, the sIII phase proposed by Huang et al. ${ }^{138}$ is replaced by the sL phase at pressures lower than -5584 bar. The ultralow density and weak H-bond of sL phase may both originate from the unique polyhedral H-bond network. 


\section{Acknowledgements}

I would like to thank all the kind people I met during the $\mathrm{PhD}$ studies in Sweden. Particularly,

- to my supervisor Lars Ojamäe, thanks for all the help and collaboration during the scientific researches done in the four years, I learned a lot from you.

- to my assistant supervisor Per-Olov Käll, my colleagues Edvin Erdtman, Annika Lenz, Emil Kalered, and Maria Lundqvist in our group, thanks for the help on the scientific studies and nice chat during the $\mathrm{PhD}$ studies.

- to all the helpful colleagues in the Chemistry division, it is my honor to be a colleague with you and occasionally party together. Especially, thanks our administrator Susanne Andersson for all the help and quick answers of my questions during my $\mathrm{PhD}$ studies.

- to all my Chinese friends I met in Linköping, thanks for the accompany and having fun together.

- to all the members of my family, thanks for always supporting me whatever I do.

- to the scholarship I got from China government under the State Scholarship Fund of China Scholarship Council (File No. 201206060016), which support me to have a happy life in Sweden. 


\section{References}

1. Liu, Y.; Ojamäe, L., C-C Stretching Raman Spectra and Stabilities of Hydrocarbon Molecules in Natural Gas Hydrates: A Quantum Chemical Study. J. Phys. Chem. A 2014, 118, 11641-11651.

2. Liu, Y.; Ojamäe, L., Ch-Stretching Vibrational Trends in Natural Gas Hydrates Studied by QuantumChemical Computations. J. Phys. Chem. C 2015, 119, 17084-17091.

3. Liu, Y.; Ojamäe, L., ${ }^{13} \mathrm{C}$ Chemical Shift in Natural Gas Hydrates from First-Principles Solid-State NMR Calculations. J. Phys. Chem. C 2016, 120, 1130-1136.

4. Liu, Y.; Ojamäe, L., Fingerprints in IR OH Vibrational Spectra of $\mathrm{H}_{2} \mathrm{O}$ Clusters from Different H-Bond Conformations by Means of Quantum-Chemical Computations. J. Mol. Model. 2014, 20, 2281.

5. Liu, Y.; Ojamäe, L., Raman and IR Spectra of Ice Ih and Ice XI with an Assessment of DFT Methods. J. Phys. Chem. B 2016, DOI: 10.1021/acs.jpcb.6b07001.

6. Sloan, E. D.; Koh, C. A., Clathrate Hydrates of Natural Gases, third ed.; CRC Press/Taylor\&Francis Group: Boca Raton, FL, 2008.

7. Sloan, E. D., Fundamental Principles and Applications of Natural Gas Hydrates. Nature 2003, 426, 353-359.

8. Koh, C. A., Towards a Fundamental Understanding of Natural Gas Hydrates. Chem. Soc. Rev. 2002, 31, 157167.

9. Mao, W. L.; Mao, H. K.; Goncharov, A. F.; Struzhkin, V. V.; Guo, Q. Z.; Hu, J. Z.; Shu, J. F.; Hemley, R. J.; Somayazulu, M.; Zhao, Y. S., Hydrogen Clusters in Clathrate Hydrate. Science 2002, 297, 2247-2249.

10. Florusse, L. J.; Peters, C. J.; Schoonman, J.; Hester, K. C.; Koh, C. A.; Dec, S. F.; Marsh, K. N.; Sloan, E. D., Stable Low-Pressure Hydrogen Clusters Stored in a Binary Clathrate Hydrate. Science 2004, 306, 469-471.

11. Voronov, V. P.; Gorodetskii, E. E.; Muratov, A. R., Experimental Study of Methane Replacement in Gas Hydrate by Carbon Dioxide. J. Phys. Chem. B 2010, 114, 12314-12318.

12. Bai, D. S.; Zhang, X. R.; Chen, G. J.; Wang, W. C., Replacement Mechanism of Methane Hydrate with Carbon Dioxide from Microsecond Molecular Dynamics Simulations. Energy Environ. Sci. 2012, 5, 7033-7041.

13. Cha, I.; Lee, S.; Lee, J. D.; Lee, G. W.; Seo, Y., Separation of SF6 from Gas Mixtures Using Gas Hydrate Formation. Environ. Sci. Technol. 2010, 44, 6117-6122.

14. Seo, Y.; Tajima, H.; Yamasaki, A.; Takeya, S.; Ebinuma, T.; Kiyono, F., A New Method for Separating Hfc134a from Gas Mixtures Using Clathrate Hydrate Formation. Environ. Sci. Technol. 2004, 38, 4635-4639.

15. Cha, J. H.; Seol, Y., Increasing Gas Hydrate Formation Temperature for Desalination of High Salinity Produced Water with Secondary Guests. ACS Sustainable Chem. Eng. 2013, 1, 1218-1224.

16. Hatakeyama, T.; Aida, E.; Yokomori, T.; Ohmura, R.; Ueda, T., Fire Extinction Using Carbon Dioxide Hydrate. Ind. Eng. Chem. Res. 2009, 48, 4083-4087.

17. Gutt, C.; Asmussen, B.; Press, W.; Johnson, M. R.; Handa, Y. P.; Tse, J. S., The Structure of Deuterated Methane-Hydrate. J. Chem. Phys. 2000, 113, 4713-4721.

18. Rawn, C. J.; Rondinone, A. J.; Chakoumakos, B. C.; Circone, S.; Stern, L. A.; Kirby, S. H.; Ishii, Y., Neutron Powder Diffraction Studies as a Function of Temperature of Structure II Hydrate Formed from Propane. Can. J. Phys. 2003, 81, 431-438.

19. Udachin, K. A.; Ratcliffe, C. I.; Enright, G. D.; Ripmeester, J. A., Structure H Hydrate: A Single Crystal Diffraction Study of 2,2-Dimethylpentane $5\left(\mathrm{Xe}_{2} \mathrm{H}_{2} \mathrm{~S}\right) \cdot 34 \mathrm{H}_{2} \mathrm{O}$. Supramol. Chem. 1997, 8, 173-176.

20. Goldschleger, I. U.; Kerenskaya, G.; Janda, K. C.; Apkarian, V. A., Polymorphism in $\mathrm{Br}_{2}$ Clathrate Hydrates. J. Phys. Chem. A 2008, 112, 787-789.

21. Yang, L.; Tulk, C. A.; Klug, D. D.; Moudrakovski, I. L.; Ratcliffe, C. I.; Ripmeester, J. A.; Chakoumakos, B. C.; Ehm, L.; Martin, C. D.; Parise, J. B., Synthesis and Characterization of a New Structure of Gas Hydrate. Proc. Natl. Acad. Sci. USA 2009, 106, 6060-6064.

22. Vatamanu, J.; Kusalik, P. G., Unusual Crystalline and Polycrystalline Structures in Methane Hydrates. J. Am. Chem. Soc. 2006, 128, 15588-15589.

23. Loveday, J. S.; Nelmes, R. J.; Guthrie, M.; Belmonte, S. A.; Allan, D. R.; Klug, D. D.; Tse, J. S.; Handa, Y. P., Stable Methane Hydrate above $2 \mathrm{Gpa}$ and the Source of Titan's Atmospheric Methane. Nature 2001, 410, 661-663.

24. Loveday, J. S.; Nelmes, R. J.; Guthrie, M.; Klug, D. D.; Tse, J. S., Transition from Cage Clathrate to Filled Ice: The Structure of Methane Hydrate III. Phys. Rev. Lett. 2001, 87, 215501.

25. Vos, W. L.; Finger, L. W.; Hemley, R. J.; Mao, H. K., Novel $\mathrm{H}_{2}-\mathrm{H}_{2} \mathrm{O}$ Clathrates at High-Pressures. Phys. Rev. Lett. 1993, 71, 3150-3153.

26. Ludwig, R., Water: From Clusters to the Bulk. Angew. Chem. Int. Ed. 2001, 40, 1808-1827.

27. Lenz, A.; Ojamäe, L., A Theoretical Study of Water Clusters: The Relation between Hydrogen-Bond Topology and Interaction Energy from Quantum-Chemical Computations for Clusters with up to 22 Molecules. Phys. Chem. Chem. Phys. 2005, 7, 1905-1911. 
28. Lenz, A.; Ojamäe, L., On the Stability of Dense Versus Cage-Shaped Water Clusters: Quantum-Chemical Investigations of Zero-Point Energies, Free Energies, Basis-Set Effects and IR Spectra of $\left(\mathrm{H}_{2} \mathrm{O}\right)_{12}$ and $(\mathrm{H} 2 \mathrm{O})_{20}$. Chem. Phys. Lett. 2006, 418, 361-367.

29. Li, F. Y.; Wang, L.; Zhao, J. J.; Xie, J. R. H.; Riley, K. E.; Chen, Z. F., What Is the Best Density Functional to Describe Water Clusters: Evaluation of Widely Used Density Functionals with Various Basis Sets for $\left(\mathrm{H}_{2} \mathrm{O}\right)_{\mathrm{N}}$ (N=1-10). Theor. Chem. Accounts 2011, 130, 341-352.

30. Li, F. Y.; Liu, Y.; Wang, L.; Zhao, J. J.; Chen, Z. F., Improved Stability of Water Clusters $\left(\mathrm{H}_{2} \mathrm{O}\right)_{30-48}: A$ Monte Carlo Search Coupled with Dft Computations. Theor. Chem. Accounts 2012, 131, 1163.

31. Huisken, F.; Kaloudis, M.; Kulcke, A., Infrared Spectroscopy of Small Size-Selected Water Clusters. J. Chem. Phys. 1996, 104, 17-25.

32. Diken, E. G.; Robertson, W. H.; Johnson, M. A., The Vibrational Spectrum of the Neutral $\left(\mathrm{H}_{2} \mathrm{O}\right)_{6}$ Precursor to the "Magic" (H2O)6 ${ }^{-}$Cluster Anion by Argon-Mediated, Population-Modulated Electron Attachment Spectroscopy. J. Phys. Chem. A 2004, 108, 64-68.

33. Sun, Q., The Single Donator-Single Acceptor Hydrogen Bonding Structure in Water Probed by Raman Spectroscopy. J. Chem. Phys. 2010, 132, 054507.

34. Steinbach, C.; Andersson, P.; Melzer, M.; Kazimirski, J. K.; Buck, U.; Buch, V., Detection of the Book Isomer from the Oh-Stretch Spectroscopy of Size Selected Water Hexamers. Phys. Chem. Chem. Phys. 2004, 6, 3320-3324.

35. Liu, X. J.; Lu, W. C.; Wang, C. Z.; Ho, K. M., Energetic and Fragmentation Stability of Water Clusters $\left(\mathrm{H}_{2} \mathrm{O}\right)_{\mathrm{N}}, \mathrm{N}=2-30$. Chem. Phys. Lett. 2011, 508, 270-275.

36. Liu, J. J.; Wang, L.; Zhao, J. J., Density Functional Theory Calculations of Water Fullerenes: $\left(\mathrm{H}_{2} \mathrm{O}\right)_{\mathrm{N}}$ Clusters with N=20-40. J. Comput. Theor. Nanosci. 2009, 6, 454-458.

37. Xantheas, S. S., Cooperativity and Hydrogen Bonding Network in Water Clusters. Chem. Phys. 2000, 258, 225-231.

38. Kuo, J. L.; Coe, J. V.; Singer, S. J.; Band, Y. B.; Ojamäe, L., On the Use of Graph Invariants for Efficiently Generating Hydrogen Bond Topologies and Predicting Physical Properties of Water Clusters and Ice. J. Chem. Phys. 2001, 114, 2527-2540.

39. Hamashima, T.; Mizuse, K.; Fujii, A., Spectral Signatures of Four-Coordinated Sites in Water Clusters: Infrared Spectroscopy of Phenol- $\left(\mathrm{H}_{2} \mathrm{O}\right)_{\mathrm{N}}$ (Similar to $20<=\mathrm{N}<=$ Similar to 50). J. Phys. Chem. A 2011, 115, 620-625.

40. Bai, J.; Su, C. R.; Parra, R. D.; Zeng, X. C.; Tanaka, H.; Koga, K.; Li, J. M., Ab Initio Studies of Quasi-OneDimensional Pentagon and Hexagon Ice Nanotubes. J. Chem. Phys. 2003, 118, 3913-3916.

41. Hermansson, K.; Ojamae, L., From Molecule to Cluster to Bulk - Water OH Vibrations in Different Surroundings. Int. J. Quantum Chem. 1992, 42, 1251-1270.

42. Bernal, J. D.; Fowler, R. H., A Theory of Water and Inoic Solution, with Particular Reference to Hydrogen and Hydroxyl Ions. J. Chem. Phys. 1933, 1, 515.

43. Fortes, A. D.; Wood, I. G.; Grigoriev, D.; Alfredsson, M.; Kipfstuhl, S.; Knight, K. S.; Smith, R. I., No Evidence for Large-Scale Proton Ordering in Antarctic Ice from Powder Neutron Diffraction. J. Chem. Phys. 2004, 120, 11376-11379.

44. Dowell, L. G.; Rinfret, A. P., Low Temperatre Forms of Ice as Studied by X-ray Diffraction. Nature 1960, 188, 1144-1148.

45. Kamb, B.; Prakash, A., Structure of Ice Iii. Acta Cryst. B 1968, 24, 1317-1327.

46. Engelhardt, H.; Kamb, B., Structure of Ice-IV, a Metastable High-Pressure Phase. J. Chem. Phys. 1981, 75, 5887-5899.

47. Kamb, B.; Prakash, A.; Knobler, C., Structure of Ice V. Acta Crystallogr. 1967, 22, 706-715.

48. Kamb, B., Structure of Ice VI. Science 1965, 150, 205-209.

49. Kamb, B.; Davis, B. L., Ice VII, the Densest Form of Ice. Proc. Natl. Acad. Sci. USA 1964, 52, 1433-1439.

50. Lobban, C.; Finney, J. L.; Kuhs, W. F., The Structure of a New Phase of Ice. Nature 1998, 391, 268-270.

51. Falenty, A.; Hansen, T. C.; Kuhs, W. F., Formation and Properties of Ice XVI Obtained by Emptying a Type Sii Clathrate Hydrate. Nature 2014, 516, 231-233.

52. Kamb, B., Ice II: A Proton-Ordered Form of Ice. Acta Crystallogr. 1964, 17, 1437-1449.

53. Besson, J. M.; Pruzan, P.; Klotz, S.; Hamel, G.; Silvi, B.; Nelmes, R. J.; Loveday, J. S.; Wilson, R. M.; Hull, S., Variation of Interatomic Distances in Ice-VIII to 10 GPa. Phys. Rev. B 1994, 49, 12540-12550.

54. Placa, S. J. L.; Hamilton, W. C., On a Nearly Proton-Ordered Structure for Ice IX. J. Chem. Phys. 1972, 58, 567.

55. Hemley, R. J.; Jephcoat, A. P.; Mao, H. K.; Zha, C. S.; Finger, L. W.; Cox, D. E., Static Compression of $\mathrm{H}_{2} \mathrm{O}$-Ice to $128 \mathrm{GPa}$ (1.28 Mbar). Nature 1987, 330, 737-740.

56. Leadbetter, A. J.; Ward, R. C.; Clark, J. W.; Tucker, P. A.; Matsuo, T.; Suga, H., The Equilibrium LowTemperature Structure of Ice. J. Chem. Phys. 1985, 82, 424-428. 
57. Salzmann, C. G.; Radaelli, P. G.; Hallbrucker, A.; Mayer, E.; Finney, J. L., The Preparation and Structures of Hydrogen Ordered Phases of Ice. Science 2006, 311, 1758-1761.

58. Salzmann, C. G.; Radaelli, P. G.; Mayer, E.; Finney, J. L., Ice XV: A New Thermodynamically Stable Phase of Ice. Phys. Rev. Lett. 2009, 103, 105701

59. Tajima, Y.; Matsuo, T.; Suga, H., Phase-Transition in KOH-Doped Hexagonal Ice. Nature 1982, 299, 810812.

60. Tajima, Y.; Matsuo, T.; Suga, H., Calorimetric Study of Phase-Transition in Hexagonal Ice Doped with Alkali Hydroxides. J. Phys. Chem. Solids 1984, 45, 1135-1144.

61. Jackson, S. M.; Whitworth, R. W., Evidence for Ferroelectric Ordering of Ice Ih. J. Chem. Phys. 1995, 103, 7647-7648.

62. Iedema, M. J.; Dresser, M. J.; Doering, D. L.; Rowland, J. B.; Hess, W. P.; Tsekouras, A. A.; Cowin, J. P., Ferroelectricity in Water Ice. J. Phys. Chem. B 1998, 102, 9203-9214.

63. Wang, H.; Bell, R. C.; Iedema, M. J.; Tsekouras, A. A.; Cowin, J. P., Sticky Ice Grains Aid Planet Formation: Unusual Properties of Cryogenic Water Ice. Astrophys. J. 2005, 620, 1027-1032.

64. Fukazawa, H.; Hoshikawa, A.; Ishii, Y.; Chakoumakos, B. C.; Fernandez-Baca, J. A., Existence of Ferroelectric Ice in the Universe. Astrophys. J. 2006, 652, L57-L60.

65. Finney, J. L., Water? What's So Special About It? Phil. Trans. R. Soc. B 2004, 359, 1145-1163.

66. Ball, P., Water: Water - an Enduring Mystery. Nature 2008, 452, 291-292.

67. Nilsson, A.; Pettersson, L. G. M., The Structural Origin of Anomalous Properties of Liquid Water. Nature Communications 2015, 6, 8998.

68. Russo, J.; Tanaka, H., Understanding Water's Anomalies with Locally Favoured Structures. Nature Communications 2014, 5, 3556.

69. Conde, M. M.; Vega, C.; Tribello, G. A.; Slater, B., The Phase Diagram of Water at Negative Pressures: Virtual Ices. J. Chem. Phys. 2009, 131, 034510.

70. Kosyakov, V. I.; Shestakov, V. A., On the Possibility of the Existence of a New Ice Phase under Negative Pressures. Dokl. Phys. Chem. 2001, 376, 49-51.

71. Davitt, K.; Rolley, E.; Caupin, F.; Arvengas, A.; Balibar, S., Equation of State of Water under Negative Pressure. J. Chem. Phys. 2010, 133, 174507.

72. Caupin, F.; Arvengas, A.; Davitt, K.; Azouzi, M. E.; Shmulovich, K. I.; Ramboz, C.; Sessoms, D. A.; Stroock, A. D., Exploring Water and Other Liquids at Negative Pressure. J. Phys. Condens. Matter 2012, 24, 284110 .

73. Herbert, E.; Balibar, S.; Caupin, F., Cavitation Pressure in Water. Phys. Rev. E 2006, 74, 041603.

74. Zheng, Q.; Durben, D. J.; Wolf, G. H.; Angell, C. A., Liquids at Large Negative Pressures - Water at the Homogeneous Nucleation Limit. Science 1991, 254, 829-832.

75. Martin, R. M. Electronic Structure: Basic Theory and Practical Methods; Cambridge, 2004.

76. Sholl, D. S.; Steckel, J. A., Density Functional Theory. John Wiley \& Sons, Inc., Hoboken: New Jersey, 2009.

77. Engel, T.; Reid, P., Thermodynamics, Statistical Thermodynamics, \& Kinetics. Third Edition ed.; Pearson Education, Inc.: 2013.

78. Liu, Y.; Zhao, J. J.; Li, F. Y.; Chen, Z. F., Appropriate Description of Intermolecular Interactions in the Methane Hydrates: An Assessment of DFT Methods. J. Comput. Chem. 2013, 34, 121-131.

79. Chai, J. D.; Head-Gordon, M., Long-Range Corrected Hybrid Density Functionals with Damped Atom-Atom Dispersion Corrections. Phys. Chem. Chem. Phys. 2008, 10, 6615-6620.

80. Hehre, W. J.; Ditchfield, R.; Pople, J. A., Self-Consistent Molecular Orbital Methods. XII. Further Extensions of Gaussian-Type Basis Sets for Use in Molecular Orbital Studies of Organic Molecules. J. Chem. Phys. 1972, 56, 2257.

81. Subramanian, S.; Sloan, E. D., Trends in Vibrational Frequencies of Guests Trapped in Clathrate Hydrate Cages. J. Phys. Chem. B 2002, 106, 4348-4355.

82. Subramanian, S.; Kini, R. A.; Dec, S. F.; Sloan, E. D., Evidence of Structure II Hydrate Formation from Methane Plus Ethane Mixtures. Chem. Eng. Sci. 2000, 55, 1981-1999.

83. Sum, A. K.; Burruss, R. C.; Sloan, E. D., Measurement of Clathrate Hydrates Via Raman Spectroscopy. J. Phys. Chem. B 1997, 101, 7371-7377.

84. Frisch, M. J.; Trucks, G. W.; Schlegel, H. B.; et al., Gaussian 09, Gaussion Inc.:Wallingford, CT: 2011.

85. Perdew, J. P.; Burke, K.; Ernzerhof, M., Generalized Gradient Approximation Made Simple. Phys. Rev. Lett. 1996, 77, 3865-3868.

86. Tkatchenko, A.; Scheffler, M., Accurate Molecular van der Waals Interactions from Ground-State Electron Density and Free-Atom Reference Data. Phys. Rev. Lett. 2009, 102, 073005.

87. Clark, S. J.; Segall, M. D.; Pickard, C. J.; Hasnip, P. J.; Probert, M. J.; Refson, K.; Payne, M. C., First Principles Methods Using Castep. Z. Kristallogr. 2005, 220, 567-570. 
88. Pickard, C. J.; Mauri, F., All-Electron Magnetic Response with Pseudopotentials: NMR Chemical Shifts. Phys. Rev. B 2001, 63, 245101.

89. Bonhomme, C.; Gervais, C.; Babonneau, F.; Coelho, C.; Pourpoint, F.; Azais, T.; Ashbrook, S. E.; Griffin, J. M.; Yates, J. R.; Mauri, F.; Pickard, C. J., First-Principles Calculation of NMR Parameters Using the Gauge Including Projector Augmented Wave Method: A Chemist's Point of View. Chem. Rev. 2012, 112, 5733-5779.

90. Buhl, M.; van Mourik, T., NMR Spectroscopy: Quantum-Chemical Calculations. Wiley Interdiscip. Rev. Comput. Mol. Sci. 2011, 1, 634-647.

91. Reed, A. E.; Weinhold, F., Natural Localized Molecular-Orbitals. J. Chem. Phys. 1985, 83, 1736-1740.

92. Glendening, E. D.; Landis, C. R.; Weinhold, F., Natural Bond Orbital Methods. Wiley Interdiscip. Rev. Comput. Mol. Sci. 2012, 2, 1-42.

93. Weinhold, F., Natural Bond Orbital Analysis: A Critical Overview of Relationships to Alternative Bonding Perspectives. J. Comput. Chem. 2012, 33, 2363-2379.

94. Miyazaki, M.; Fujii, A.; Ebata, T.; Mikami, N., Infrared Spectroscopic Evidence for Protonated Water Clusters Forming Nanoscale Cages. Science 2004, 304, 1134-1137.

95. Shin, J. W.; Hammer, N. I.; Diken, E. G.; Johnson, M. A.; Walters, R. S.; Jaeger, T. D.; Duncan, M. A.; Christie, R. A.; Jordan, K. D., Infrared Signature of Structures Associated with the $\mathrm{H}^{+}\left(\mathrm{H}_{2} \mathrm{O}\right)_{\mathrm{N}}(\mathrm{N}=6$ to 27$)$ Clusters. Science 2004, 304, 1137-1140.

96. Lee, H. M.; Suh, S. B.; Lee, J. Y.; Tarakeshwar, P.; Kim, K. S., Structures, Energies, Vibrational Spectra, and Electronic Properties of Water Monomer to Decamer. J. Chem. Phys. 2000, 112, 9759-9772.

97. Fanourgakis, G. S.; Apra, E.; Xantheas, S. S., High-Level Ab Initio Calculations for the Four Low-Lying Families of Minima of $\left(\mathrm{H}_{2} \mathrm{O}\right)_{20}$. I. Estimates of MP2/CBS Binding Energies and Comparison with Empirical Potentials. J. Chem. Phys. 2004, 121, 2655-2663.

98. Fanourgakis, G. S.; Apra, E.; de Jong, W. A.; Xantheas, S. S., High-Level Ab Initio Calculations for the Four Low-Lying Families of Minima of $\left(\mathrm{H}_{2} \mathrm{O}\right)_{20}$. II. Spectroscopic Signatures of the Dodecahedron, Fused Cubes, Face-Sharing Pentagonal Prisms, and Edge-Sharing Pentagonal Prisms Hydrogen Bonding Networks. J. Chem. Phys. 2005, 122, 134304.

99. Kang, D. D.; Dai, J. Y.; Hou, Y.; Yuan, J. M., Structure and Vibrational Spectra of Small Water Clusters from First Principles Simulations. J. Chem. Phys. 2010, 133, 014302.

100. Becke, A. D., Density-Functional Thermochemistry .3. The Role of Exact Exchange. J. Chem. Phys. 1993, 98, 5648-5652.

101. Lee, C. T.; Yang, W. T.; Parr, R. G., Development of the Colle-Salvetti Correlation-Energy Formula into a Functional of the Electron-Density. Phys. Rev. B 1988, 37, 785-789.

102. Delley, B., An All-Electron Numerical-Method for Solving the Local Density Functional for PolyatomicMolecules. J. Chem. Phys. 1990, 92, 508-517.

103. Delley, B., From Molecules to Solids with the Dmol ${ }^{3}$ Approach. J. Chem. Phys. 2000, 113, 7756-7764.

104. Brandenburg, J. G.; Maas, T.; Grimme, S., Benchmarking Dft and Semiempirical Methods on Structures and Lattice Energies for Ten Ice Polymorphs. J. Chem. Phys. 2015, 142, 124104.

105. Whalley, E., Energies of the Phases of Ice at Zero Temperature and Pressure. J. Chem. Phys. 1984, 81, 4087-4092.

106. Johari, G. P., An Interpretation for the Thermodynamic Features of Ice Ih - Ice XI Transformation. J. Chem. Phys. 1998, 109, 9543-9548.

107. Jorgensen, J. D.; Beyerlein, R. A.; Watanabe, N.; Worlton, T. G., Structure of $\mathrm{D}_{2} \mathrm{O}$ Ice-VIII from Insitu Powder Neutron-Diffraction. J. Chem. Phys. 1984, 81, 3211-3214.

108. Yoshimura, Y.; Stewart, S. T.; Somayazulu, M.; Mao, H.; Hemley, R. J., High-Pressure X-ray Diffraction and Raman Spectroscopy of Ice VIII. J. Chem. Phys. 2006, 124, 024502.

109. Londono, J. D.; Kuhs, W. F.; Finney, J. L., Neutron-Diffraction Studies of Ice-III and Ice-IX on underPressure and Recovered Samples. J. Chem. Phys. 1993, 98, 4878-4888.

110. Line, C. M. B.; Whitworth, R. W., A High Resolution Neutron Powder Diffraction Study of $\mathrm{D}_{2} \mathrm{O}$ Ice XI. $J$. Chem. Phys. 1996, 104, 10008-10013.

111. Shigenari, T.; Abe, K., Vibrational Modes of Hydrogens in the Proton Ordered Phase XI of Ice: Raman Spectra above $400 \mathrm{~cm}^{-1}$. J. Chem. Phys. 2012, 136, 174504.

112. Abe, K.; Shigenari, T., Raman Spectra of Proton Ordered Phase XI of Ice I. Translational Vibrations Below $350 \mathrm{~cm}^{-1}$. J. Chem. Phys. 2011, 134, 104506.

113. Wojcik, M. J.; Glug, M.; Boczar, M.; Boda, L., Spectroscopic Signature for Ferroelectric Ice. Chem. Phys. Lett. 2014, 612, 162-166.

114. Glug, M.; Boczar, M.; Boda, L.; Wojcik, M. J., Analysis of Librational Modes of Ice XI Studied by CarParrinello Molecular Dynamics. Chem. Phys. 2015, 459, 102-111.

115. Li, J. C.; Nield, V. M.; Jackson, S. M., Spectroscopic Measurements of Ice-XI. Chem. Phys. Lett. 1995, 241, 290-294. 
116. Erba, A.; Casassa, S.; Dovesi, R.; Maschio, L.; Pisani, C., Periodic Density Functional Theory and LocalMP2 Study of the Librational Modes of Ice XI. J. Chem. Phys. 2009, 130, 074505.

117. Badger, R. M.; Bauer, S. H., Spectroscopic Studies of the Hydrogen Bond. II. The Shift of the OH Vibrational Frequency in the Formation of the Hydrogen Bond. J. Chem. Phys. 1937, 5, 839-851.

118. Huggins, C. M.; Pimentel, G. C., Systematics of the Infrared Spectral Properties of Hydrogen Bonding Systems: Frequency Shift, Half Width and Intensity. J. Phys. Chem. 1956, 60, 1615-1619.

119. Mecke, R., Infra-Red Spectra of Hydroxylic Compounds. Discuss. Faraday Soc. 1950, 9, 161-177.

120. Li, J. C.; Ross, D. K., Evidence for Two Kinds of Hydrogen-Bond in Ice. Nature 1993, 365, 327-329.

121. Li, J. C.; Bennington, S. M.; Ross, D. K., Further Evidence for the Existence of 2 Kinds of H-Bonds in Ice Ih. Phys. Lett. A 1994, 192, 295-300.

122. Tse, J. S.; Klug, D. D., Further Evidence for the Existence of 2 Kinds of H-Bonds in Ice Ih - Comments. Phys. Lett. A 1995, 198, 464-466.

123. Momma, K.; Ikeda, T.; Nishikubo, K.; Takahashi, N.; Honma, C.; Takada, M.; Furukawa, Y.; Nagase, T.; Kudoh, Y., New Silica Clathrate Minerals That Are Isostructural with Natural Gas Hydrates. Nat. Commun 2011, 2, 196.

124. Wilson, M.; McMillan, P. F., Crystal-Liquid Phase Relations in Silicon at Negative Pressure. Phys. Rev. Lett. 2003, 90, 135703.

125. Gryko, J.; McMillan, P. F.; Marzke, R. F.; Ramachandran, G. K.; Patton, D.; Deb, S. K.; Sankey, O. F., Low-Density Framework Form of Crystalline Silicon with a Wide Optical Band Gap. Phys. Rev. B 2000, 62, R7707-R7710.

126. Ramachandran, G. K.; McMillan, P. F.; Deb, S. K.; Somayazulu, M.; Gryko, J.; Dong, J. J.; Sankey, O. F., High-Pressure Phase Transformation of the Silicon Clathrate $\mathrm{Si}_{136}$. J. Phys. Condens. Matter 2000, 12, 40134020.

127. Guloy, A. M.; Ramlau, R.; Tang, Z. J.; Schnelle, W.; Baitinger, M.; Grin, Y., A Guest-Free Germanium Clathrate. Nature 2006, 443, 320-323.

128. Baranowski, L. L.; Krishna, L.; Martinez, A. D.; Raharjo, T.; Stevanovic, V.; Tamboli, A. C.; Toberer, E. S., Synthesis and Optical Band Gaps of Alloyed Si-Ge Type II Clathrates. J. Mater. Chem. C 2014, 2, 3231-3237.

129. Svishchev, I. M.; Kusalik, P. G., Quartzlike Polymorph of Ice. Phys. Rev. B 1996, 53, R8815-R8817.

130. Svishchev, I. M.; Kusalik, P. G.; Murashov, V. V., Orthorhombic Quartzlike Polymorph of Silica: A Molecular-Dynamics Simulation Study. Phys. Rev. B 1997, 55, 721-725.

131. Tribello, G. A.; Slater, B.; Zwijnenburg, M. A.; Bell, R. G., Isomorphism between Ice and Silica. Phys. Chem. Chem. Phys. 2010, 12, 8597-8606.

132. Woodley, S. M.; Catlow, R., Crystal Structure Prediction from First Principles. Nat. Mater. 2008, 7, $937-$ 946.

133. Fischer, C. C.; Tibbetts, K. J.; Morgan, D.; Ceder, G., Predicting Crystal Structure by Merging Data Mining with Quantum Mechanics. Nat. Mater. 2006, 5, 641-646.

134. Curtarolo, S.; Morgan, D.; Persson, K.; Rodgers, J.; Ceder, G., Predicting Crystal Structures with Data Mining of Quantum Calculations. Phys. Rev. Lett. 2003, 91, 135503.

135. Watkins, M. B.; Shevlin, S. A.; Sokol, A. A.; Slater, B.; Catlow, C. R. A.; Woodley, S. M., Bubbles and Microporous Frameworks of Silicon Carbide. Phys. Chem. Chem. Phys. 2009, 11, 3186-3200.

136. Woodley, S. M.; Watkins, M. B.; Sokol, A. A.; Shevlin, S. A.; Catlow, C. R. A., Construction of Nano- and Microporous Frameworks from Octahedral Bubble Clusters. Phys. Chem. Chem. Phys. 2009, 11, 3176-3185.

137. Lee, K.; Murray, E. D.; Kong, L. Z.; Lundqvist, B. I.; Langreth, D. C., Higher-Accuracy van der Waals Density Functional. Phys. Rev. B 2010, 82, 081101.

138. Huang, Y. Y.; Zhu, C. Q.; Wang, L.; Cao, X. X.; Su, Y.; Jiang, X.; Meng, S.; Zhao, J. J.; Zeng, X. C., A New Phase Diagram of Water under Negative Pressure: The Rise of the Lowest-Density Clathrate s-III. Sci. Adv. 2016, 2, e1501010. 



\section{Papers}

The articles associated with this thesis have been removed for copyright reasons. For more details about these see:

http://urn.kb.se/resolve?urn=urn:nbn:se:liu:diva-132428 